\title{
Negative Components of the Electroretinogram from Proximal Retina and Photoreceptor
}

\author{
RoY H. STEINBerG*, LAURA J. Frishman* and PAUl A. Sieving ${ }^{\dagger}$ \\ *Departments of Physiology and Ophthalmology, University of California, San Francisco, CA, USA \\ ${ }^{\dagger}$ Department of Ophthalmology, University of Michigan, Ann Arbor, MI, USA
}

\section{CONTENTS}

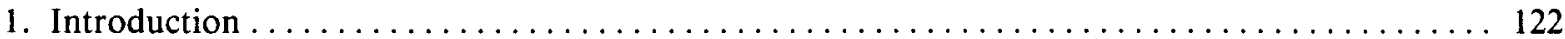

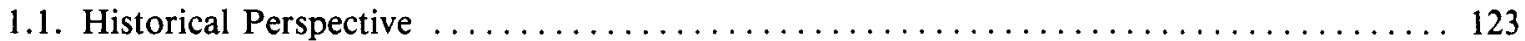

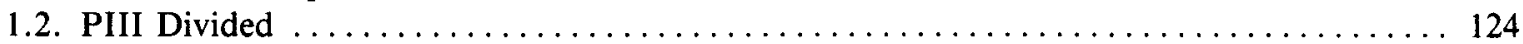

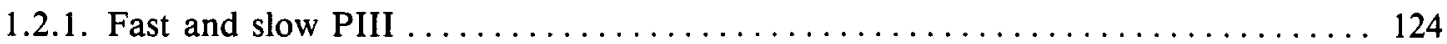

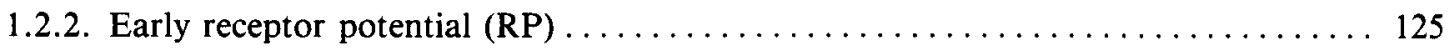

1.2.3. Proximal and distal PIII $\ldots \ldots \ldots \ldots \ldots \ldots \ldots \ldots \ldots \ldots \ldots \ldots \ldots \ldots \ldots$

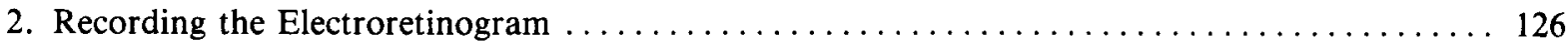

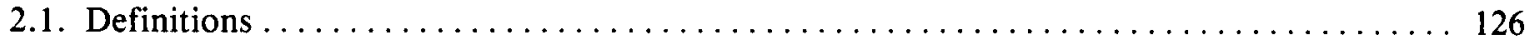

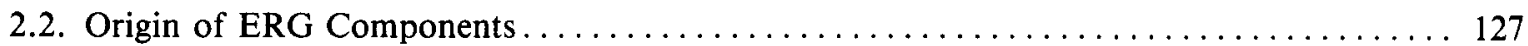

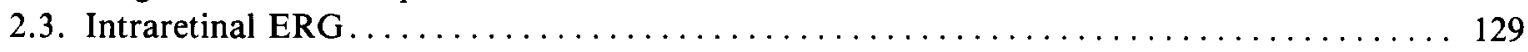

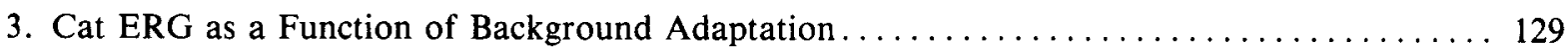

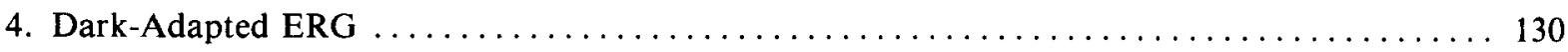

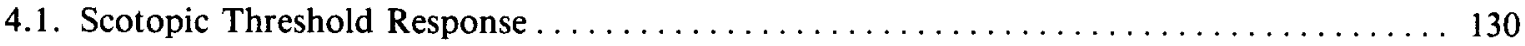

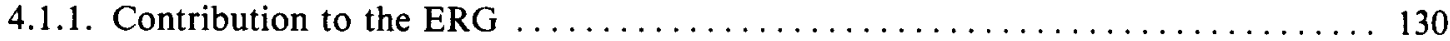

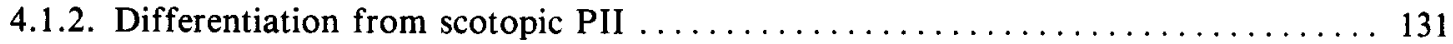

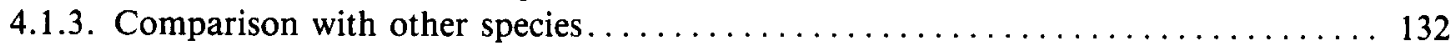

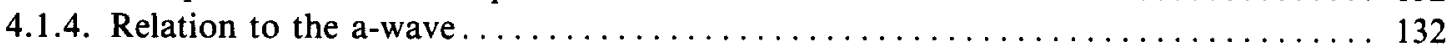

4.2. Slow Negative Response $\ldots \ldots \ldots \ldots \ldots \ldots \ldots \ldots \ldots \ldots \ldots \ldots \ldots \ldots \ldots \ldots \ldots \ldots \ldots$

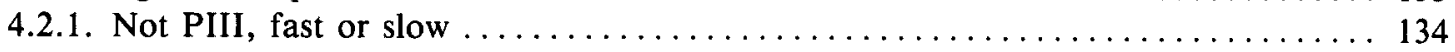

4.2.2. Comparison with other species $\ldots \ldots \ldots \ldots \ldots \ldots \ldots \ldots \ldots \ldots \ldots \ldots \ldots \ldots \ldots$

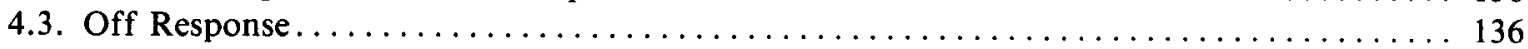

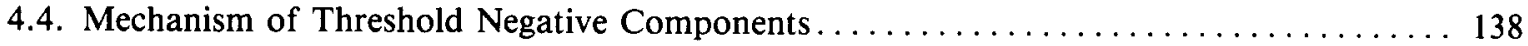

4.4.1. Current source density analysis and depth profiles $\ldots \ldots \ldots \ldots \ldots \ldots \ldots \ldots \ldots$

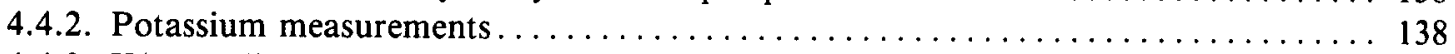

4.4.3. $\mathrm{K}^{+}$- Müller-cell mechanism $\ldots \ldots \ldots \ldots \ldots \ldots \ldots \ldots \ldots \ldots \ldots \ldots \ldots \ldots \ldots \ldots \ldots$

4.4.4. Neuronal origins $\ldots \ldots \ldots \ldots \ldots \ldots \ldots \ldots \ldots \ldots \ldots \ldots \ldots \ldots \ldots \ldots \ldots \ldots \ldots$

4.4.5. Threshold circuit $\ldots \ldots \ldots \ldots \ldots \ldots \ldots \ldots \ldots \ldots \ldots \ldots \ldots \ldots \ldots \ldots \ldots \ldots \ldots . \ldots \ldots$

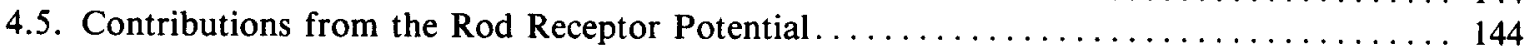

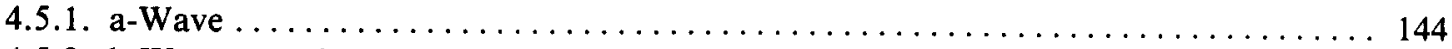

4.5.2. b-Wave trough $\ldots \ldots \ldots \ldots \ldots \ldots \ldots \ldots \ldots \ldots \ldots \ldots \ldots \ldots \ldots \ldots \ldots \ldots \ldots \ldots$

4.5.3. In the absence of positive components $\ldots \ldots \ldots \ldots \ldots \ldots \ldots \ldots \ldots \ldots \ldots \ldots$

Correspondence address: Roy H. Steinberg, Department of Physiology, University of California, San Francisco, CA 94143-0444. 


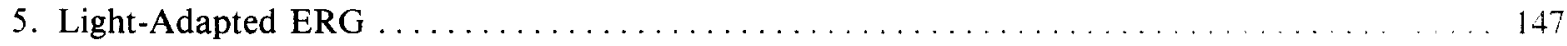

5.1. Sustained Negative Response and Negative Off Response . . . . . . . . . . . . . . 147

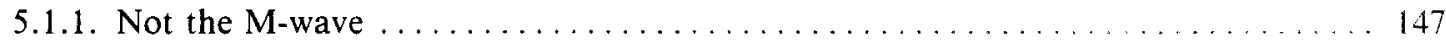

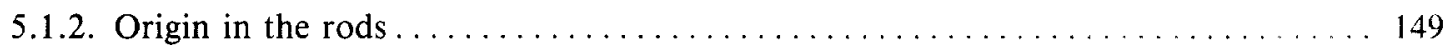

5.1.3. Prominence of the rod receptor potential $\ldots \ldots \ldots \ldots \ldots \ldots \ldots \ldots \ldots \ldots \ldots \ldots$

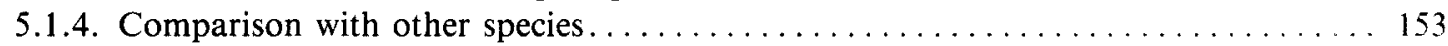

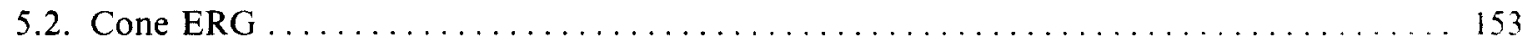

5.2.1. Cone receptor potential in the ERG $\ldots \ldots \ldots \ldots \ldots \ldots \ldots \ldots \ldots \ldots \ldots \ldots$

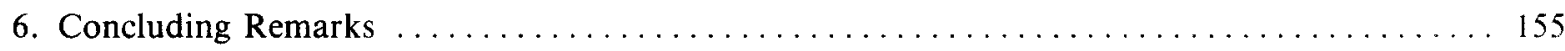

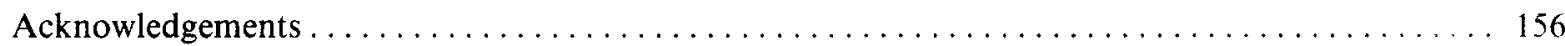

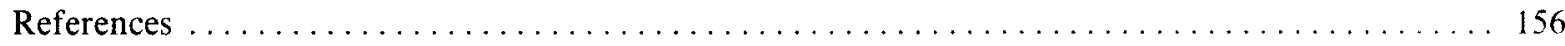

\section{INTRODUCTION}

The electroretinogram (ERG), as usually recorded at the cornea or in the vitreous (corneal or vitreal or "diffuse" ERG), is the electrical response of the retina to a flash of light that diffusely illuminates it. While this response forms a complex wave that can last for minutes after the onset of illumination, our chapter only considers a small portion of the total response, the negative components that occur in the initial seconds after the onset of illumination. This is the time of occurrence of the $a-, b$ - and c-waves of the traditional ERG. Since our topic is the negative components, the positive components receive limited attention and the reader is referred to other reviews or chapters for more thorough analyses of all components (Brown, 1968; Rodieck, 1972; Ripps and Witkovsky, 1985; Steinberg et al., 1985; Ikeda, 1987; Berson, 1987; Heckenlively and Arden, 1990).

Emphasis on the negative components derives from research in our laboratories that produced some surprises about the origins of certain components in the mammalian retina and their contributions to the ERG. Although the ERG has been studied for many years, recent studies have taken advantage of modern techniques of recording and data analysis, such as improved intraretinal recordings with glass micropipettes, the use of ion-selective micropipettes, advances in pharmacology, and computer-assisted analysis of waveforms. In addition, we have been able to build upon recent knowledge of retinal circuitry and of the part played by the Müller cell in contributing components to the ERG. Using such techniques and modern knowledge of the retina it has been possible to uncover intraretinal fieldpotentials that were not previously thought to contribute to the ERG, as well as to reevaluate the contributions of ones better known. Our main goal is to review the following findings, especially with regard to their significance for the corneal ERG, and to consider them in an historical context.

(1) New intraretinal field potentials have been found in the dark adapted proximal retina (scotopic threshold response and slow negative response) that contribute significantly to the ERG at dim levels of illumination. These potentials identify the operation of a retinal circuit that activates at absolute threshold. In the ERG they are represented by negative components that were previously thought to be generated directly by the rods, as the rod receptor potential (rod photoresponse).

(2) The M-wave, a light-adapted intraretinal field potential previously identified in coldblooded retinas, was found, as well, in the mammalian retina. In fact, under certain conditions it is the largest intraretinal response in lightadapted retina. While it may make a very small contribution to the diffuse ERG, it may contribute more significantly to the pattern ERG (PERG). (The pattern ERG is not considered further in this chapter.) 


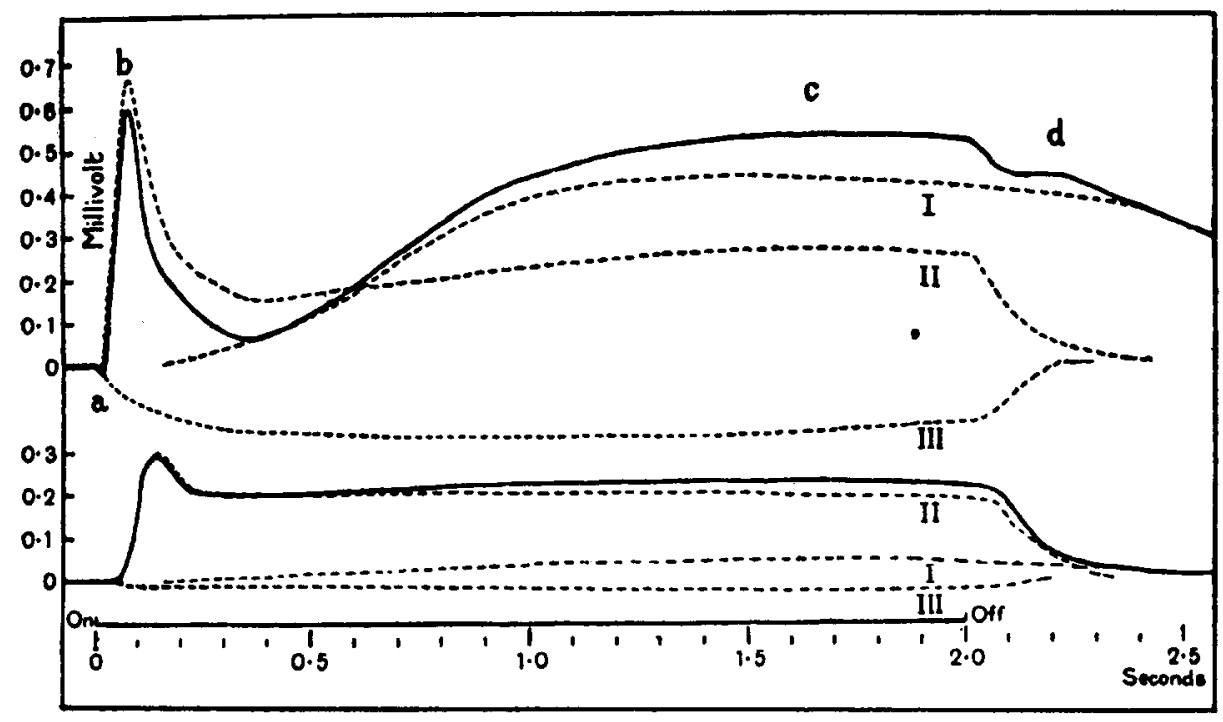

FIG. 1. Granit's analysis of the predominantly rod electroretinogram (ERG) (E-ERG) of the cat at stimulus intensities of $14 \mathrm{ml}$ (upper) and $0.14 \mathrm{ml}$ (lower). (From Granit, 1933.)

(3) The rod receptor potential forms a dominant negative component of the light-adapted ERG in certain mammalian retinas over a range of background levels and incremental stimulus intensities.

\subsection{Historical Perspective}

Our current understanding of the ERG reaches back to those early workers who realized that its waveform represented an envelope of components. Each component had a positive or negative polarity at the cornea and had a specific time course that was determined by the onset and of fset of illumination. The ERG, then, represents an algebraic sum of underlying components that change in amplitude with time. While more than one interpretation was offered, Granit's analysis is the one commonly used today. It was based on the numerous experiments performed in his laboratory and a synthesis of what was then known from the work of others (Granit, 1947, 1959, 1962).

Granit (1947) subdivided the ERG into three components, PI (process I), PII and PIII (Fig. 1), based on the order of disappearance of the $c$-, b- and a-waves of the dark-adapted cat during ether inhalation. These components were understood to underly the waves of the ERG. Thus, PI, a slow corneal positive potential, was responsible for the c-wave and disappeared first, followed by PII, a faster positivity and the basis of the b-wave, and finally PIII, the negative component and the basis for the a-wave. (For a history of this analysis, see Granit, 1947, 1962.)

While there was some evidence at the time, considered carefully by Granit (1947), associating PIII with the photoreceptors, he was perplexed by its polarity:

"Returning now to PIII let us first consider what appears to be the main reason against assigning this potential to the receptors, namely, its electrical sign. Even if the retina is removed from the bulb and placed between the electrodes the direction of PIII remains the same; the inner surface of the retina becomes negative and the outer surface positive. This means, if the receptors are involved, that their free ends become positive relative to their bases when they are subjected to illumination. If we accept this conclusion we must believe that PIII differs from all the isolated receptor potentials hitherto discovered with respect to its electrical sign"' (Granit, 1947, p. 112). 
This prophesy Granit was unwilling to accept in 1947 , but as evidence accumulated, the photoreceptor contribution to PIII became more compelling (Granit, 1962). Microelectrode studies began to localize ERG components to retinal layers in amphibian (Tomita, 1959; Byzov, 1959) and mammalian retinas (Brown and Wiesel, 1961). PIII could be assigned to the photoreceptors in cat because its maximum intraretinal amplitude was located just on the retinal side of the retinal pigment epithelium (RPE), and because of its presence in cold-blooded preparations in the absence of the RPE (Brown and Wiesel, 1961). This interpretation was supported by intraretinal recordings from the fovea and peripheral retina in cynomologous (macaque) monkey, with and without clamping of the retinal circulation to suppress neuronal activity proximal to the photoreceptors (Brown and Watanabe, 1962; Brown, 1968). The intraretinal potential that remained had a time course and polarity that was associated with the a-wave of the corneal ERG.

\subsection{PIII Divided}

PIII did not long remain a unitary potential. It came to be subdivided into fast and slow components, early and late receptor potentials of rods and cones, and finally, into proximal and distal components. A brief review of these subdivisions and how they relate to each other may be helpful in placing our recent findings into a proper context.

\subsubsection{FAST AND SLOW PIII}

Granit $(1947,1962)$ already had noted that PIII appeared to have fast and slow components. The slow component was observed after stimulus offset in the isolated PIII of frog ERGs, as having a slow return of the potential towards the baseline, or "remnant negativity" (Granit and Riddel, 1934), which followed a faster return (termed fast and slow PIII by Granit, 1962).

In the intraretinal recordings on cat and monkey of Brown and coworkers a major advance was the subdivision of PIII or as they designated it - the late receptor potential (late RP), into rod- dependent and cone-dependent subcomponents (rod late RP, cone late RP) (Brown, 1968). Among other differences from the cone late RP, the rod late RP was distinguished by its slower overall time course. Especially emphasized was its slow recovery at stimulus offset, its "slow decay". In experiments in dark-adapted cat, Arden and Brown (1965) then assigned the "remnant negativity" of Granit and Riddel (1934) to this prolonged recovery of the rod late RP.

While the rod receptor potential does have a slower rise at stimulus onset and fall at stimulus offset than the cone receptor potential, its unique slowness at stimulus offset only occurs at relatively high intensities. At intensities above that which saturates its amplitude, the rod receptor potential increases in duration, to continue beyond stimulus offset and then recover slowly towards baseline (Baylor and Lamb, 1982; Baylor et al., 1984). This was earlier termed the "rod after-effect" in horizontal cell recordings from cat (Steinberg, 1969b,c) and occurs, as well, in all roddependent post-photoreceptoral responses. From results of our later studies, the "remnant negativity" of Arden and Brown (1965) in cat, can be assigned to a response originating in proximal retina, the slow negative response, which occurs at relatively low intensities in the dark-adapted retina. At these intensities the rod receptor potential does not contribute to the ERG. This does not necessarily explain the "remnant negativity" originally observed in frog in isolated PIII recordings (Granit and Riddell, 1934). This, indeed, may have had a contribution from the prolongation of rod-driven responses at high stimulus intensities.

The term slow PIII no longer is used to refer to the slow recovery following stimulus offset. It now specifically identifies a negative potential of Müller-cell origin whose times of rise and fall are both slower than those of the rod receptor potential. This slow PIII was discovered by Noell (1953) and later intensely studied by his student, Faber (1969). It was uncovered in rabbit corneal recordings by using sodium iodate injection and cathodal polarization, methods that suppressed the positive potentials of the ERG, especially the $c$-wave. It exhibited a slow onset and slow offset, and an overall time course that resembled PI (i.e. 
the c-wave). The designation "slow PIII" was meant to distinguish it from the photoreceptor component, which was termed "fast PIII". Recordings of this slow response across the neural retina, with RPE cell activity suppressed and depth profiles to localize its origin, led to the hypothesis that it was generated by Müller cells (Faber, 1969). (See also, Böck et al., 1965; Bornschein and von Lützow, 1965; Bornschein et al., 1966; Hanitzsch, 1973; Hanitzsch and Bykow, 1981.) Slow PIII also has been well characterized in cold-blooded retinas (Witkovsky, et al., 1975; Fujimoto and Tomita, 1979) and more recently even in monkey (Valeton and van Norren, 1982). (For further consideration of slow PIII and the Müller cell, see Ripps and Witkovsky, 1985.)

At about the same time as Faber's studies on rabbit, Rodieck and Ford (1969) identified a large negative response in the dark-adapted ERG of cat, which was isolated by sodium iodate. Like Faber (1969), Rodieck and Ford (1969) recognized that it summed algebraically with an RPE component to form the c-wave, but following Brown (1968) they termed this response the late RP.

Intracellular recordings in Müller cells have confirmed the origin of a slow potential originating in these cells that has the time course of the cwave (Karwoski and Proenza, 1977; Dick and Miller, 1985; Dick et al., 1985). It is considered to originate from a hyperpolarization of the distal end of the cell in response to the light-evoked decrease in extracellular potassium concentration $\left(\left[\mathrm{K}^{+}\right]_{\mathrm{o}}\right)$ that accompanies the photoresponse in the subretinal space (Oakley, 1977; Oakley and Green, 1976; Oakley et al., 1979; Steinberg et al., 1980). Under normal conditions the c-wave of the corneal ERG is now considered to represent an algebraic summation of a positive RPE component, and a negative component from Müller cells, slow PIII. Both are generated by cellular hyperpolarizations in response to the light-evoked $\left[\mathrm{K}^{+}\right]_{0}$ decrease (Faber, 1969; Steinberg et al., 1970; Witkovsky et al., 1975; Oakley and Green, 1976; Oakley, 1977; Karwoski and Proenza, 1977; Steinberg et al., 1980).

In sum, methods to block the positive components of the ERG from the RPE and neural retina had revealed two distinct rod-dependent corneal negative components. The remaining negative corneal ERG response and intraretinal response were capable of containing contributions from both negative components. Thus, the original roddependent PIII (or rod late RP) component had been subdivided into photoreceptoral and Müllercell subcomponents. While, the term slow PIII is most commonly used, it also can be called the "retinal or Müller-cell component of the c-wave" to distinguish it from the RPE component. Similarly, the rod contribution can be termed fast PIII when it is being distinguished from the Müller-cell response, although more appropriate terms are the rod receptor potential or rod photoresponse.

With respect to ERG recordings several points need to be emphasized. The discovery and analysis of the two negative components depended, in part, upon techniques that eliminated the positive components of the ERG so that the negative components were isolated. Therefore, whenever negative ERG responses are isolated, for example, by sodium iodate, they may consist of both Müller-cell and photoreceptoral components (Lurie and Marmor, 1980; Nilsson, 1984; Wioland et al., 1988; Yoshimura et al., 1988). However, these two negative components may or may not be observed in the corneal ERG as negative potentials because of their summation with the positive components. The size of the contribution from each of the two negative components will depend on the animal studied, as well as the state of adaptation and overall stimulus conditions.

\subsubsection{EARLY RECEPTOR POTENTIAL (RP)}

Brown and Murakami (1964) identified a short latency response, primarily negative in polarity, from the photoreceptor layer of the macaque monkey in the foveal region. It preceded the usual a-wave and was named the early RP. For a variety of species from squid (Hagins and McGaughy, 1968) to human (Yonemura et al., 1966), the biphasic waveform starts with a small positive component (R1) that is cone-dominated, followed by a larger negative component R2 (Fig. 2). R2 has both rod and cone contributions, but the cone contribution is larger than would be expected 


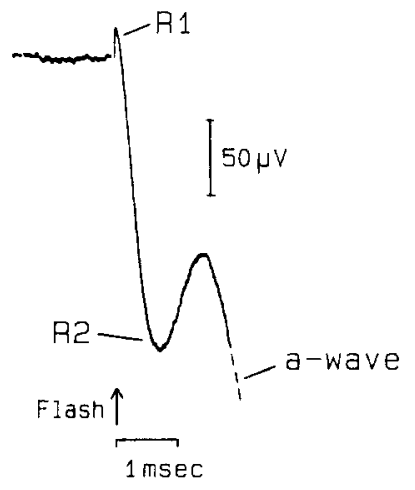

FIG. 2. Early RP of the human ERG. For this "white" stimulus of 7.5 scotopic $\log \mathrm{Td}-\mathrm{sec}, 400 \mu \mathrm{sec}$ duration, and subtending $50^{\circ}$ of visual angle, the negative R2 component is approximately $50 \%$ rod and $50 \%$ cone driven. The a-wave interrupts the return to baseline of R2. (From Sieving and Fishman, 1982, with permission from Documenta Ophthalmologica.)

from the percentage of cones in the retina (Goldstein and Berson, 1970; Goldstein et al., 1975). For a human achromat, in the absence of cone vision, only a reduced negative $\mathrm{R} 2$ remains (Goldstein and Berson, 1970).

The early RP begins $0.7 \mu \mathrm{sec}$ after an intense stimulus that bleaches much or all of the visual pigment (Cone, 1964), and it is complete within $1.5 \mathrm{msec}$ (Berson, 1987). This short latency suggested a role for the early RP in the signaling of quantum absorption by the visual pigments. However, the presence of an early RP in physiologically inert tissues argued against this hypothesis (Brown and Murakami, 1964; Cone, 1964; Brindley and Gardner-Medwin, 1965), and the response now is considered to be an epiphenomenon reflecting charge displacement in the outer segments during the cascade of photochemical reactions following quantum absorption (Cone and Cobbs, 1969). Cones are probably represented more than rods in the response because the pigment molecules in cone outer segments are in disc membranes that are in contact with the extracellular space, whereas pigment molecules in rod outer segments are shielded by the plasma membrane (Berson, 1987).

The early RP provides a unique and direct ERG measure of visual pigment concentration, since its amplitude is proportional to the net quantity of pigment molecules bleached per stimulus. Human photoreceptor dysfunction can be assessed in a variety of conditions, for instance, in inherited photoreceptor dystrophies, such as retinitis pigmentosa (Berson and Goldstein, 1970), and in metabolic iron toxicity, where the a-wave is reduced, but the early $\mathrm{RP}$ is normal (Sieving et al., 1983). Since the early RP does not enter into the analysis of the components considered below, it will not be considered further in this chapter.

\subsubsection{Proximal AND DISTAL PIII}

In isolated cold-blooded retinas intraretinal recordings with a coaxial microelectrode identified a PIII component whose origin was proximal to that of a more distal one (Murakami and Kaneko, 1966). The latter could be attributed to the photoreceptors. The proximal component had a slower onset than the distal component and had less resistance to ammonium vapor. Later, a proximal component also was observed in cat and rat retinas with similar techniques (Pautler et al., 1968). Hanitzsch (1973) identified a proximal PIII component in rabbit that was eliminated by aspartate. It is not clear how these proximal PIII components are related to each other or to our current understanding about slow PIII and the proximal negative potentials described below (Section 4). However, in the case of the cat, the proximal PIII response could well be the scotopic threshold response and slow negative response. The term proximal PIII is not now in common use.

\section{RECORDING THE ELECTRORETINOGRAM}

\subsection{Definitions}

The clinical ERG is usually recorded at the cornea in response to diffuse and uniform illumination of the retina (diffuse or Ganzfeld ERG). The experimental ERG in research animals can be recorded from the cornea as well, but it is often recorded from the vitreous body (vitreal ERG) where the signal is larger (Steinberg et al., 


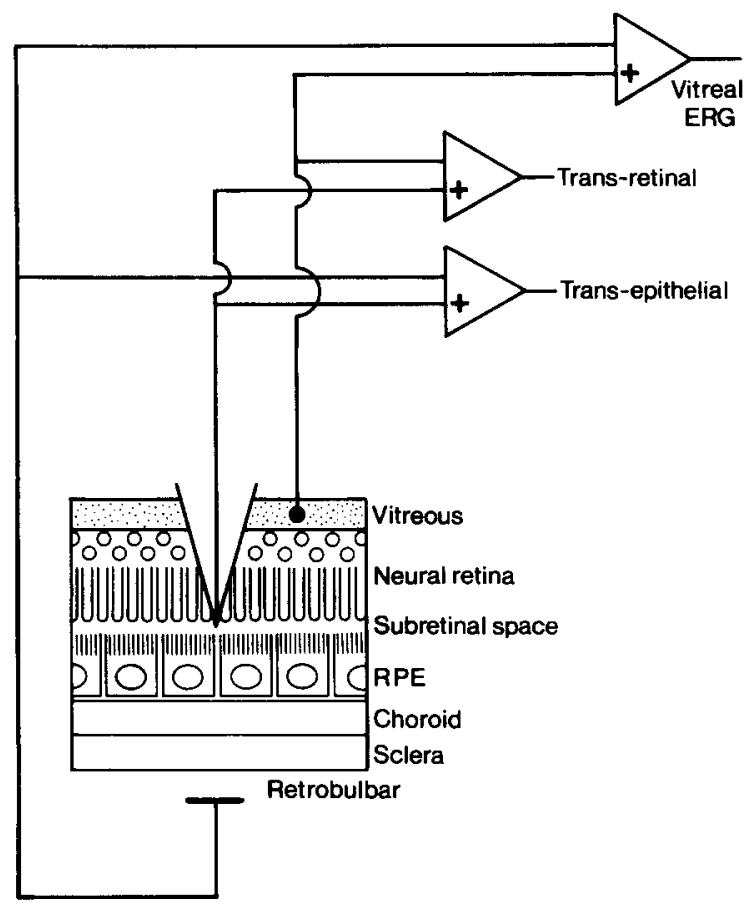

FIG. 3. Diagram of recording system. The ERG was recorded between the vitreal reference and the retrobulbar reference (vitreal reference positive). The microelectrode was referenced to the vitreal reference for the trans-retinal recording, and to the retrobulbar reference for the transepithelial recording. (Modified from Frishman and Steinberg, 1989a, with permission from Journal of Neurophysiology.)

1985). Diffuse illumination is effective at producing ample ERG voltages since responses are evoked from the entire retina. In subjects having rod-dominated retinas, especially nocturnal species, the large peripheral rod population tends to produce the largest ERG components, across a wide range of stimulus conditions.

Figure 3 diagrams the recording system for obtaining ERGs in cat. The vitreal ERG is recorded between a chlorided silver wire placed in the vitreous humor and a retrobulbar reference electrode on the scleral surface. (For the corneal ERG in man the recording electrode is located on or touching the cornea and the reference electrode is placed to make contact with periocular tissues, such as the eyelid or forehead.)

The ERG represents a voltage envelope of temporally overlapping components having distinct time courses and amplitudes. ERG form will depend on how the conditions of stimulation and recording affect each component. For instance, stimulus duration can be a key variable. Components that change in form after stimulus onset will be most fully developed with stimuli of relatively long duration. Components triggered at the offset of the stimulus will also be clearer with long, rather than short, stimuli. In animal experiments ERGs are often elicited by stimuli lasting seconds and recorded with DC amplification, so they usually include the complete or nearly complete waveform of each component. It can be difficult to compare these ERGs with the clinical ERG, which is usually provoked by a very brief stimulus (less than $5 \mathrm{msec}$ ), and recorded with a selective bandpass of $0.3-300 \mathrm{~Hz}$, which does not extend to DC.

\subsection{Origin of ERG Components}

ERG components originate from distinct classes of cells in the vertebrate retina. Three types of cells produce most of the known components: retinal pigment epithelial cells, photoreceptors, and Müller cells. In the neural retina (retina without the RPE), components are often referred to as originating either in the distal retina or the proximal or inner retina. Proximal commonly refers to the interactions that occur among bipolar cell terminals, amacrine cells, and ganglion cells. In cat, we can define proximal as the region from the inner limiting membrane to about half the depth of the inner nuclear layer, roughly the proximal $40-45 \%$ of the thickness of the retina. The distal retina comprises the photoreceptors, horizontal cells, and bipolar cells (Sieving et al., 1986a).

Within each class - RPE, photoreceptors, and Müller cells - the cells are uniformly oriented and for all three classes the orientation is longitudinal (radial), i.e. aligned with the vitreal-scleral axis of the retina. With diffuse illumination, cells in each class tend to undergo similar changes in membrane potential, simultaneously, across a wide population, so that a large extracellular current is generated. This current flows radially through the retina and extends extraocularly to produce the ERG. ERG currents can be initiated 
by either depolarization or hyperpolarization of cells as long as dipoles are created such that current flows in the radial direction. ERG currents are often generated both at the onset and offset of illumination with the resultant components having opposite polarity. (For a more complete discussion of ERG generation, see Faber, 1969; Rodieck, 1973; Steinberg et al., 1985.)

Müller cells serve as the origin for a number of ERG components and contribute substantially to the negative components considered in this chapter. Müller-cell membrane potentials change significantly in response to changes in the concentration of potassium in the extracellular space outside their cell membranes, which are highly selective for $\mathrm{K}^{+}$. These responses are thought to reflect a mechanism for the spatial buffering of potassium released by neuronal activity in their vicinity (Newman et al., 1984; Ripps and Witkovsky, 1985; Newman, 1988; Karwoski et al., 1989). Since the Müller-cell membrane is permeable to $\mathrm{K}^{+}$it will be depolarized by increases in $\left[\mathrm{K}^{+}\right]_{0}$ and hyperpolarized by decreases in accord with the change in the $\mathrm{K}^{+}$equilibrium potential. The Müller cell spans the distance between the inner limiting membrane (endfoot) and subretinal space (microvilli), and Müller-cell polarizations can be created by changes in $\left[\mathrm{K}^{+}\right]_{0}$ at various locations along its length.

We have chosen the Müller cell to illustrate the initiation of ERG components. Figure 4 diagrammatically illustrates the current flow setup by an increase in the extracellular potassium concentration occurring at an arbitrarily chosen point along the Müller cell. The cell is depolarized at that point, creating two opposing loops of current that flow through the cell toward each end and return extracellularly to the origin. These two currents, $i_{1}$ and $i_{2}$, flow across the respective extracellular resistances, $r_{1}$ and $r_{2}$. The polarity and size of the ERG component produced by this depolarization depends on the relative sizes of the voltage drops, $i_{1} r_{1}$ and $i_{2} r_{2}$. From inspection of Fig. 4 it should be clear that $i_{1} r_{1}$ will contribute an ERG component that is vitreal (corneal) positive in polarity and that $i_{2} r_{2}$ will contribute a component of negative polarity. Thus, if $i_{1} r_{1}>i_{2} r_{2}$, the ERG component will be positive, while if the opposite obtains it will be negative. Figure 4 illustrates an example where

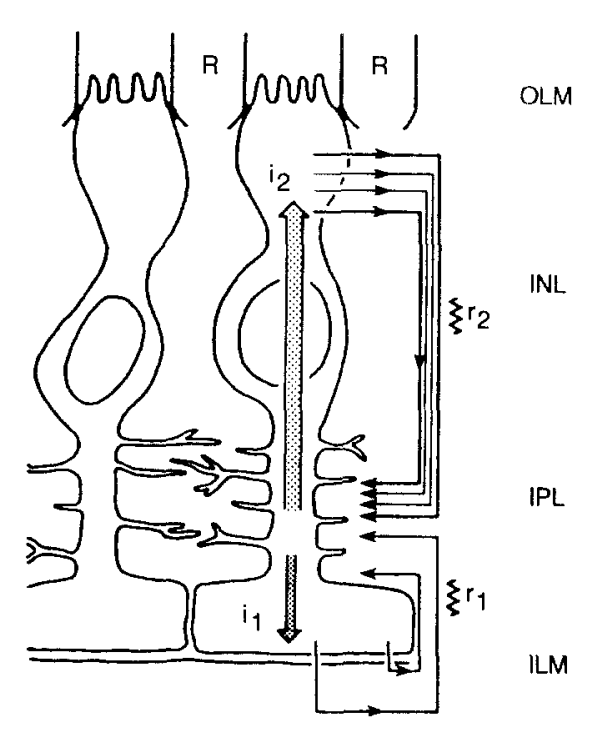

FIG. 4. Model of $\mathrm{K}^{+}$-induced current flow through Müller cells and the extracellular space. In the Müller cell, the proximally directed current, the $i_{1} r_{3}$ loop, carries $\mathbf{K}$. released in the retina toward the endfoot in the vitreous, and the distally directed current, the $\mathrm{i}_{2} \mathrm{r}_{2}$ loop, flows toward the subretinal space. The return paths are through the extracellular spaces. (From Frishman and Steinberg, 1989b, with permission from Journal of

$\mathrm{i}_{2} \mathrm{r}_{2}>\mathrm{i}_{1} \mathrm{r}_{1}$, and causes a vitreal negative ERG, which is the case for the threshold negative components of dark-adapted retina (Section 4.4.3).

With regard to the relative sizes of the $i_{1}$ and $i_{2}$ currents, recent work by Newman indicates that the relative potassium conductance at specific regions along the length of the cell holds the key. This conductance, the $\mathrm{K}^{+}$conductance of Newman $(1984,1985 \mathrm{a}, 1987)$, will depend on the type and number of $\mathrm{K}^{+}$channels in the membrane and the total number of channels, and this is a direct function of the total area of membrane. Müller cells differ considerably among species regarding this measure for the endfoot region compared to the distal portion of the cell (Newman, 1987). The other key variable, extracellular resistance, will depend on the length of the path and probably also on the packing density of cell membrane and on the extracellular structure in the paths. It is becoming clear, for example, 
that extracellular resistance is lower in the plexiform layers than in the nuclear layers (Karwoski et al., 1985a).

\subsection{Intraretinal ERG}

A microelectrode placed somewhere in the extracellular space of the retina records a field potential, which is referred to as the local or intraretinal ERG (Brown and Wiesel, 1961). The waveform of this response depends upon the current flowing between this electrode and a reference electrode. Ideally, it will reflect the electrical activity generated by cells in the immediate vicinity of the microelectrode. The amplitude and polarity of the waveform will depend upon the relative position of the electrode with respect to the current sinks and sources of cells nearby. For monopolar recording a good indifferent reference is considered to be an electrode placed in the vitreous (Rodieck, 1973; Brown and Wiesel, 1961). Figure 3 shows the microelectrode placed in the subretinal space near the apical surface of the RPE. When referenced to the vitreal electrode it records the voltage generated by the neural retina. This type of intraretinal ERG is referred to as the trans-retinal ERG (or trans-retinal potential).

Local ERGs can be generated by relatively local illumination of the retina in the vicinity of the microelectrode, for example, by a small $(<1.0 \mathrm{~mm})$ spot of light. In that case the microelectrode can record the voltage, but the current that leaves the retina may be too small to produce a vitreal or corneal signal, unless sophisticated response averaging is employed. With large retinal currents from diffuse illumination, a corneal ERG can be elicited simultaneously with a local ERG.

Sometimes the intraretinal microelectrode is referenced to an "indifferent" electrode placed behind the eye on the scleral surface. This is usually done when the microelectrode is positioned at the apical surface of the RPE in order to obtain a measure of the trans-epithelial potential, the potential generated by the RPE (Fig. 3). In the case where diffuse illumination is used, there is also a substantial voltage drop of the "diffuse

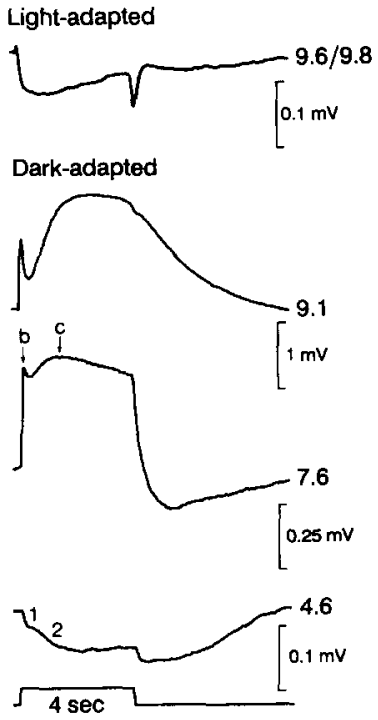

FIG. 5. Vitreal electroretinograms in response to diffuse stimuli of $4.0 \mathrm{sec}$ duration under light- and dark-adapted conditions. Light-adapted ERG (top) in response to flash illumination at $9.6 \mathrm{log} q \mathrm{deg}^{-2} \mathrm{sec}^{-1}$ with steady background illumination at $9.8 \log q \mathrm{deg}^{-2} \mathrm{sec}^{-1}$. Darkadapted ERGs in response to increasing intensities of illumination at 4.6, 7.6 and $9.1 \log q \mathrm{deg}^{-2} \mathrm{sec}^{-1}$. (Modified from Frishman and Steinberg, 1990, with permission from Journal of Neurophysiology.)

ERG" (non-local ERG) between the microelectrode and the reference because of the high resistance of the RPE and sclera. This leads to "contamination" of the local signal. (This contamination will, of course, occur when the microelectrode is at any intraretinal location and it is referred to the scleral reference) (Brown and Wiesel, 1961; Rodieck, 1973).

\section{CAT ERG AS A FUNCTION OF BACKGROUND ADAPTATION}

In cat, the ERG changes dramatically with state of adaptation and with intensity of illumination. Figure 5 shows these changes at selected intensities for dark-adapted and light-adapted conditions, produced by a $4.0 \mathrm{sec}$ stimulus and recorded with DC amplification. Each ERG exhibits negative components, whose precise origin in the retina with respect to cellular location and physiological mechanism must be understood. 
Dark-adapted ERGs at threshold and with dim illumination (4.6) are completely negative. They begin with a rapid negativity following stimulus onset, which gives way to a much slower negative wave, and then at stimulus offset, a negativegoing Off response. At a $3.0 \mathrm{log}$ higher intensity (7.6) the ERG has become predominantly positive in polarity, having prominent $b$ - and c-waves. Finally, at a relatively high intensity (9.1) the dark-adapted ERG is still dominated by the positive $b$-wave and $c$-wave but now a negative trough clearly separates them.

In the light-adapted ERG, over a range of background levels and incremental intensities, the ERG again exhibits prominent negativity (Fig. 4; 9.6/9.8). A sustained negative potential follows the b-wave and at stimulus offset there is a negative Off response.

In the remaining sections we will follow this sequence of changes of the cat's ERG.

\section{DARK-ADAPTED ERG}

It has long been known that ERGs at threshold in dark-adapted mammalian retinas, including human, are negative in polarity (Schweitzer and Troelstra, 1965; Finkelstein et al., 1968; Knave et al., 1972; Jacobson and Ikeda, 1983; Sieving et al., 1986b; Sieving and Nino, 1988). The notion has been that the principle negative component originates from the rods as the rod receptor potential, but this has been found not to be so. As shown in Fig. 5, there are actually two negative components during illumination: a rapid onset component, which has been termed the scotopic threshold response or STR (Sieving et al., 1986b), and a slow negativity that follows it, the slow negative response (Sieving et al., 1986b; Frishman and Steinberg, 1989a). Our analysis indicates that both components originate in proximal retina. These responses are followed at stimulus offset by a negative Off response that does not have a unique cellular origin but represents a composite of components.

\subsection{Scotopic Threshold Response}

\subsubsection{CONTRIBUTION TO THE ERG}

The STR can be observed in relative isolation from the slow negative response by using flashes

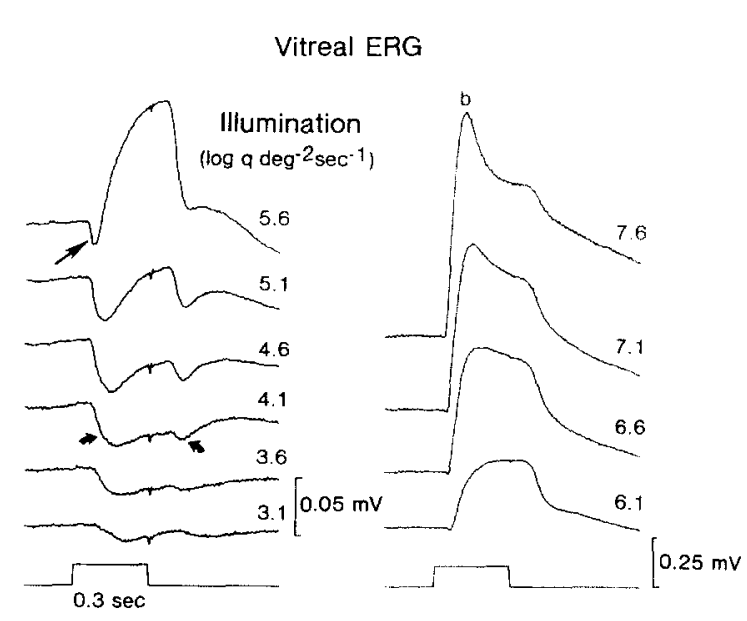

FIG. 6. Dark-adapted vitreal ERG in response to diffuse stimuli of increasing intensity of illumination from 3.1 to $7.6 \log q \mathrm{deg}^{-2} \mathrm{sec}^{-1}$. The b-wave is indicated at 7.6 (b). A straight arrow at $5.6 \log q \mathrm{deg}^{-2} \mathrm{sec}^{-1}$ marks where the STR resembles the a-wave. Two curved arrows at $4.1 \log q \mathrm{deg}^{-2} \mathrm{sec}^{-1}$ indicate the onset and offset of the STR. (Modified from Sieving et al., $1986 \mathrm{~b}$, with permission from Journal of Neurophysiology.)

of a brief duration so that the latter does not fully develop. Typically, as shown in Fig. 6, the ERG at threshold, i.e. when it can be first measured, begins with a negative-going potential following stimulus onset which grows in amplitude $(3.1-4.6 \log q)$ and then is overtaken by a positive component at higher intensities $(5.6 \log q)$. The negative component, whose onset and offset is indicated by arrows at 4.1 $\log q$, is defined as the STR, while the positive component represents the DC component of PII. [PII consists of two components, the DC component at threshold and dim intensities, and the b-wave, an initial peak at higher intensities (Brown and Wiesel, 1961; Steinberg, 1969a).]

The STR was shown to originate from a response in intraretinal depth recordings that had a similiar threshold and dynamic range and also was negative in polarity. As shown in Fig. 7, with a dim stimulus that elicited the STR in the vitreal ERG, a negative-going intraretinal potential was located in proximal retina at $17 \%$ retinal depth, and it became positive in polarity in distal retina.

The contribution of the intraretinal response to the vitreal ERG was demonstrated further by recording the ERG with the microelectrode placed about $25 \mu \mathrm{m}$ in front of the retinal surface. This 


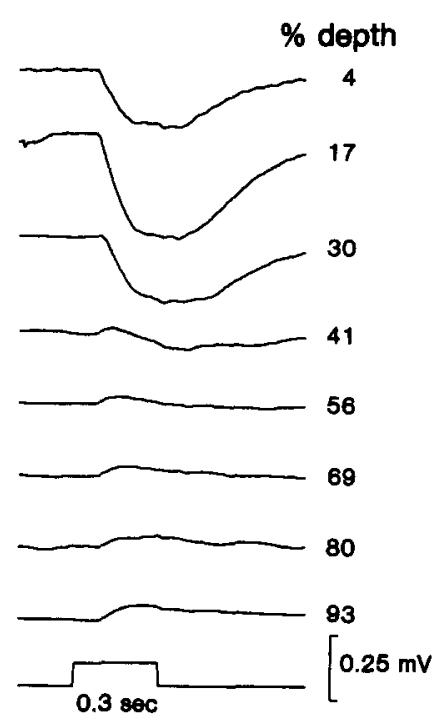

FIG. 7. Retinal depth distribution of dark-adapted responses at a low stimulus intensity of $3.8 \log q \mathrm{deg}^{-2} \mathrm{sec}^{-1}$. The stimulus was a spot $9.9^{\circ}$ in diameter. (From Sieving et al., 1986b, with permission from Journal of Neurophysiology.)

"surface ERG" emphasized the vitreal response from the retinal region in the immediate vicinity of the microelectrode, where the intraretinal responses were obtained. As shown in Fig. 8, the negative threshold ERG in the vitreous could be synthesized by scaling the proximally recorded intraretinal response at its recorded polarity (negative) or by inverting and scaling the distal response, suggesting a single generator for the vitreal signal.

\subsubsection{DifFERENTIATION FROM SCOTOPIC PII}

Two important characteristics of the STR are its presence at dark-adapted threshold and its limited dynamic range, with saturation occurring in the range of $3.0-3.5 \mathrm{log}$ units above threshold, as shown in Fig. 9. This and other features of the STR clearly distinguished it from PII (Sieving et al., 1986b). As is well known, PII, intraretinally, shows an amplitude maxima which is relatively distal (Brown and Wiesel, 1961), and in our studies it occurred, on average, at $48 \%$ retinal depth vs $17 \%$ for the STR. PII also had a higher threshold than the STR, and scotopic PII
A

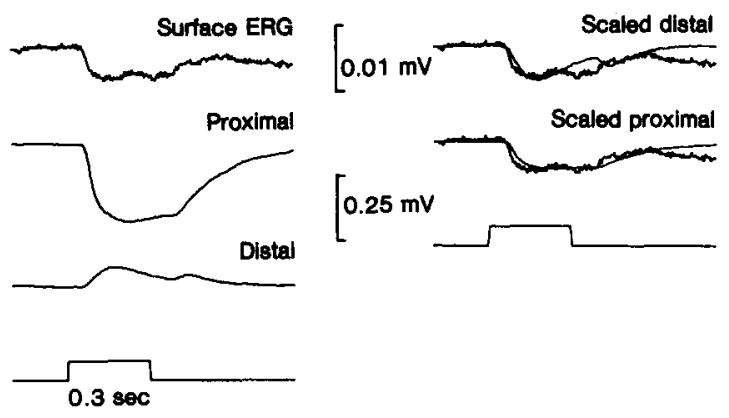

FIG. 8. Reconstruction of the surface electroretinogram from intraretinal recordings in proximal and distal retina for a stimulus that was below the threshold for PII in distal retina. On the left of the figure (A) the top trace is the surface ERG recorded with the microelectrode placed about $25 \mu \mathrm{m}$ from the retinal surface, and the bottom two traces are recordings of the STR in proximal retina at about $6 \%$ retinal depth, and the inverted STR recorded in distal retina at about $50 \%$ retinal depth. Spot size, $9.9^{\circ}$; flash illumination, $4.8 \log q \mathrm{deg}^{-2} \mathrm{sec}^{-1}$. The right of the figure (B) shows scaled distal and proximal responses superimposed on the surface ERG. (From Sieving et al., $1986 \mathrm{~b}$, with permission from Journal of Neurophysiology.)

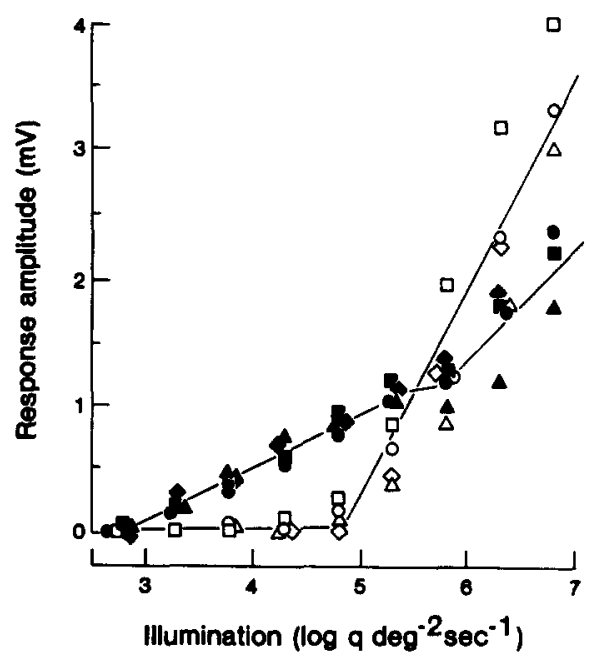

FIG. 9. Amplitudes of dark-adapted proximal (filled symbols) and distal (open symbols) responses as a function of stimulus illumination. Measurements in four cats were made in proximal retina where the STR was maximal and in distal retina, where PII was maximal. In distal retina, measurements were from negative-going responses only, and they were made at the peak of the response, which means that the DC-component of PII was measured at low intensities, and the b-wave was measured at high intensities. (From Sieving et al., 1986b, with permission from Journal of Neurophysiology.) 


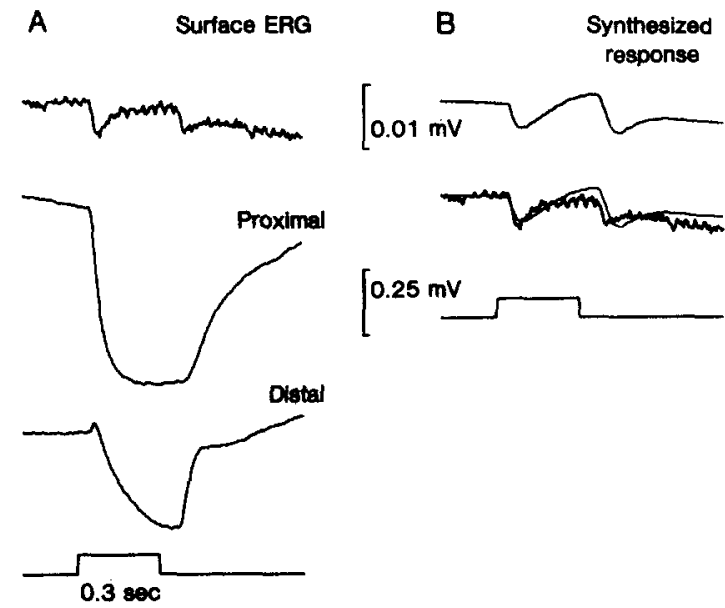

FIG. 10. Reconstruction of the surface electroretinogram from intraretinal recordings in proximal and distal retina for a stimulus that was above the threshold for PII. On the left of the figure (A) the top trace is the surface ERG recorded with the microelectrode placed about $25 \mu \mathrm{m}$ from the retinal surface, and the bottom two traces are recordings of the STR in proximal retina at about $6 \%$ retinal depth, and the inverted PII recorded in distal retina at about $50 \%$ retinal depth. Spot size, $9.9^{\circ}$; flash illumination, $5.8 \log q \mathrm{deg}^{-2} \mathrm{sec}^{-1}$. The right of the figure (B) shows the (scaled) response synthesized by adding the inverted distal response and the proximal response in a ratio of 2.1 to 1 . The synthesized response (fine line) is superimposed on the surface ERG directly below. (From Sieving et al., 1986b, with permission from Journal of Neurophysiology.)

saturated at rod saturation (Linsenmeier and Steinberg, 1982; Sieving et al., 1986b), which is $2.5-3.0 \mathrm{log}$ units above STR saturation.

As shown in Fig. 6, PII adds algebraically with the negative STR to form a composite potential in the ERG of mixed negative-positive polarity. Reconstruction of the surface ERG when both components were present (Fig. 10) provided for the identification of the intraretinally recorded proximal STR and more distal PII in the ERG.

\subsubsection{COMPARISON WITH OTHER SPECIES}

The ERGs of both monkey and human contain a small negative wave near visual threshold that closely resembles the STR of cat, as shown in Fig. 11. For all three species the STR appears at similar intensities of illumination, is of similar size, increases in amplitude linearly with $\log$ intensity, and is masked by PII at comparable intensities. Only the latencies differ: the cat STR has a faster response onset than either the monkey or the human STR, which have identical latencies. The STR also has been described in the dog where it behaves similarly to that of cat and is prominent in the ERG in response to dim illumination (Brabaender and Zrenner, in press).

The suppression of the monkey response by aspartate, with the a-wave remaining intact (Wakabayashi et al., 1988), as in cat (Section 4.1.4), further supports its identification as an STR. For the human, a separation of the STR from the a-wave was found in males with X-linked retinoschisis, which primarily affects the proximal retina during the early stages of disease. Figure 12 shows ERGs from a subject in whom the STR was fully attentuated while the a-wave was preserved. The b-wave (PII) is diminished, as expected for retinoschisis.

As shown by the ERG recordings of the normal subject in Fig. 12, the STR can be observed readily from untrained human subjects, even in the psychologically stressful environment of a diagnostic clinical examination. This figure also points to the potential clinical value of studying the human STR, which may provide different information about retinal function than the a- and b-waves.

\subsubsection{RELATION TO THE A-WAVE}

In the ERG the a-wave can be defined as the fast negative component that precedes the $b$-wave and it is generally held to originate from photoreceptors. As shown in Fig. 13A there is a limited intensity range in cat over which the initial negative transient that precedes the $b$-wave is actually the STR (Sieving et al., 1986b; Wakabayashi et al., 1988). This occurs for several reasons. (1) As will be discussed below (Section 4.5.1), the photoreceptor contribution to the ERG has a relatively high threshold. (2) The STR has a lower threshold than PII. (3) PII at and near threshold has a relatively slow onset so that it is preceded by the onset of the STR (Sieving $e t$ al., 1986b). The distinction from the a-wave can be clearly seen when the STR is pharmacologically 

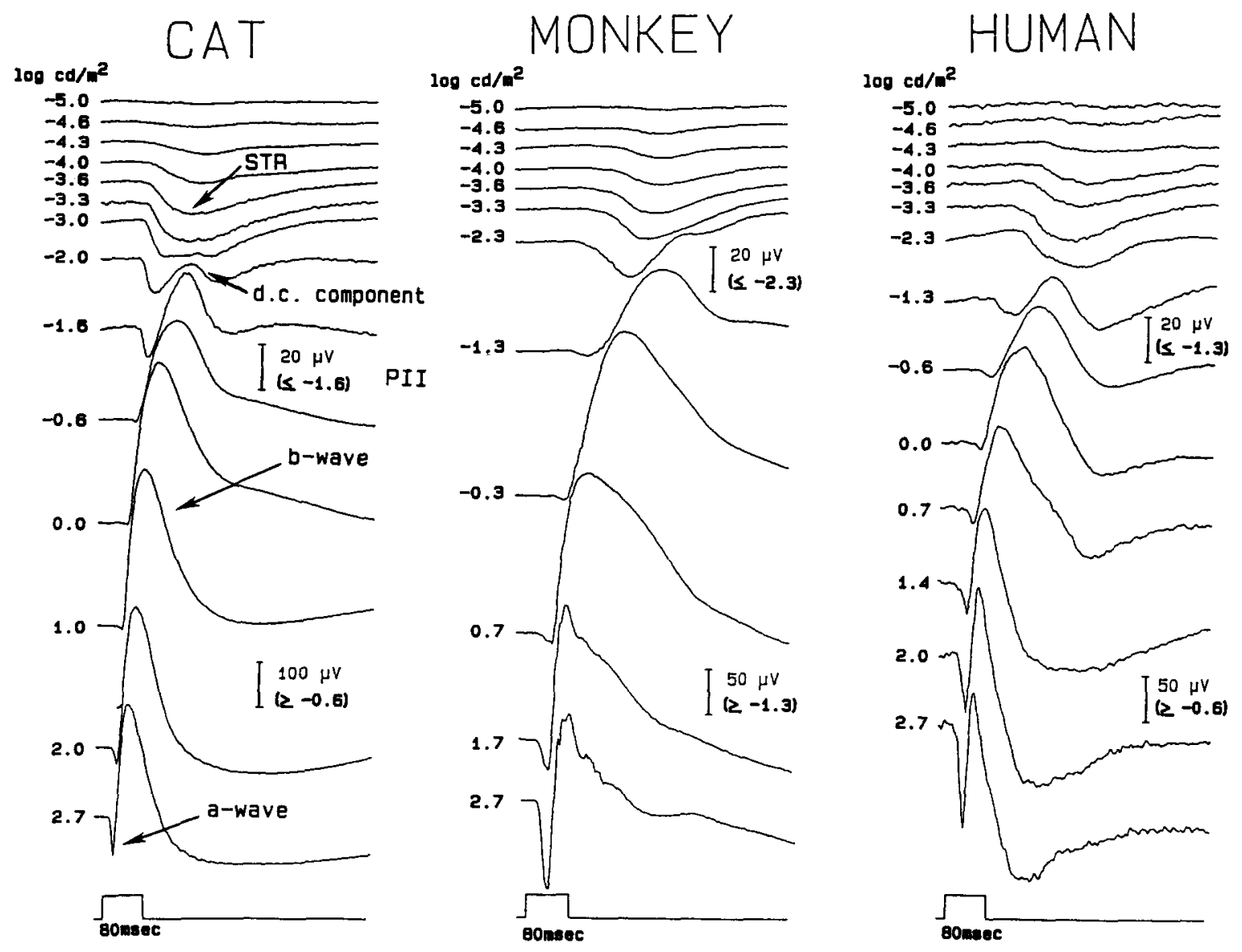

FIG. 11. ERG intensity series for cat, monkey and human, recorded at the cornea. All stimuli were 80 msec, full-field white flashes. Stimulus intensity is given as the surface luminosity of the Ganzfeld bowl. (From Sieving and Wakabayashi, 1990, with permission from Clinical Vision Sciences.)

suppressed. Figure 13B shows that an intravitreal injection of sodium aspartate, which blocks activity post-synaptic to photoreceptors, markedly reduced STR amplitude but not the a-wave.

The STR in the monkey and human ERG also appears to have a much lower threshold than the a-wave (Figs 11 and 12). [In monkeys, the DC component of PII also has a relatively slow onset (Heynen and van Norren, 1985).] Recordings in human indicate that the threshold for the appearance in the ERG of the rod receptor potential actually is about $4.0 \mathrm{log}$ higher than STR threshold (Sieving and Nino, 1988). As suggested, there is no reason to alter current terminology (Wakabayashi et al., 1988). The term a-wave should be reserved for the rod response that occurs with bright stimuli, while STR can be used for the response to dim stimuli.

\subsection{Slow Negative Response}

A slow negative response follows the STR in the ERG in response to dim illumination. This response increases in amplitude following stimulus onset until it plateaus at about $2.0 \mathrm{sec}$. Its growth as a function of flash duration can be observed in Fig. 14, in a duration series from $0.1-4.0 \mathrm{sec}$ and Fig. 15 shows an intensity series. Note that the three separate components of the dark-adapted ERG can be observed with a $4.0 \mathrm{sec}$ stimulus 

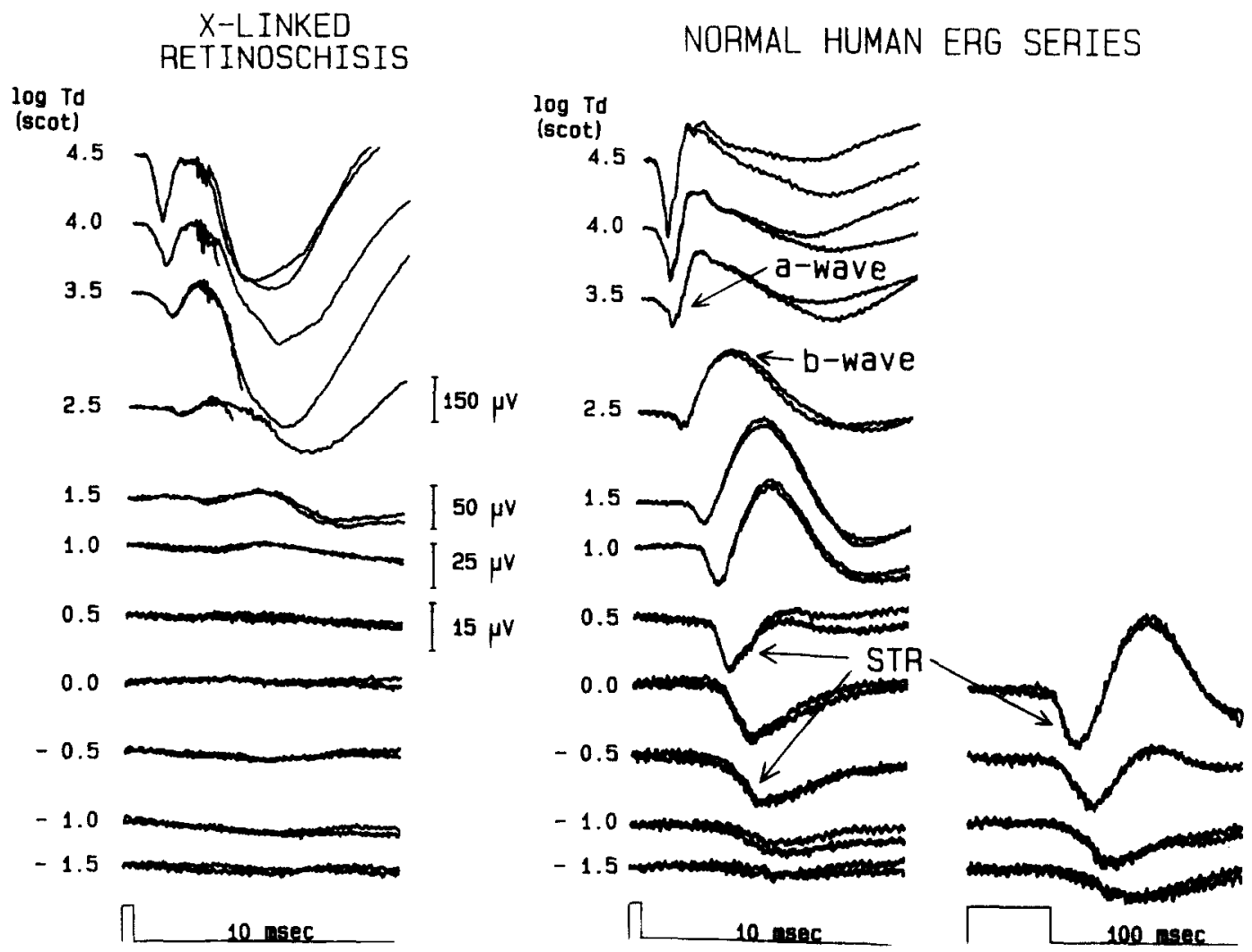

FIG. 12. Human ERG intensity series recorded at the cornea from untrained clinical subjects. Stimuli were full-field white flashes in a Ganzfeld bowl. Tracings at and below $1.0 \mathrm{log}$ Td are 15 averages each with the amplifier at a gain of 10,000 . $3 \mathrm{~dB}$ cut-off at $1-1000 \mathrm{~Hz}$. The amplitude scales apply to tracings alongside and above or below. Left: ERG from a male with X-linked retinoschisis (which primarily affects the inner retina), shows a nearly complete loss of the STR, but full preservation of a-wave amplitude. As expected for retinoschisis, the $V_{\max }$ of PII was reduced, while PII threshold was elevated by only about $0.5 \log$ units. For this subject, psychophysical rod final thresholds were elevated by 0.5 log units or less at fixation and at four points of the peripheral retina. Schisis was present in the fovea but not in the periphery. Right: ERG from a clinically normal subject shows PII threshold near $0.5 \log$ Td for $10 \mathrm{msec}$ flashes and near $-0.5 \log$ Td for $100 \mathrm{msec}$ flashes. The STR is evident below PII threshold. Human psychophysical absolute threshold is roughly $-3.2 \mathrm{log}$ Td for $100 \mathrm{msec}$, wide-field stimuli.

(Fig. 15, $5.1 \log q$ ). In temporal order they are (1) the STR, (2) slow negative response and (3) Off response. Observe that as duration was shortened below $2.0 \mathrm{sec}$ (Fig. 14), a trough developed that was composed of a merger between the negativegoing slope of the slow negative response and the even steeper negative-going portion of the Off response.

The slow negative response behaves practically identically to the STR as a function of stimulus intensity. Figure 16 shows a plot of the amplitude of the ERGs of Fig. 15 at $300 \mathrm{msec}$ when the STR was at a plateau (open symbols), and at $4.0 \mathrm{sec}$ (filled symbols) when the slow negative response had reached a plateau. Thus, the two responses occur at a similar threshold and increase in amplitude from threshold to around $6.0 \log q$, above which the positive $b$-wave and $c$-wave components (measured at $4.0 \mathrm{sec}$ ) begin to dominate the ERG.

\subsubsection{NOT PIII, FAST OR SLOW}

Since slow negative responses in the ERG were previously thought to represent either the rod receptor potential (fast PIII) or a Müller-cell component (slow PIII), it is necessary to 
A

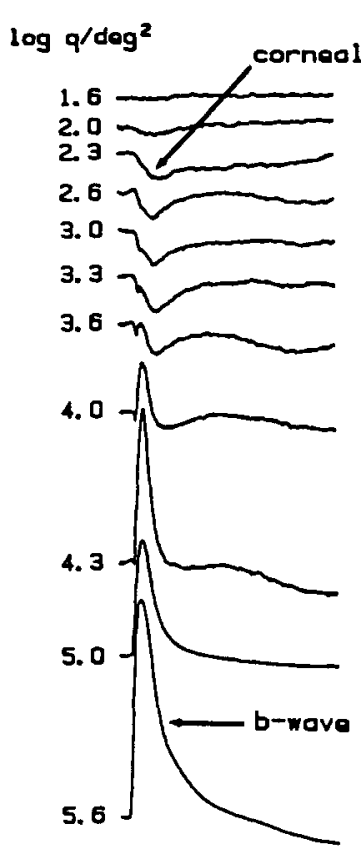

B ASPARTATE

\author{
$\log q / \operatorname{dog}^{2}$
}

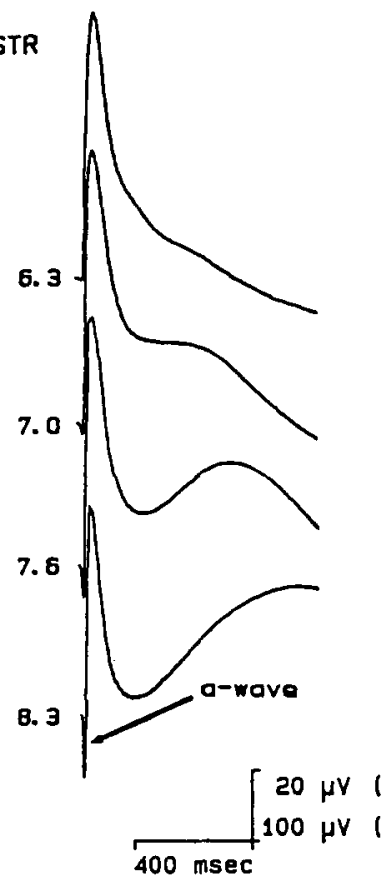

(4.3 \& below)

(5.0\& above)
3.6

4.0

4. 3 a

5. 0

5.3

$5.6 \sim$

$6.0 \sim$

$6.3 \sim$

6.67

7.0

7.

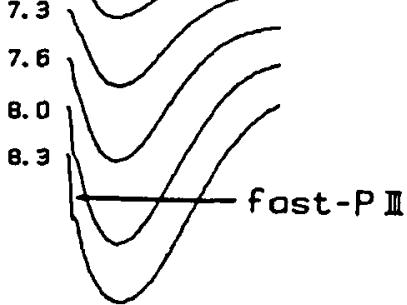

FIG. 13. Cat ERG intensity series recorded at the cornea before (A, Control) and after an intravitreal injection of $130 \mu \mathrm{mol}$ of monosodium L-aspartate (B, Asparate). The $10 \mu \mathrm{sec}$ Xenon flash stimulus occurred at the beginning of each trace. Recordings began $1 \mathrm{hr}$ after injecting aspartate and continued for $\mathbf{4 5} \mathrm{min}$, for dim to bright stimuli. An STR was evident in the control series, but it was absent after aspartate, while fast PIII (a-wave) was unchanged after aspartate. (Modified from Wakabayashi et al., 1988, with permission from Investigative Ophthalmology and Visual Science.)

distinguish the slow negative response described here from these other negative components.

The data indicated that it could not be slow PIII (Frishman and Steinberg, 1989a). First, its time course was considerably slower than slow PIII as measured intraretinally both at stimulus onset and offset. Second, is the evidence from the effect of stimulus intensity on $\left[\mathrm{K}^{+}\right]_{0}$ in the subretinal space recorded with a $\mathrm{K}^{+}$-selective microelectrode (Fig. 17). At the lowest intensity (3.6) the slow negative response appears in the vitreal ERG (Fig. 17, left column) as the slow negative-going potential that follows the STR at stimulus onset. Observe that a slow increase in potassium appears at this intensity. [The source of this increase from proximal retina is considered below (Section 4.4.2). $]$ The increase in $\left[\mathrm{K}^{+}\right]_{0}$ became larger at 5.1 as did the slow negative response in the ERG. A
$\left[\mathrm{K}^{+}\right]_{0}$ decrease in the subretinal space generates slow PIII, and this decrease showed up at the highest intensity (7.1), when the vitreal ERG had a combined PII and c-wave response. (At this intensity intraretinal recordings showed the presence of slow PIII.) Thus the slow negative response is present in the absence of the potassium decrease in subretinal space that causes slow PIII.

Experimental manipulations that eliminate or severely depress activity proximal to the photoreceptors were used to establish conclusively that the slow negative response did not originate in photoreceptors. APB prevents On-type bipolar cells from receiving photoreceptor input (Slaughter and Miller, 1981) and therefore eliminates responses to the onset of illumination in the path from photoreceptors to On-type ganglion cells. Figure 18 shows that intravitreal APB 


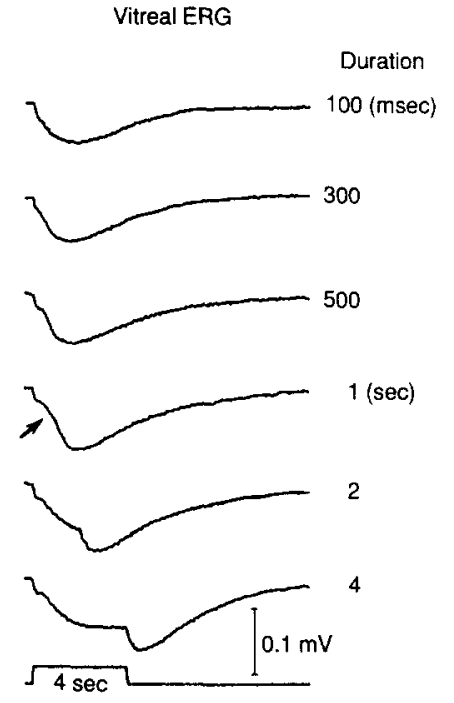

FIG. 14. Dark-adapted vitreal ERGs to diffuse stimuli of increasing duration over a range from $100 \mathrm{msec}$ to $4.0 \mathrm{sec}$ at an intensity of $5.1 \log q \mathrm{deg}^{-2} \mathrm{sec}^{-1}$. The arrow marks where the slow negative and negative Off responses merged. (From Frishman and Steinberg, 1989a, with permission from Journal of Neurophysiology.)

eliminated the entire negative-going $E R G$ in response to dim illumination as well as the $b$-wave at higher intensities. Only the c-wave survived.

\subsubsection{COMPARISON WITH OTHER SPECIES}

The slow negative response was described earlier in sheep (Knave et al., 1972), where it had been attributed to the rod photoreceptors (Fig. 19). Because of its slow time course it is more difficult to record it in the human ERG, since good DC recordings are required and it is not yet clear that it is present. The published recordings of Knave et al. (1973) showed a slow corneal negativity in a human subject that resembled the slow negative response, with its maximum amplitude occurring about $2.5 \mathrm{sec}$ after stimulus onset.

\subsection{Off Response}

The Off response to dim illumination consists of a relatively rapid negative-going phase at

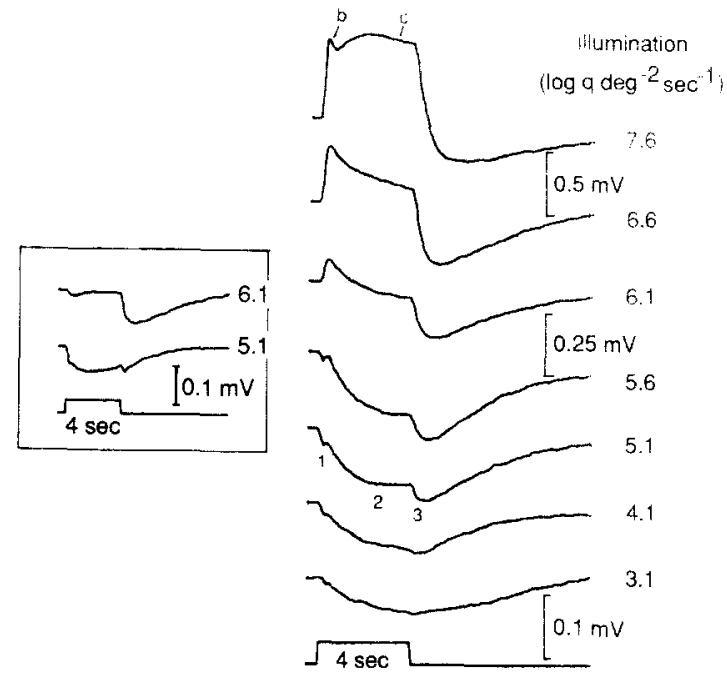

FIG. 15. Dark-adapted vitreal electroretinograms in response to diffuse stimuli increasing in intensity of illumination over the range from 3.1 to $7.6 \log q \mathrm{deg}^{-2} \mathrm{sec}^{-1}$. The numbers, 1, 2, and 3 at $5.1 \log q \mathrm{deg}^{-2} \mathrm{sec}^{-1}$, indicate, respectively, the three negative components of the dark-adapted ERG: the STR, the slow negative response, and the negative $O f f$ response. The $b$ - and c-waves are indicated at $7.6 \log q \mathrm{deg}^{-2} \mathrm{sec}^{-1}$. The inset shows results from another cat at two intensities 5.1 and $6.1 \log q \mathrm{deg}^{-2} \mathrm{sec}^{-1}$. Amplitude calibrations apply for all traces above the calibration mark. (From Frishman and Steinberg, 1989a, with permission from Journal of Neurophysiology.) stimulus offset, followed by a negative trough and slow recovery towards the baseline (Figs 5, 14 and 15). Unlike the STR, and the slow negative response, a single component does not create this Off response. Instead, it is formed from PII and the slow negative response as they recover following the offset of illumination. It is generated, therefore, by the recovery of the On system upon reentry into darkness.

Brown (1968) had earlier identified the rapid component as the decay of PII, using stimulus intensities well above threshold. This interpretation was confirmed for dim illuminations as well (Frishman and Steinberg, 1989 a). Briefly, the threshold of this rapid phase and its growth with intensity followed that of PII; 


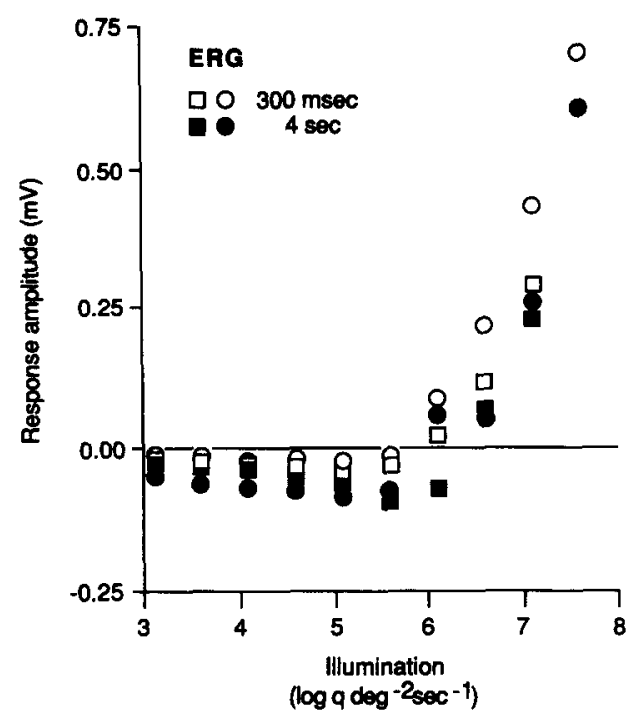

FIG. 16. Amplitude of the dark-adapted vitreal ERG as a function of stimulus illumination for the cat whose data appear in Fig. 15 (circles) and for another cat (squares). Open symbols show measurements made at $300 \mathrm{msec}$ after stimulus onset where the STR was maximal, and filled symbols designate measurements at $4 \mathrm{sec}$ where the slow negative response was maximal. At $7.5 \log q \mathrm{deg}^{-2} \mathrm{sec}^{-1}$ the measurement for the open symbol was made at $150 \mathrm{msec}$ where the b-wave was maximal. (From Frishman and Steinberg, 1989a, with permission from Journal of Neurophysiology.)
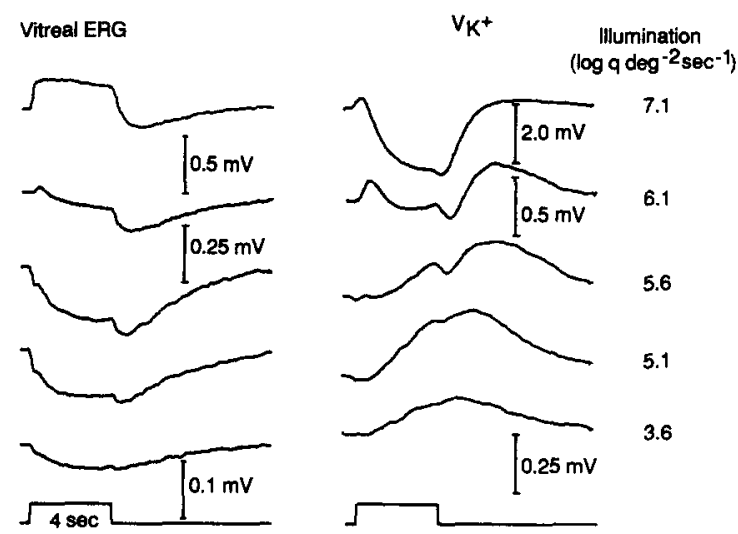

FIG. 17. Simultaneous recordings of the dark-adapted vitreal $E R G$ and $V_{K^{+}}$in response to diffuse stimuli of increasing illumination from 3.6 to $7.1 \log q \mathrm{deg}^{-2} \mathrm{sec}^{-1}$. The double-barreled $\mathrm{K}^{+}$sensitive microelectrode was placed in subretinal space. (Modified from Frishman and Steinberg, 1989a, with permission from Journal of Neurophysiology.)

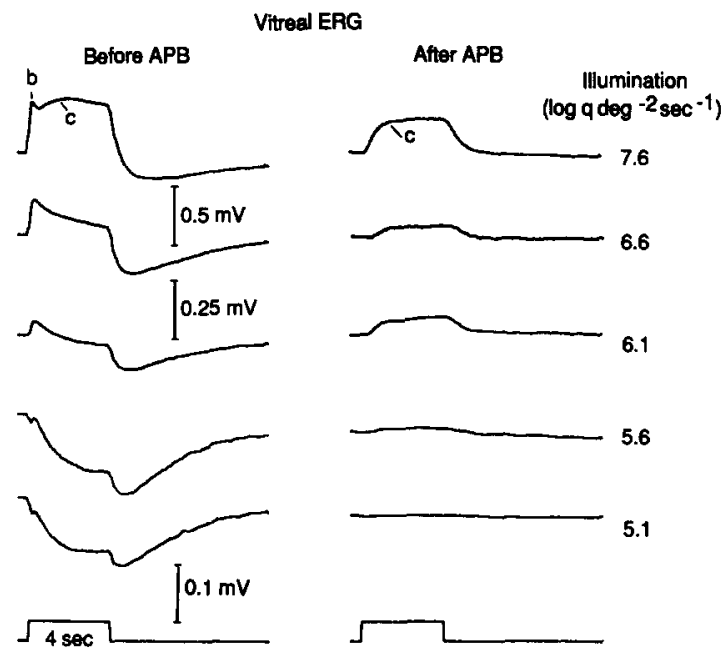

Fig. 18. Effects of APB upon the dark-adapted vitreal ERG. Dark-adapted responses are shown before (left) and about $4.5 \mathrm{hr}$ after (right) intravitreal injection of APB (1.2 mM) to stimuli of increasing illumination between 5.1 and $7.6 \log q \mathrm{deg}^{-2} \mathrm{sec}^{-1}$. (Modified from Frishman and Steinberg, 1989a, with permission from Journal of Neurophysiology.)

\section{Sheep ERG}

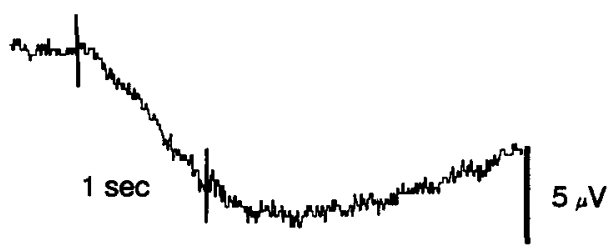

FIG. 19. ERG of the sheep recorded from the cornea in response to dim illumination. Intensity of light stimulus was $2.4 \log$ units below b-wave threshold for the darkadapted eye. Onset and cessation of light stimulus (1 sec) is marked by vertical bars in the record. Amplitude calibration, $5 \mu \mathrm{V} ; 200$ responses were summated. Interval between stimuli, $10 \mathrm{sec}$. (Modified from Knave et al., 1972, with permission from Vision Research.) 
like PII it was also eliminated by APB, and again, like PII, but unlike the STR and slow negative response, it survived an intravitreal injection of $\mathrm{Ba}^{2+}$ (Section 4.4.2). Similarly, with dim illuminations the slow recovery phase has been identified with the return to baseline of the slow negative response (Frishman and Steinberg, 1989a). Thus, it followed the stimulus - response characteristics of the slow negative response and was eliminated from the ERG when the slow negative response was eliminated by $\mathrm{APB}$ or intravitreal $\mathrm{Ba}^{2+}$.

Previously it was conjectured that the slow recovery phase, which had been termed "remnant negativity" represented the slow return to baseline of the rod receptor potential (Arden and Brown, 1965; Brown, 1968). It is now clear, however, that with dim illumination this response originates in more proximal retina as the recovery phase of the slow negative response (Frishman and Steinberg, $1989 \mathrm{a}, \mathrm{b})$. This is consistent with observations discussed in Section 4.5 that the rod receptor potential appears in the ERG only at relatively high intensities in the scotopic and mesopic range. At these intensity levels the ERG is dominantly positive in polarity, consisting of PII and the c-wave.

\subsection{Mechanism of Threshold Negative Components}

Since the STR and slow negative responses have similar stimulus-response properties we will consider them together. At this writing the complete mechanism for these responses has not been worked out, and much remains to be done. The data so far indicates that a $\mathrm{K}^{+}$-Müller cell mechanism generates the voltage of the STR and probably the slow negative response as well, where neurons in proximal retina release $\mathrm{K}^{+}$, which then depolarizes the Müller cell. These neurons may be elements in a proximal retinal circuit that is active at threshold with dim illumination in the darkadapted retina.

\subsubsection{CURRENT SOURCE DENSITY ANALYSIS AND DEPTH PROFILES}

The first recordings of the STR as a function of retinal depth (Fig. 7) showed that it is a negative potential of maximum amplitude in proximal retina around the inner plexiform layer, which inverts in mid-retina so that in distal retina it has a positive polarity. This suggests the presence of a current sink proximal to the reversal point, and a source distal to the point. A preliminary current source density analysis of the STR in cat (performed by taking the second spatial derivative of locally recorded intraretinal ERG voltages, weighted by the tissue resistivity at each retinal depth), supports this suggestion (Sieving et al., 1988). The analysis revealed a current sink near the inner plexiform layer/inner nuclear boundary, and a source more distally in the inner nuclear layer. This analysis, which placed the major source/sink activity in mid-retina, is also consistent with the negative polarity of the STR in both the proximal retina and the vitreous. In contrast, the b-wave reverses polarity quite proximally in the retina, and, in amphibian exhibits a large source near the retino-vitreal border, with the sinks located more distally (Newman, 1980).

While a current source density analysis is not yet available for the slow negative response, depth distributions were measured (Fig. 20). The initial transient (STR) reached its maxima in proximal retina $(30 \%$ depth in this figure, which is deeper than the average), and reversed polarity in distal retina $(59 \%)$ depth. Following the STR, the response occurring at the time course of the slow negative was represented in proximal retina by a slow positive-going climb toward baseline. Measurements of field potential amplitudes from the baseline at progressively longer latencies in Fig. 21 showed a proximal march of the reversal point in the retina with time after stimulus onset. The potential at $4.0 \mathrm{sec}$ reversed on average $9.2 \%+/-6.8 \%(n=4)$ more proximally than at $300 \mathrm{msec}$. Thus, as the slow negative response grows in amplitude the reversal point shifts proximally, a finding that also predicts a proximal shift in source/sink, and this was corroborated by $\mathrm{K}^{+}$measurements (Section 4.4.3).

\subsubsection{Potassium measurements}

From measurements in cold-blooded retinas we know that a prominent light-evoked source of $\mathrm{K}^{+}$ 

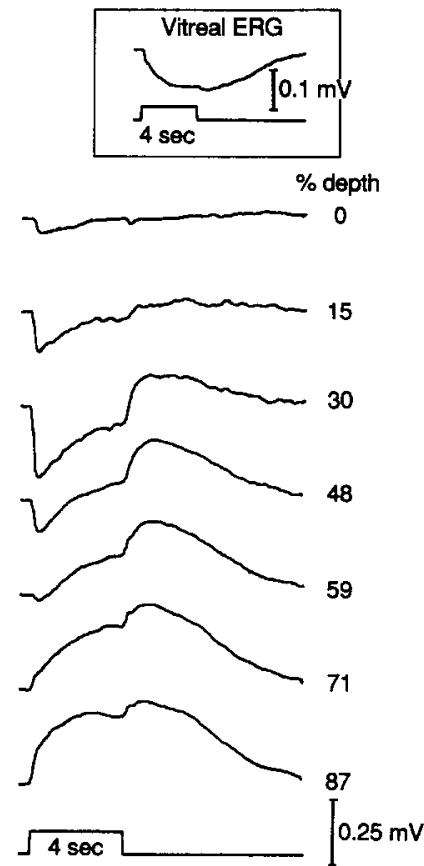

FIG. 20. Depth distribution of dark-adapted intraretinal responses to a diffuse $4.0 \mathrm{sec}$ stimulus at a low intensity of $3.6 \log q \mathrm{deg}^{-2} \mathrm{sec}^{-1}$. Inset shows the simultaneously recorded vitreal ERG. (From Frishman and Steinberg, $1989 \mathrm{a}$, with permission from Journal of Neurophysiology.)

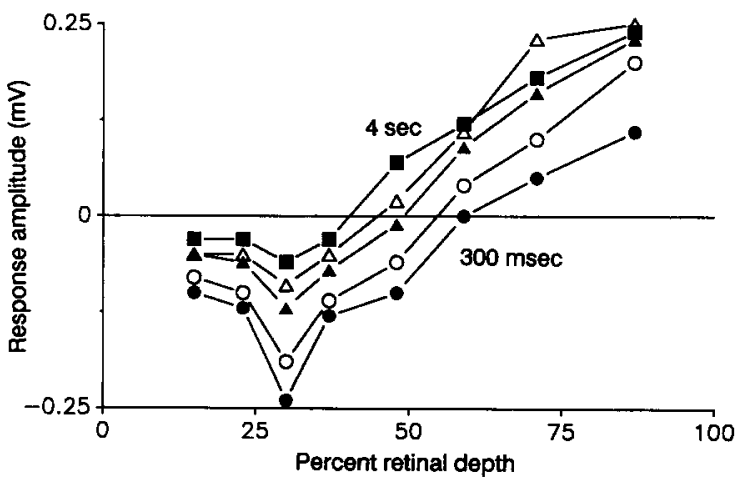

FIG. 21. Amplitudes of dark-adapted intraretinal responses in Fig. 20 vs percent retinal depth. Measurements were made at $300 \mathrm{msec}$ (filled circles) where the STR had reached a plateau, and $1.0 \mathrm{sec}$ (open circles), $2.0 \mathrm{sec}$ (filled triangles), $2.5 \mathrm{sec}$ (open triangles), and $4.0 \mathrm{sec}$ (filled squares) after stimulus onset when the slow positive-going climb at the time-course of the slow negative response had reached a plateau in proximal retina. (From Frishman and Steinberg, 1989a, with permission from Journal of Neurophysiology.) exists in proximal retina (Dick and Miller, 1978; Karwoski and Proenza, 1977; Kline et al., 1978; Oakley and Green, 1976; Vogel, 1980). For lightadapted responses such $\mathrm{K}^{+}$changes were shown to depolarize Müller cells to cause the M-wave, a field potential of proximal retina (see Section 5.1.1). Also, Vogel (1980) had described a proximal $\mathrm{K}^{+}$increase in dark-adapted frog retina that was probably rod dependent. It had been hypothesized, therefore, that the STR may be analagous to the $\mathrm{M}$-wave in representing a $\mathrm{K}^{+}$dependent depolarization of the Müller cell in proximal retina (Sieving et al., 1986b).

Measurements of intraretinal $\mathrm{K}^{+}$changes have supported this hypothesis in cat as shown in Fig. 22. Up to the intensity where the STR saturated (6.1), extracellular $\mathrm{K}^{+}$concentration rose quickly at light onset to a level that was maintained during the $4.0 \mathrm{sec}$ stimulus and then returned more gradually towards baseline at light offset. Most importantly, the $\mathrm{K}^{+}$increase occurred at the same threshold intensity as the field potentials in proximal retina. Also, the dynamic range (Fig. 23), latencies and rates of rise for the increase in $\mathrm{K}^{+}$followed similar functions of intensity as the field potentials. Finally, the amplitude of this light-evoked increase in $\left[\mathrm{K}^{+}\right]_{\mathrm{o}}$ exhibited a similar relationship to retinal depth as the field potential. For example, in the experiment illustrated in Fig. 24 (Frishman and Steinberg, $1989 \mathrm{~b}$ ) both the field potential and the increase in $\left[\mathrm{K}^{+}\right]_{0}$ had maxima at $20 \%$ retinal depth. As the electrode was moved distally in the retina the onset of the increase in $\left[\mathrm{K}^{+}\right]_{0}$ slowed and the response became smaller.

In summary, the recordings of potassium showed that a light-evoked increase originated in proximal retina at a location similar to the point where the field potentials were maximal and that the increase in $\mathrm{K}^{+}$had a stimulus-response relationship that was similar to that of the field potentials. This supported an hypothesis for a role of $\mathrm{K}^{+}$in causing the field potentials by depolarizing Müller cells. $\mathrm{Ba}^{2+}$ blocks the $\mathrm{K}^{+}$ conductance of Müller cells (Newman, 1985b; Newman, 1989; Karwoski et al., 1989) and experiments with $\mathrm{Ba}^{2+}$ provided further evidence in support of this hypothesis.

Figure 25 shows that an intravitreal injection of 


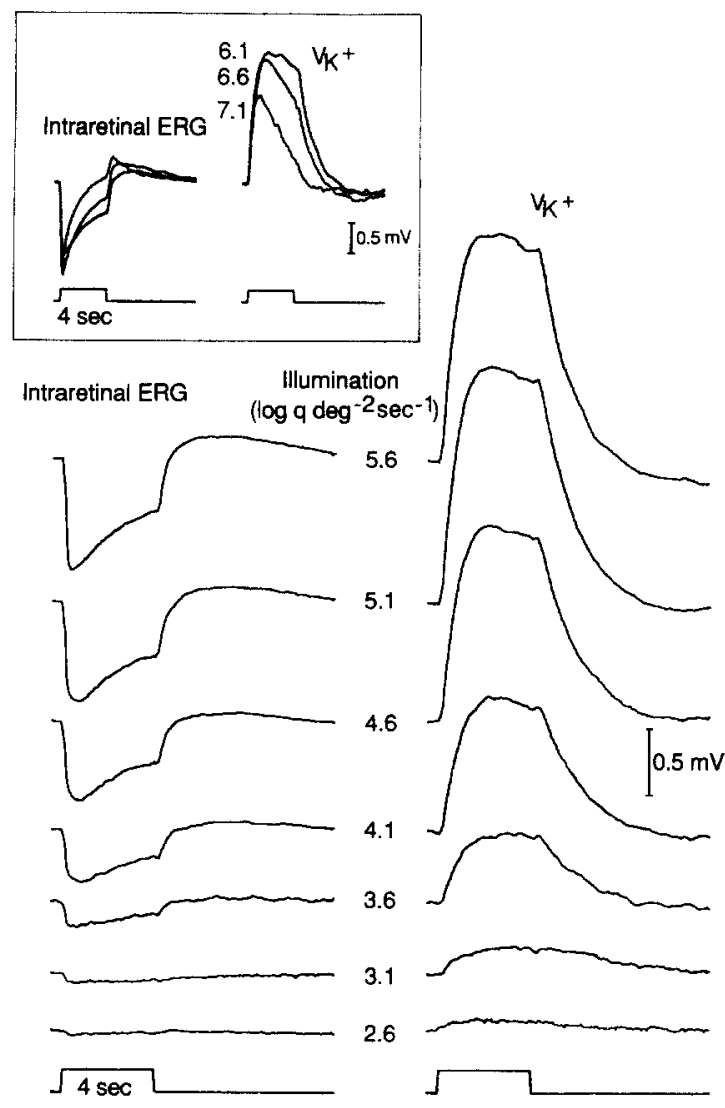

FIG. 22. Proximal intraretinal dark-adapted responses to diffuse stimuli of increasing illumination over the range from 2.6 to $5.6 \log q \mathrm{deg}^{-2} \mathrm{sec}^{-1}$. Responses were recorded at a retinal depth where the STR was maximal. Intraretinal ERGs (field potentials) are shown on the left, and $\mathrm{V}_{\mathrm{K}^{+}}$, recorded simultaneously with the $\mathrm{K}^{+}$-sensitive barrel of the double-barrelled microelectrode, on the right. The inset shows superimposed responses to stimuli of 6.1, 6.6, and 7.1 $\log q \mathrm{deg}^{-2} \mathrm{sec}^{-1}$. (From Frishman and Steinberg, $1989 \mathrm{~b}$, with permission from Journal of

Neurophysiology.)

barium chloride blocked both the STR and the slow negative response in the vitreal ERG. Intraretinally, the field potential in proximal retina was also completely absent following the barium. PII remained, and dominated both the ERG and the intraretinal recordings from subretinal space. A similar experiment with a $\mathrm{K}^{+}$ electrode in place (Fig. 26) showed that when $\mathrm{Ba}^{2+}$ eliminated the STR in proximal retina, the $\mathrm{K}^{+}$ increase was still present.

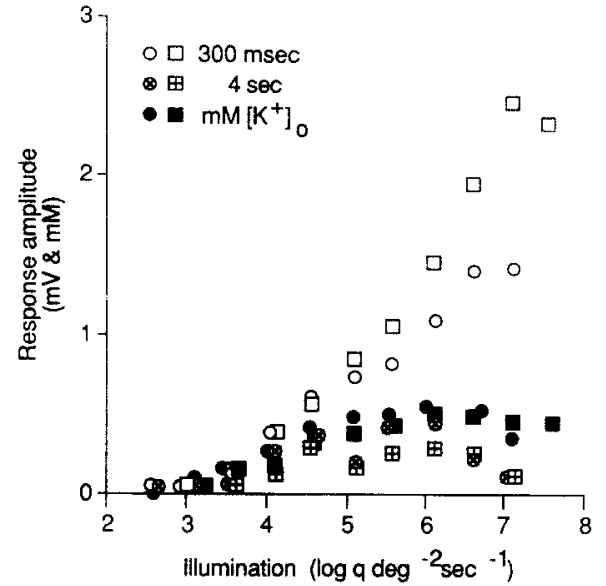

FIG. 23. Amplitudes of dark-adapted proximal intraretinal ERGs and $\left[\mathrm{K}^{+}\right]_{0}$ (filled symbols) for the data in Fig. 22 (circles), and for one other cat (squares). The plot includes amplitudes of the intraretinal ERG at 300 msec (open symbols), and $4.0 \mathrm{sec}$ (crossed symbols) after stimulus onset. $\left[\mathrm{K}^{+}\right]_{0}$ was measured at the peak of the response. (From Frishman and Steinberg, 1989b, with permission from Journal of Neurophysiology.)

\subsection{3. $\mathrm{K}^{+}-$MÜLLER-CELL MECHANISM}

As described in Section 2, the Müller cell extends longitudinally in the neural retina from inner to outer limiting membrane, and thus can be a carrier of radial currents in the retina and the eye. Currents can flow intracellularly either toward the vitreal endfoot, the proximally directed $i_{1} r_{1}$ loop, or toward the distal end, the $i_{2} r_{2}$ loop (Fig. 4). In amphibian Müller cells, Newman and Odette (1984) modeled the b-wave so that current flow was virtually all toward the vitreal endfoot $\left(i_{1} r_{1}\right)$ where $K^{+}$-conductance is highest (Newman, 1984, 1985a). The polarity of the b-wave supports this model; it is negative-going throughout most of the retina, and positive-going in the vitreous. The current source density analysis (Newman, 1980) was also consistent, showing a large current source at the vitreal endfoot, and sinks more distally, around the outer plexiform layer and inner plexiform layer where light-evoked $\left[\mathrm{K}^{+}\right]_{0}$ increases have been recorded in several species (Kline et al., 1978, 1985; Dick and Miller, 1978, 1985; Dick et al., 1985; Karwoski and 


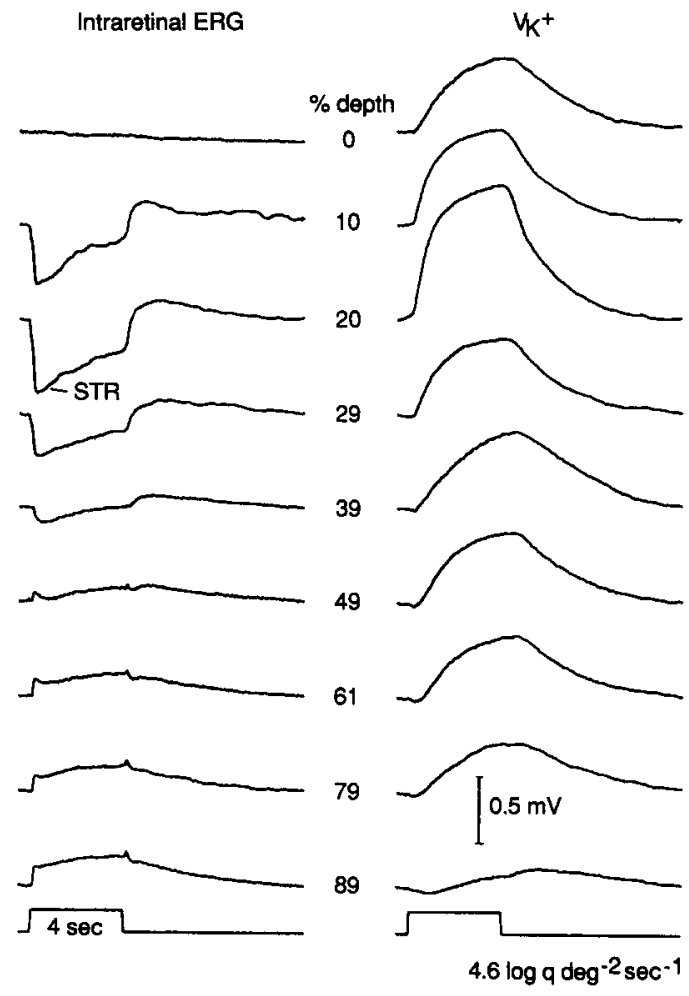

FIG. 24. Retinal depth distribution of dark-adapted responses at a relatively low stimulus intensity of $4.6 \log q \mathrm{deg}^{-2} \mathrm{sec}^{-1}$. (From Frishman and Steinberg, $1989 \mathrm{~b}$, with permission from Journal of Neurophysiology.)

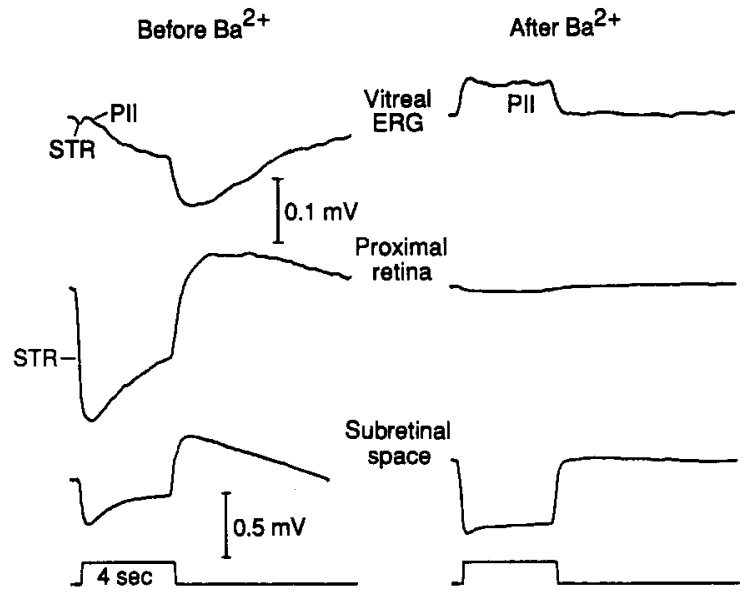

FIG. 25. Effect of intravitreal injection of $\mathrm{BaCl}_{2}(3 \mathrm{mM})$ on the dark-adapted vitreal ERG, the proximal intraretinal response (approximately $20 \%$ depth) and the response recorded distally in subretinal space (approximately $90 \%$ depth) for a $4.0 \mathrm{sec}$ flash, at an intensity of $5.6 \log q \mathrm{deg}^{-2} \mathrm{sec}^{-1}$. The presence of the STR and PII before $\mathrm{BaCl}_{2}$, and of PII after $\mathrm{BaCl}_{2}$ is marked in several places. (From Frishman and Steinberg, 1989a, with permission from Journal of Neurophysiology.)
Proenza, 1978; Karwoski et al., 1985b). The direction of current flow for the STR in the cat retina must be different from that of the b-wave since the STR is negative-going in the vitreous, and proximal retina, and it inverts half-way through the retina. Furthermore, the current source for the STR occurred in mid-retina, and was distal to the current sink. This suggests that the $\mathrm{i}_{2} \mathrm{r}_{2}$ loop is much larger for the STR than it is for the b-wave, and that it is the dominant loop. The distribution of $\mathrm{K}^{+}$conductivity in the cat Müller cell is consistent with this interpretation, since the cat Müller cell has high conductances at both ends, with the distal end higher than the proximal end (Newman, 1987). A difference between the cat retina and the amphibian retina,

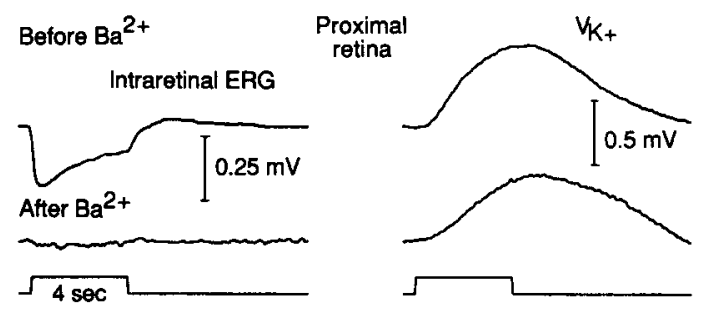

Fic. 26. Effect of an intravitreal injection of $\mathrm{BaCl}_{2}$ (3.9 mM vitreal concentration) on the intraretinal STR and slow negative response (left), and the simultaneously recorded light-evoked increase in $\left[\mathrm{K}^{+}\right]_{\mathrm{o}}$ (right) in proximal retina at approximately $10 \%$ retinal depth. Responses before $\mathrm{Ba}^{2+}$ are shown on the top, and responses $56 \mathrm{~min}$ after $\mathrm{Ba}^{2+}$, on the bottom (5.0 log $q \mathrm{deg}^{-1} \mathrm{sec}^{-1}$ ). (From Frishman and Steinberg, 1989b, with permission from Journal of Neurophysiology.) 
which may affect the distribution of $\mathrm{K}^{*}$ conductances in the Müller cell, is that the cat (monkey and human as well), but not the amphibian, has an inner retinal circulation.

There is strong evidence in amphibia that Müller cells buffer extracellular $\left[\mathrm{K}^{+}\right]_{0}$ changes in the retina by siphoning $\mathrm{K}^{+}$from one region to another (Newman et al., 1984; Karwoski et al., 1989). In the cat, a spread of the proximal retinal $\left[\mathrm{K}^{+}\right]_{0}$ increase elicited at low stimulus intensities into distal retina was observed (Frishman and Steinberg, 1989b). The $\left[\mathrm{K}^{+}\right]_{0}$ increase in distal retina was eliminated by $\mathrm{Ba}^{2+}$, supporting the idea that $\mathrm{K}^{+}$released in proximal retina was carried distally via the Müller cell.

With regard to the slow negative response its reversal more proximally in the retina than the STR (Fig. 21) suggests that current in the $i_{2} r_{2}$ circuit is even more dominant than it is for the STR. A possible mechanism is that following an initial rise in $\left[\mathrm{K}^{+}\right]_{0}$ in the proximal retina, $\mathrm{K}^{+}$ diffuses proximally, raising $\left[\mathrm{K}^{+}\right]_{0}$ near the Müllercell endfoot and as $\mathrm{K}^{+}$accumulates there, less current flows in the proximal loop making the distal loop even more dominant. Examination of the time course of light-evoked $\left[\mathrm{K}^{+}\right]_{0}$ increases for $10 \mathrm{msec}$ flashes, showed that the $\left[\mathrm{K}^{+}\right]_{0}$ increase, measured at $300 \mathrm{msec}$ after stimulus onset, was maximal at $18 \%$ depth where the STR was maximal, but at $1.0 \mathrm{sec}$, and at longer delays, as predicted by the hypothesis, the $\left[\mathrm{K}^{+}\right]_{0}$ increase was maximal at $0 \%$ retinal depth (Frishman and Steinberg, 1989b).

Although there is much evidence to support a $\mathrm{K}^{+}$- Müller-cell hypothesis for the STR and slow negative response, the possibility can not be completely eliminated that an initial portion of the proximal field potential in dark-adapted retina is neuronal in origin, in analogy to the proximal negative response (PNR), a response of neuronal origin first described in amphibian retina (Burkhardt, 1970). Since measurements were limited by the rise time of the $\mathrm{K}^{+}$electrode, it was not possible to determine whether the latency and rise time of the $\left[\mathrm{K}^{+}\right]_{0}$ increase matched exactly that of the STR.

\subsubsection{NEURONAL ORIGINS}

Since the STR and slow negative response are

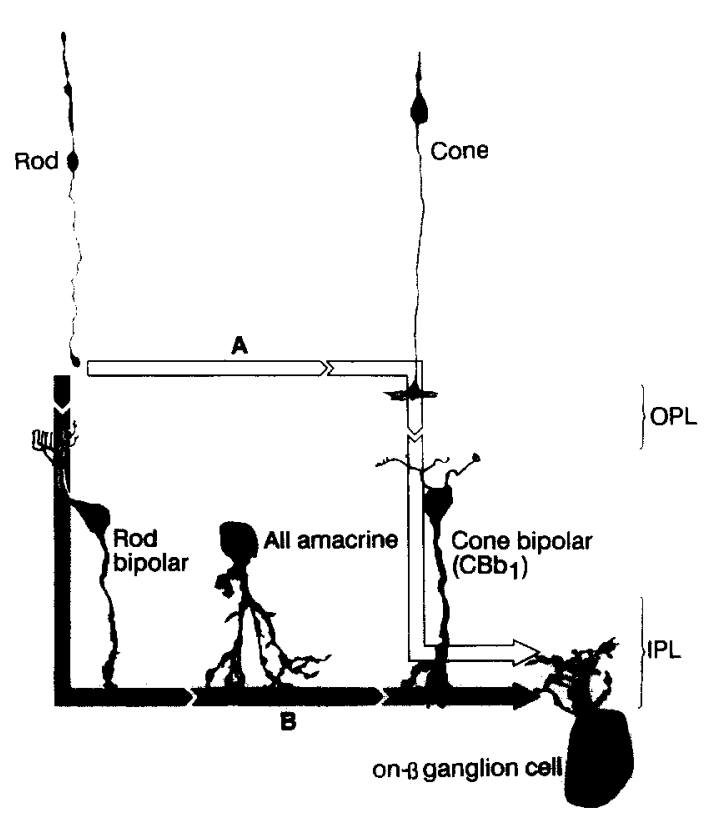

FIG. 27. Two rod pathways to the On- $\beta$ ganglion cell in cat. A: Cone bipolar pathway. B: Rod bipolar pathway. (Modified from Smith et al., 1986, with permission from Journal of Neuroscience.)

low threshold rod-dependent responses, it is likely that they are generated in the rod to rod-bipolar to amacrine to cone bipolar to ganglion cell circuitry that is thought to underly transmission of rod responses to ganglion cells (Kolb and Nelson, 1983; Smith et al., 1986; Müller et al., 1988). Anatomical evidence for this circuit, illustrated schematically in Fig. 27, has been provided for several species, including cats (Famiglietti and Kolb, 1975; Kolb and Nelson, 1983) and rabbits (Dacheux and Raviola, 1986), and it appears to exist in monkeys (Famiglietti and Kolb, 1975; Hendrickson et al., 1988) and humans (Marc and Liu, 1985) as well.

Note that rod signals can also reach ganglion cells via cone bipolar cells since there are gap junctions between rods and cones in cats (Kolb, 1977) and monkeys (Raviola and Gilula, 1975), and rod signals in cats have been recorded in cones (Nelson, 1977) and cone bipolar cells (Nelson, 1980; Kolb and Nelson, 1983). It has been 
speculated that the rod to rod bipolar circuit passes quantal signals to ganglion cells whereas the rod to cone to cone bipolar circuit begins to operate at intensities of illumination near cone threshold (Smith et al., 1986).

Pharmacological experiments suggest that third order neurons are involved in the generation of the STR and slow negative response. Studies with glycine and GABA, two neurotransmitters localized to third order neurons in cats, also showed that the STR differs from PII, which is generally thought to arise in bipolar cells (Naarendorp et al., 1988; Frishman, Yamamoto, and Steinberg, unpublished observations). GABA suppressed the STR completely, but enhanced PII near threshold (Fig. 28). Use of GABA agonists and antagonists suggested that primarily $\mathrm{GABA}_{\mathrm{A}}$ receptors mediated the GABA effects. For instance in Fig. 29, picrotoxin, a GABA $_{A}$ antagonist, had an effect opposite to that of GABA: it enhanced the suprathreshold STR and slow negative response, and suppressed PII. Finally, like GABA, glycine also suppressed the STR, and although it suppressed PII as well, the suppression of the STR was much greater (Fig. 30A). Figure 30B shows that pretreatment with the glycine antagonist, strychnine, blocked the effect of the glycine on the STR. [It should be noted that three other neurotransmitters localized to third order neurons: dopamine, acetylcholine, and serotonin, did not produce selective effects on the STR (Naarendorp and Sieving, 1990).]

Amacrine cells rather than ganglion cells are likely to be the third order neurons primarily involved in generating these responses. Ganglion cells were eliminated as a major contributor because experimental optic nerve section, which eventually led to a complete loss of ganglion cells, did not eliminate the STR (Sieving, 1989). Two depolarizing amacrine cells that figure prominently in the threshold rod circuitry are the AII and the A17 cells. In the cat retina, AII cells relay scotopic signals from rod bipolar cells to ganglion cells via cone bipolar terminals (Kolb and Nelson, 1983), and A17 cells, which also receive input from rod bipolar cells, feed back onto the same bipolar cells (Kolb, 1979; Kolb and Nelson, 1983; McGuire et al., 1984). AII amacrine cells are glycinergic, whereas A17 cells are GABAergic (Pourcho, 1980; Pourcho and Goebel, 1983, 1985). Neither the AII nor the A17 amacrine cell

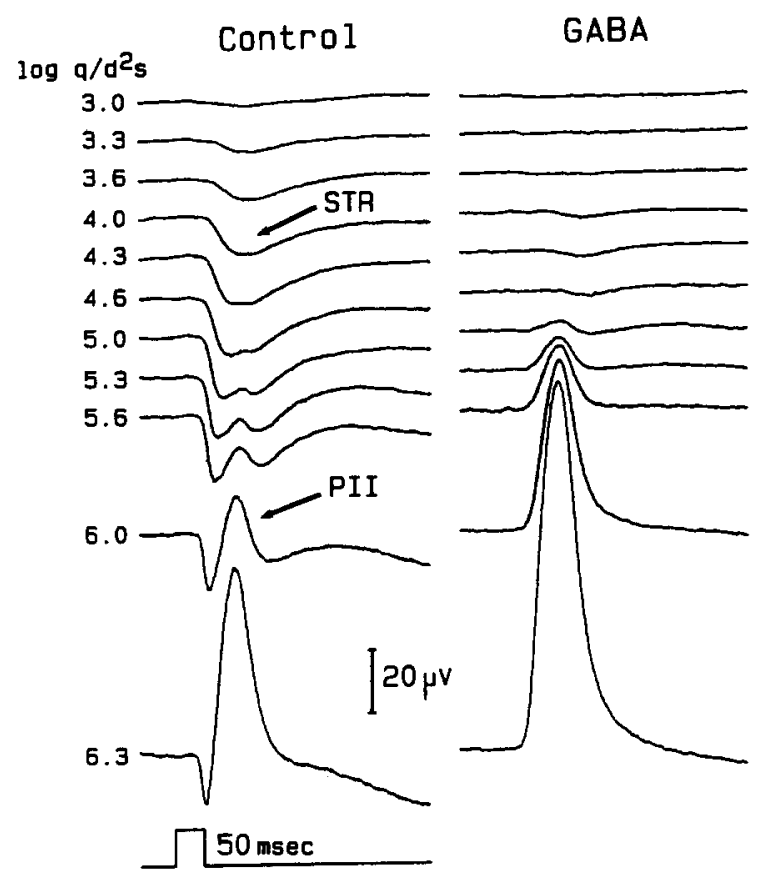

FIG. 28. Effect of an intravitreal injection of $20 \mu \mathrm{mol}$ of GABA on the STR and PII of the ERG in cat (right) compared with control responses (left). Illumination was increased from 3.0 to $6.3 \log q \mathrm{deg}^{-2} \mathrm{sec}^{-1}$; flash duration $50 \mathrm{msec}$. GABA was injected immediately after the control series and the intensity series was repeated $2 \mathrm{hr}$ later. (From Naarendorp and Sieving, 1990.)

had the exact response characteristics of the STR and the slow negative response. Receptive field characteristics differed, and the absolute darkadapted thresholds of the amacrine cells, measured in eye cup preparations (Nelson, 1982; Nelson and Kolb, 1985), were higher than the field potentials measured in the intact eye (Sieving et al., 1986b; Frishman and Steinberg, 1989a,b). However, the rod threshold for these amacrine cells was lower than the threshold for PII, and their responses saturated well below rod 

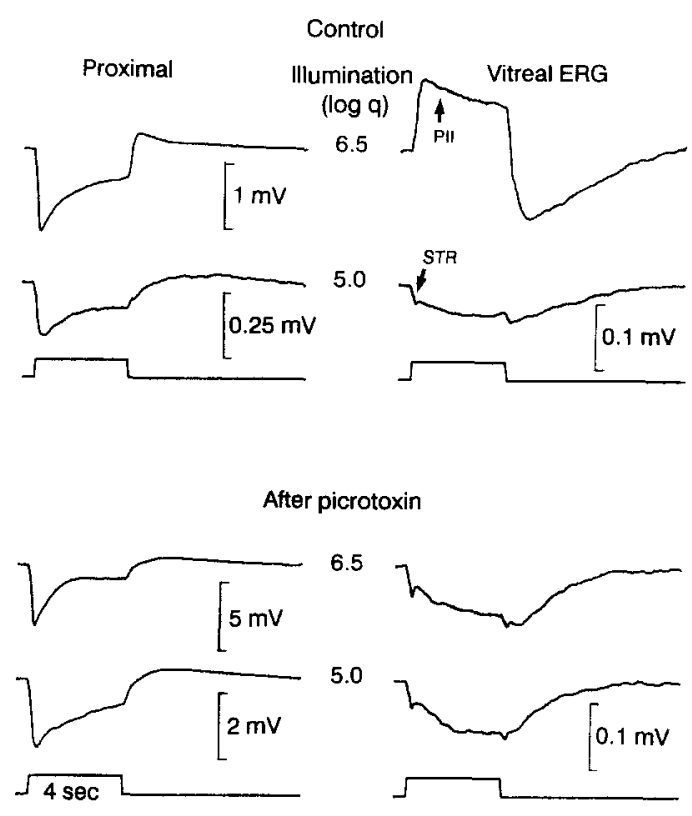

FIG. 29. Effect of an intravitreal injection of picrotoxin on proximal retinal responses measured at $33 \%$ retinal depth (left) and the simultaneously recorded vitreal ERG (right). Control responses to a diffuse flash from darkness at the top are shown for two illuminations, one below $\left(5.0 \log q \mathrm{deg}^{-2} \mathrm{sec}^{-1}\right)$ and one above (6.5 log $q \mathrm{deg}^{-2} \mathrm{sec}^{-1}$ ) saturation of the STR in proximal retina. Responses at the bottom were measured $2.5 \mathrm{hr}$ after picrotoxin $(0.17 \mathrm{~mm})$ was injected. After picrotoxin, the responses in proximal retina were greatly enhanced (note calibrations), and PII was eliminated from distal retina (not shown), and the vitreal ERG.

saturation, as did the STR and slow negative response.

\subsubsection{THRESHOLD CIRCUIT}

It is significant that the threshold for these responses approaches that of the most sensitive ganglion cells in cat (Harding and Enroth-Cugell, 1978) and close to the absolute threshold for vision in cat. Similarly, the STR in human ERG recordings can be recorded near absolute threshold for human vision (Sieving and Nino, 1988). Copenhagen et al. (1989) provided evidence from studies in toad for the tremendous amplification that occurs in the retinal circuitry from photoreceptor to ganglion cell. While the gain occurs in more than one stage, the output of the photoreceptor has been amplified by a factor of about 100. It is this gain that allows the absorption of very few quanta to produce a response in the ganglion cell and ultimately to be seen by the observer. It is this gain that also allows the experimenter to find responses in the proximal retina and in the ERG that are near the absolute threshold for vision, but are large enough to be recorded. The STR and slow negative response, then, provide information about the activity of a circuit in the rod system that amplifies rod signals at threshold and over a range of dim illuminations.

\subsection{Contributions from the Rod Receptor Potential}

\subsubsection{A-WAVE}

The voltage generated by the rods when hyperpolarized by light, the rod photoresponse, contributes to the a-wave of the electroretinogram (Brown, 1968). In dark-adapted retinas, with stimuli below threshold for the cones, the a-wave is, of course, dominated by the rods. However, the rod-driven a-wave has a relatively high threshold when compared to the STR, and the STR may produce an initial negative deflection before PII in the ERG at threshold and with relatively dim illumination, creating thereby a "false" or "pseudo" a-wave (Sieving et al., 1986b; Wakabayashi et al., 1988).

That the threshold for the rod-driven or "true" a-wave is considerably higher than for the STR is really not so surprising when we compare the amplification of these two signals. As already noted (Section 4.4.5), the STR circuit produces a greatly amplified signal, one large enough to be recorded intraretinally as a field potential and also at the cornea as an ERG response. By comparison, at and near absolute threshold, it will be much more difficult, if not impossible, to record the rod receptor potential because of the small size of the current produced by an individual rod. At absolute threshold only one rod out of about two hundred absorbs a quantum and the photocurrent 

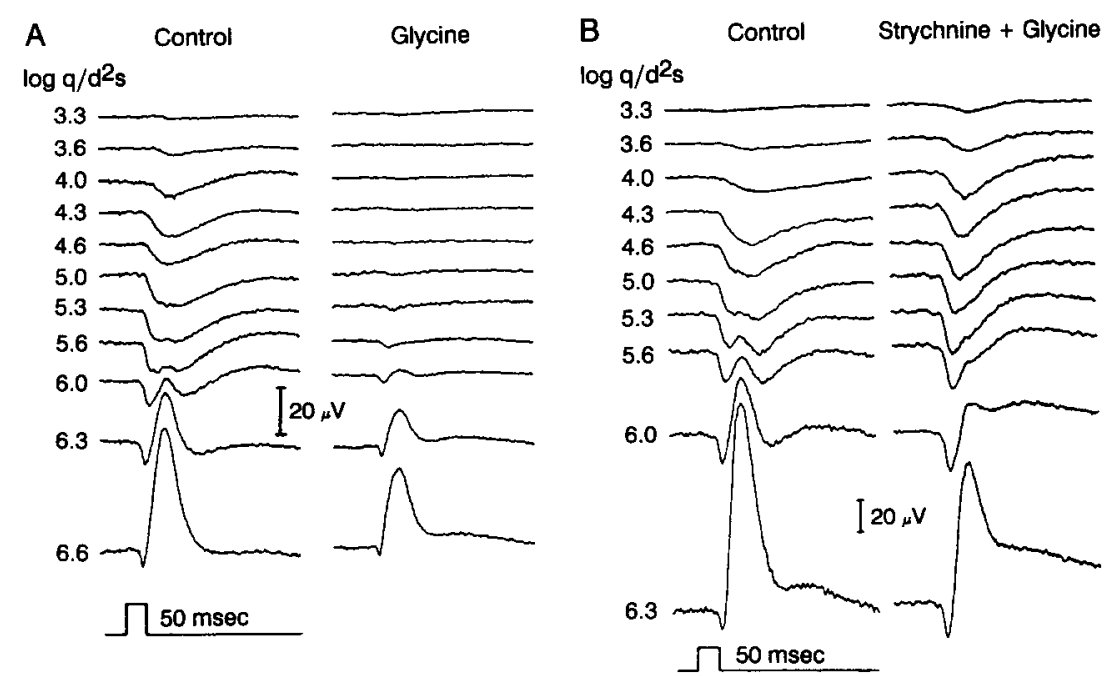

FIG. 30. Effect of an intravitreal injection of glycine (A) followed by the antagonist, strychnine (B) on the STR and PII of the ERG in cat. A: The Control (left) responses were obtained with illumination increasing from 3.3 to $6.6 \log q \mathrm{deg}^{-2} \mathrm{sec}^{-1}$ and flash duration of $50 \mathrm{msec}$. Glycine $(20 \mu \mathrm{mol})$ was injected intravitreally and the intensity series was repeated $2 \mathrm{hr}$ later (right). Flash duration $50 \mathrm{msec}$. B: Effect of an intravitreal injection of strychnine $(0.05 \mu \mathrm{mol})$, followed by glycine $(20 \mu \mathrm{mol}) 15 \mathrm{~min}$ later. This experiment was performed on the same cat as in A, 35 days later. (From Naarendorp and Sieving, 1990, submitted.)

produced by the absorption of one quantum by a single isolated rod in macaque monkey and cat is near 1 picoamp (Baylor et al., 1984; Tamura et al., 1989). It is not until the light is made about $3.0 \mathrm{log}$ more intense that every rod absorbs a quantum and this has been estimated to occur in cat at the bottom of the mesopic range of illumination (Smith et al., 1986). Rod-driven a-waves are not observed in the ERG until the light is well into the mesopic range. For instance, in Fig. 13A, in cat, absolute threshold as judged by the STR is around $2.3 \log q$, and the a-wave is not visible until $7.0 \log q$.

An advantage of the STR for clinical study is its very presence in the ERG in relative isolation with dim illumination where practically the entire response can be observed. In contrast, the rod driven a-wave, when it finally appears, does not demonstrate the entire time course of the rod receptor potential. As shown in Fig. 31, in a recording of photocurrent from an isolated cat rod outer segment (Tamura et al., 1989), the response extends the full duration of the flash, and at intensities above rod saturation (not shown) the response even extends past the offset

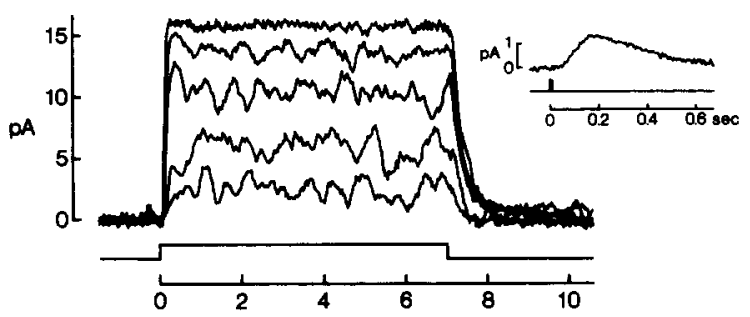

FIG. 31. Membrane currents recorded from isolated cat rods in response to light steps of increasing intensity. The currents were recorded from a single rod outer segment by the technique of sucking the outer segment into the tip of a glass micropipette. Timing of light steps $(7 \mathrm{sec})$ is indicated below the responses. In order to reduce photon fluctuations, each of the bottom four traces is from an average of two stimulus trials; the top trace is from a single trial. Step intensities are 82, 142, 503, 1074 and 2001 photons $\mu \mathrm{m}^{-2} \mathrm{sec}^{-1}$, respectively. Temperature was $39^{\circ} \mathrm{C}$. Inset: Averaged response of the same cell in zero background to a dim flash delivering 6.5 photons $\mu \mathrm{m}^{-2} \mathrm{sec}^{-1}$. (Modified from Tamura et al., 1989, with permission from Science.)

of illumination, the rod after-effect. (Note, the time course of the voltage response of the rod will differ somewhat from that of the current, and it is the voltage that contributes to the ERG.) Although the rod photoresponse will influence the 

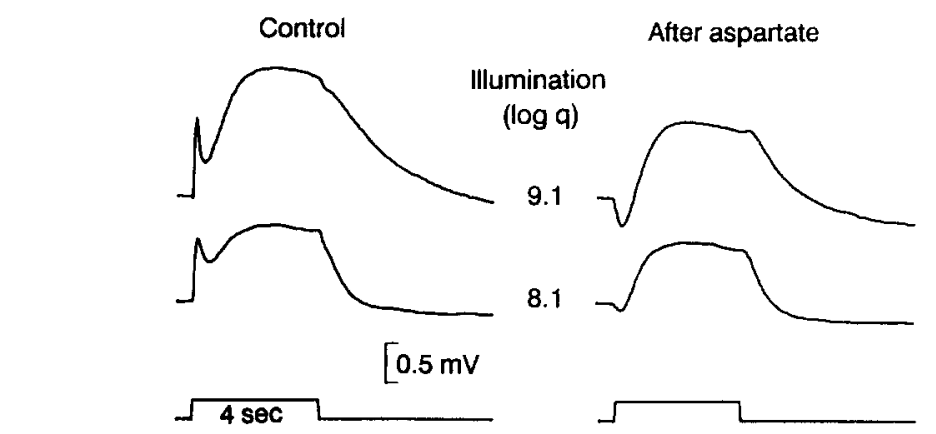

After $\mathrm{Ba}^{2+}$

FlG. 32. Dark-adapted vitreal ERGs in response to diffuse stimuli at two intensities of illumination, 8.1 and $9.1 \log q \mathrm{deg}^{-2} \mathrm{sec}^{-1}$. Left column, control responses. Middle column, responses $1 \mathrm{hr}$ after an intravitreal injection of aspartate (50 mM). Right column, response $3 \mathrm{hr}$ after two intravitreal injections of $\mathrm{Ba}^{2+}(4 \mathrm{~mm})$, and $5 \mathrm{hr}$ after aspartate.

(Modified from Frishman and Steinberg, 1990, with permission of Journal of Neurophysiology.)

shape and amplitude of the ERG following the awave, it appears at intensities that also produce the major positive components, PII (b-wave and DC component) and the c-wave, and it is overshadowed by their relatively larger amplitudes. There is, however, one additional location beyond the a-wave in the dark-adapted ERG where the rod photoresponse reappears and again becomes prominent. This is in the trough that follows the b-wave.

\subsubsection{B-WAVE TROUGH}

The b-wave trough represents a negative dip following the b-wave just before the rise of the $c$ wave that increases in relative prominence with intensity, i.e. the trough deepens (Fig. 32, left column) (Frishman and Steinberg, 1990). Pharmacological studies showed that the rod receptor potential contributes significantly to the b-wave trough (Fig. 32). An intravitreal injection of aspartate removed PII from the vitreal ERG, and an initial negative-going potential remained in the position of the a-wave which was followed by the c-wave (Fig. 32, middle column). Intravitreal $\mathrm{Ba}^{2+}$ now removed the c-wave (Fig. 32, right column), and revealed the rod receptor potential (Frishman and Steinberg, 1990). [Note, the effects of barium are complex so that these records probably do not accurately reflect the true timecourse and shape of the rod receptor potential
(Brown and Flaming, 1978; Griff et al., 1985).]

The negative trough that follows the $b$-wave was long recognized in the experimental ERG (e.g. rabbit) (Hanitzch et al., 1966) and in the human ERG, as well, where it has been referred to by a variety of names (b', Marg, 1953; b-, Monnier, 1949; M-point, Täumer et al., 1976a). Our experiments in cat suggest that this similar event in the human ERG probably also has a significant contribution from the rod receptor potential under dark-adapted conditions. This received support from the observation by Thaler et al. (1988) that the trough following the b-wave was especially prominent in three human subjects with congenital achromatoposia, where the cone contribution to the ERG is absent.

\subsubsection{IN THE ABSENCE OF POSITIVE COMPONENTS}

Any reduction in the relative amplitude of the competing positive ERG components, the b- and c-waves, should increase the relative amplitude of the rod receptor potential. It is well known that reduction of the b-wave by experimental manipulation or disease produces a "negative ERG". The c-wave is absent in certain animals, such as dog and owl monkey (Rodieck, 1972), and in albino rats that have been reared in cyclic lighting (Weidner, 1976, 1981; Ozawa, 1978; Graves et al., 1985). The retinas of these three examples are all rod-dominated and the ERGs exhibit a sustained negative potential following 
the b-wave. Slow PIII and the rod receptor potential are the responses most likely to form this potential, and measurements of the time to peak of selected responses suggests that the contribution of the rod receptor potential is significant (Frishman and Steinberg, 1990). It is not yet clear in animals without c-waves whether slow PIII is actually larger than the RPE component of the c-wave and also contributes to the negative ERG. The normal human scotopic ERG may or may not exhibit a c-wave (Hock and Marmor, 1983; Skoog and Nilsson, 1974; Täumer et al., 1976b; Tazawa, 1980) and it is also not known whether slow PIII contributes to this negative ERG. However, the rapid rise time of the negative response in published examples suggests that there is a contribution from the rod receptor potential (Täumer et al., 1976b).

\section{LIGHT-ADAPTED ERG}

\subsection{Sustained Negative Response and Negative Off Response}

The light-adapted diffuse-flash ERG in cat, as illustrated in Fig. 5, exhibits, under certain stimulus conditions, two prominent negative components - a sustained negative potential during illumination and a negative-going off response. Characteristic of the sustained negative response was the way that it increased in prominence at high backgrounds. Figure 33 shows that at high mesopic backgrounds ( $7.8 \log q \mathrm{deg}^{-2} \mathrm{sec}^{-1}$ ) a "b-wave trough" appeared between the b- and c-waves (arrow, left column, stimulus increment of 9.1). A clear negative response became dominant as the c-wave diminished at a log unit higher background (Fig. 33, middle column), which is near the illumination that saturates roddriven responses of pigment epithelial cells and horizontal cells in cat retina $\left(8.2 \log q \mathrm{deg}^{-2} \mathrm{sec}^{-1}\right)$ (Schmidt and Steinberg, 1971). At the highest background (Fig. 33, right column), with the c-wave almost completely absent, the negative response fully dominated the ERG. Note that the negative response also occurred at the two lower backgrounds with small stimulus increments that did not elicit large b- and c-waves.
For all three backgrounds (Fig. 33), the response showed an abrupt negative deflection at light offset. At the lowest background (left), the potential continued toward baseline following a negative deflection. This appeared to be the c-wave decaying towards baseline at stimulus offset, interrupted only by a small positive-going deflection (broken arrow, left column, stimulus increment of 8.1). At the two higher backgrounds, however, when the c-wave was reduced, the positive-going potential became prominent. Here it was the sustained negative potential recovering towards baseline at stimulus offset.

The light-adapted diffuse-flash ERG, when dominated by negative potentials, resembled the low-intensity dark-adapted ERG (Fig. 5). Since the dark-adapted responses, the STR and slow negative response, were both shown to be generated in proximal retina, probably by Müller cells, it was possible that the $\mathrm{M}$-wave, a light-adapted response of similar origin and mechanism, contributed the negative potentials to the lightadapted ERG (Sieving and Steinberg, 1985; Sieving et al., 1986a). An alternative possibility was that the light-adapted negative potential originated in the photoreceptors, representing the contribution either of slow PIII, or the photoresponse.

\subsubsection{Not the M-WAvE}

The $\mathrm{M}$-wave can be recorded in proximal retina of cat as negative-going potentials at light onset and light offset that are maximal in amplitude with small spots. When small spots are used, it is the most prominent intraretinal response in lightadapted retina. The $\mathrm{M}$-wave's spatial characteristics initially were described in amphibia (Karwoski and Proenza, 1977, 1980) and the M-wave was shown to be due to $\mathrm{K}^{+}$released by proximal neurons affecting Müller cells. It is likely that the mechanism is similar in cat retina (Sieving et al., 1986a; Frishman et al., 1988).

Despite the similarity of the $\mathrm{M}$-wave and the diffuse-flash ERG in form and time course (Fig. 34), comparisons of response characteristics, and results of pharmacological manipulations indicated that the $M$-wave does not, in fact, 


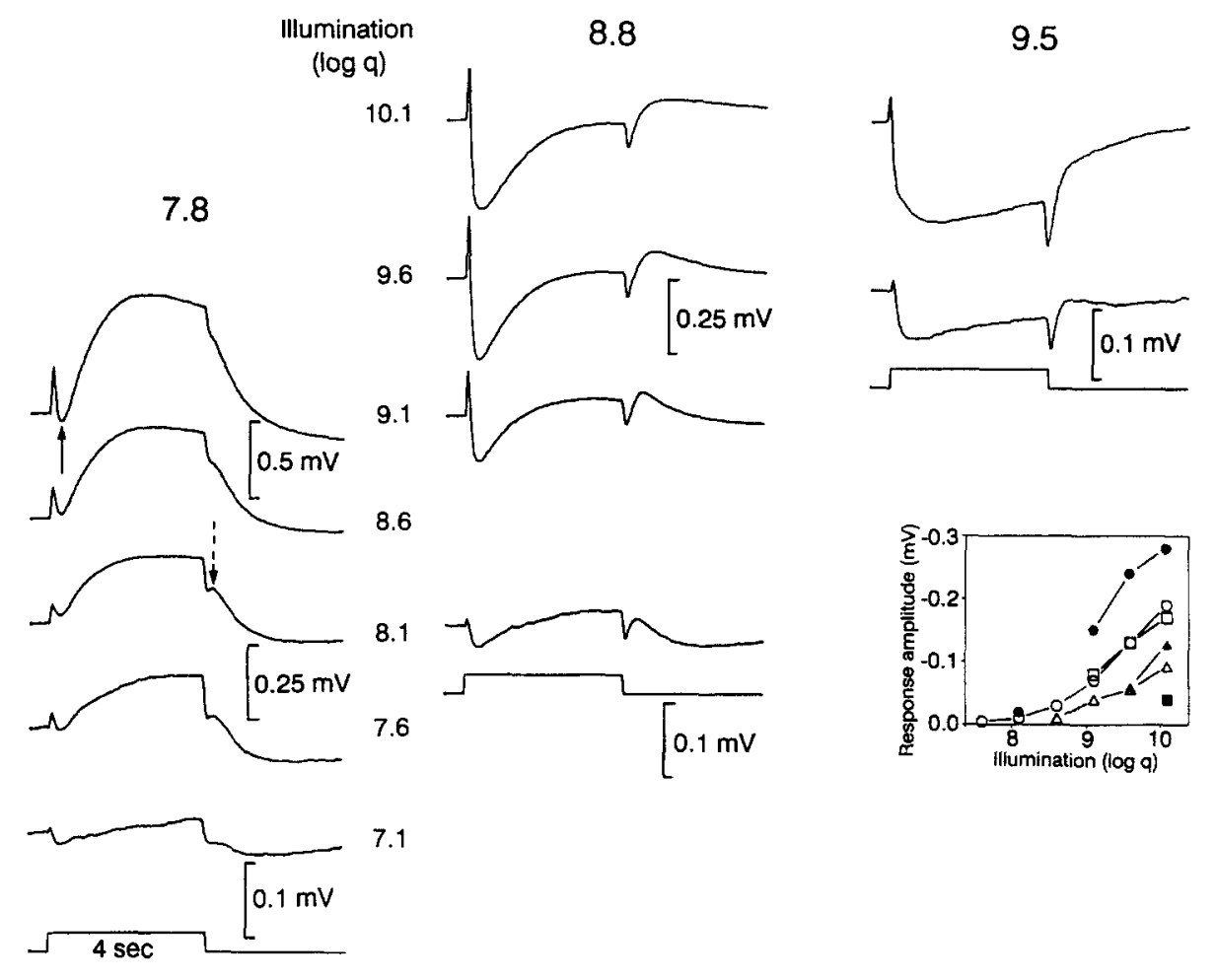

FIG. 33. Light-adapted vitreal ERGs in response to diffuse stimuli of increasing intensity of illumination at three different steady background levels. Left column, steady background at $7.8 \log q \mathrm{deg}^{-2} \mathrm{sec}^{-1}$; flash illumination over a range from 7.1 to $9.1 \log q \mathrm{deg}^{-2} \mathrm{sec}^{-1}$. Middle column, steady background illumination at $8.8 \log q \mathrm{deg}^{-2} \mathrm{sec}^{-1}$; flash illumination over a range from 8.1 to $10.1 \log q \mathrm{deg}^{-2} \mathrm{sec}^{-1}$. Right column, steady background illumination at $9.5 \log q \mathrm{deg}^{-2} \mathrm{sec}^{-1}$; flash illuminations at 9.6 and $10.1 \log q \mathrm{deg}^{-2} \mathrm{sec}^{-1}$. Inset shows amplitudes of the negative potential measured at its maximum for responses illustrated in this figure at backgrounds of 7.8 (filled square), 8.8 (filled circles), and $9.5 \log q \mathrm{deg}^{-2} \mathrm{sec}^{-1}$ (filled triangles), and for one other cat at 7.8 (open squares), 8.8 (open circles), and $9.8 \mathrm{log} q \mathrm{deg}^{-2} \mathrm{sec}^{-1}$ (open triangle). (Modified from Frishman and Steinberg, 1990, with permission from Journal of Neurophysiology.)

contribute significantly to the sustained negative response, and that it does not dominate the Off response. Figure 34 (left) shows that the M-wave was spatially tuned; M-wave responses at light onset and light offset were largest with small spots, and decreased as spot size increased. In contrast, the ERG at light onset and light offset (Fig. 34, right) increased in amplitude as the spot size increased. Several pharmacological agents affected the $\mathrm{M}$-wave differently than the vitreal ERG. For example, TTX, which blocks sodiumdependent action potentials, did not alter either the $\mathrm{M}$-wave On or Off response in proximal retina, but it eliminated the off response in the ERG (Fig. 35). In contrast, the GABA antagonist, picrotoxin, greatly enhanced the
M-wave, but not the negative potentials in the light-adapted ERG (Fig. 35, bottom).

APB (1 mM) (Fig. 36A, middle) reversed the polarity of the M-wave On response (Frishman and Steinberg, 1990), but the sustained negative response in the ERG was essentially unaffected. As expected, APB practically eliminated PII (b-wave and DC-component) (Knapp and Schiller, 1984; Frishman and Steinberg, 1989a). It also reduced the negative Off response, probably because of a contribution from the decay of the DC-component of PII at stimulus offset. Finally, aspartate $(50 \mathrm{mM})$, after $\mathrm{APB}$, removed all remaining responses from proximal retina, and it also spared the sustained negative portion of the ERG. Aspartate eliminated the remaining ERG 


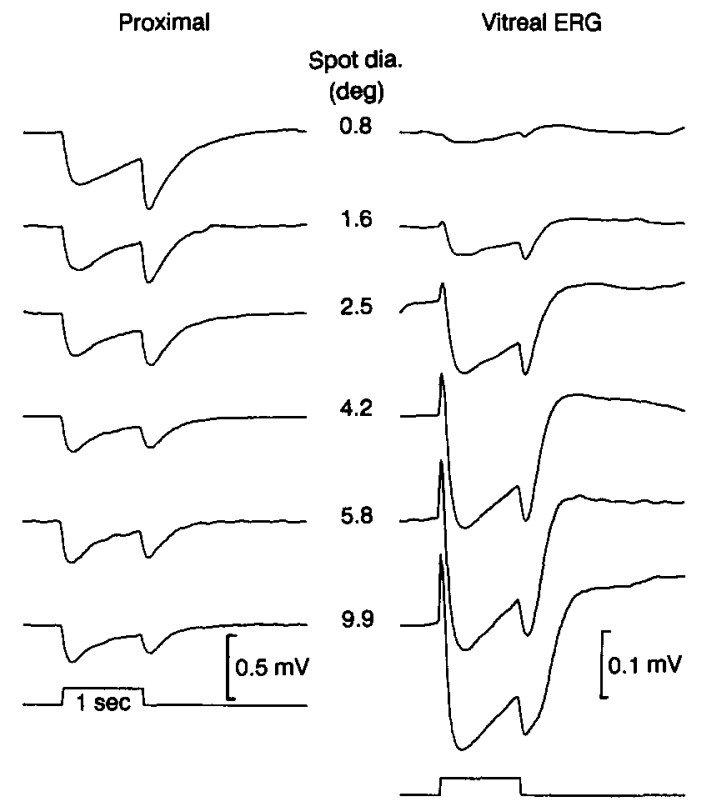

FIG. 34. Effect of changing the diameter of the stimulus spot on light-adapted responses from proximal retina (left) and the vitreal ERG, recorded simultaneously (right). Proximal responses were recorded at approximately $18 \%$ retinal depth. Steady background illumination at $11.5 \log q \mathrm{deg}^{-2} \mathrm{sec}^{-1}$; flash illumination at $11.8 \log q \mathrm{deg}^{-2} \mathrm{sec}^{-1}$. (From Frishman and Steinberg, 1990, with permission from Journal of Neurophysiology.)

Off response as well (Fig. 36A, bottom), raising the possibility of an additional post-receptoral origin in the Off pathway for that response (Frishman and Steinberg, 1990).

These studies indicated that the $\mathrm{M}$-wave contribution to the ERG, if present, had to be very small. A small negative-going contribution of the $M$-wave to the ERG was found in recordings of the "surface" ERG synthesized by adding proximal (M-wave) and distal (PII) responses to a small stimulus spot (an optimal stimulus for the $\mathrm{M}$-wave). The contribution of the $\mathrm{M}$-wave was about 1/4 that of PII; although intraretinally the M-wave was twice the size of PII (Sieving et al., 1986a).

\subsubsection{ORIGIN IN THE RODS}

The failure of either APB or aspartate to suppress the sustained negative response strongly indicated that it originated in the photoreceptors,

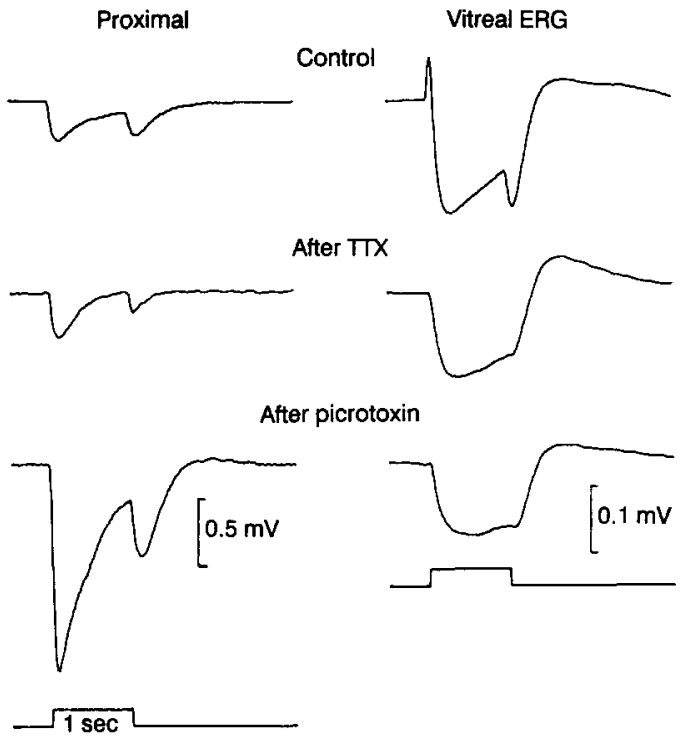

Fig. 35. Effect of TTX and picrotoxin after TTX, on the M-wave (left) at the simultaneously recorded vitreal ERG (right). Control responses are shown at the top $(18 \%$ retinal depth). Responses in the middle were recorded $10 \mathrm{hr}$ after intravitreal injection of $0.04 \mathrm{~mm}$ TTX, sufficient to arrest ganglion cell spikes $(22 \%$ retinal depth). Responses at the bottom were recorded in proximal retina (depth not recorded) $40 \mathrm{~min}$ after picrotoxin $(0.14 \mathrm{mM})$ and $13 \mathrm{hr}$ after TTX. Spot diameter, $4.2^{\circ}$; steady background illumination at $11.5 \log q \mathrm{deg}^{-2} \mathrm{sec}^{-1}$; flash illumination at $11.8 \log q \mathrm{deg}^{-2} \mathrm{sec}^{-1}$. (From Frishman and Steinberg, 1990, with permission from Journal of Neurophysiology.)

either as the photoreceptor response (fast PIII), or the Müller-cell response (slow PIII). In a depth series after aspartate, the proximal retina was silent (Fig. 36B), PII was absent from mid-retina, but a positive-going potential emerged around $42 \%$ retinal depth, and increased in amplitude as the electrode approached the photoreceptor outer segments and pigment epithelium. The positive trans-retinal potential had a dual origin, the initial onset generated by the photoreceptors (fast PIII), followed by slow PIII.

Experiments with $\mathrm{Ba}^{2+}$ indicated that the receptor potential, rather than slow PIII dominated the light-adapted ERG. It was necessary to use $\mathrm{Ba}^{2+}$ in combination with aspartate, since $\mathrm{Ba}^{2+}$ dramatically increased PII in the vitreal ERG, obscuring any effects on negative potentials (Fig. 37A). In the experiment shown in Fig. 37B, the control ERG responses resembled post $A P B$ or 
A
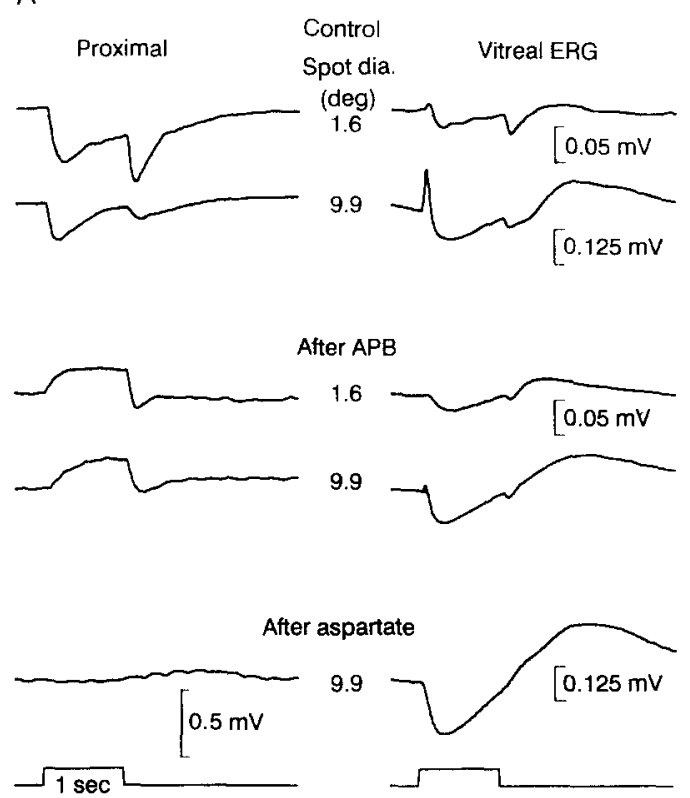

B
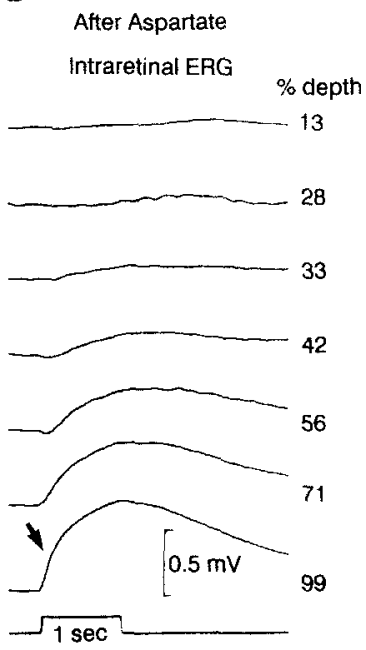

FIG. 36. Effect of APB and aspartate following APB on the intraretinal ERG and vitreal ERG. A: Effect of APB and aspartate following APB on the M-wave (left) and the simultaneously recorded vitreal ERG (right). Control responses are shown at the top for a small and a large spot (16\% retinal depth). Responses in the middle to the small and large spots were recorded $1 \mathrm{hr} 45 \mathrm{~min}$ after an intravitreal injection of APB (1 mM). The response at the bottom to a large spot was recorded $2 \mathrm{hr}$ after aspartate $(50 \mathrm{mM})$, and $7 \mathrm{hr} 20 \mathrm{~min}$ after APB (28\% retinal depth). Steady background illumination at $10.5 \log q \mathrm{deg}^{-2} \mathrm{sec}^{-1}$; flash illumination at $11.7 \log q \mathrm{deg}^{-2} \mathrm{sec}^{-1}$. B: Retinal depth distribution of the response to a large spot after aspartate $(50 \mathrm{mM})$ from which the record at the bottom of part $\mathrm{A}$ ( $28 \%$ retinal depth) was extracted. The arrow at $99 \%$ retinal depth indicates the onset of fast PIII. (From Frishman and Steinberg, 1990, with permission from Journal of Neurophysiology.)

aspartate responses because the pupil had constricted and coincidently, the c-waves and b-waves were greatly reduced. Aspartate was given to ensure, however, that all post-receptoral activity was eliminated (Sillman et al., 1969), and this was followed by $\mathrm{Ba}^{2+}$ to remove any residual $\mathrm{c}$-wave and slow PIII activity (Griff et al., 1985). The post-aspartate, post- $\mathrm{Ba}^{2+}$ responses (Fig. 37B) showed a positive trans-retinal potential, that was similar in form, but the inverse of the sustained negative component of the ERG. The early rising phase of the positive potential could be identified with fast PIII observed in the trans-retinal responses after aspartate (Fig. 36B, arrow 99\% depth).

Experiments with scotopically matched red and blue filters indicated that the sustained negative response originated in the rod, rather than the cone photoreceptors, and the spectral sensitivity of the response confirmed the finding. Figure 38A (top) shows the light-adapted vitreal ERG to diffuse white light, and responses (below) with a scotopically matched red (Wratten \#25) and a blue (Wratten \#47B) filters. The sustained negative potential was much more pronounced with the blue filter than with the red filter. The ERG obtained with the red filter contained postreceptoral contributions from the cone system that were removed by aspartate (Fig. 38B). After aspartate, the response with the red filter simply became a smaller version of the sustained negative potential elicited with the blue filter. These results strongly indicated that the sustained negative response was the rod receptor potential.

The spectral sensitivity of the sustained negative response (Fig. 38C) closely matched the spectral sensitivity of rod-dominated pigment epithelial cells (Schmidt and Steinberg, 1971; Nelson and Kolb, 1985). Whereas the curve in Fig. 38C peaked near $500 \mathrm{~nm}$, the dominant cones of the 


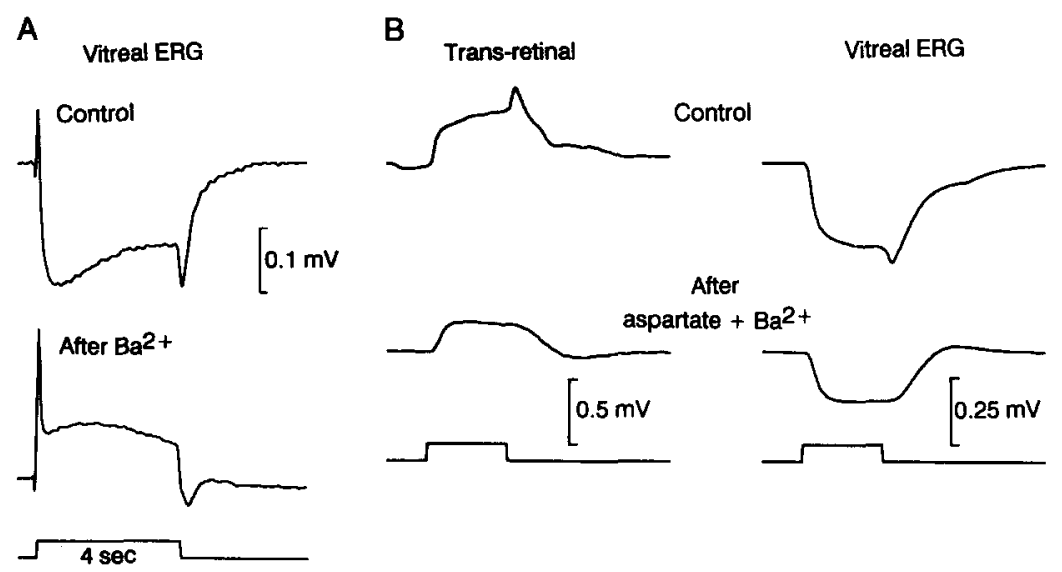

FIG. 37. Effect of $\mathrm{Ba}^{2+}$ on the light-adapted ERG and trans-retinal potentials. A: ERG responses to a diffuse flash before (top) and $20 \mathrm{~min}$ after intravitreal $\mathrm{Ba}^{2+}(4 \mathrm{mM})$. Steady background illumination at $9.3 \log q \mathrm{deg}^{-2} \mathrm{sec}^{-1}$; flash illumination at $10.4 \log q \mathrm{deg}^{-2} \mathrm{sec}^{-1}$. B: Effect of $\mathrm{Ba}^{2+}$ on the trans-retinal potential (left) and simultaneously recorded light-adapted vitreal ERG (right). Top row, control responses. Bottom row, responses $1 \mathrm{hr} 20 \mathrm{~min}$ after the last injection of $\mathrm{Ba}^{2+}(4$ injections of $5 \mathrm{~mm}$ over $2 \mathrm{hr}$ ) and $5 \mathrm{hr}$ after the last injection of aspartate ( 3 injections of $43 \mathrm{~mm}$ over $1 \mathrm{hr} 15 \mathrm{~min}$ ). Since repeated injections were needed to remove the $b$ - and c-waves, it is likely that the full volume of each injection did not reach the retina. The pupil was approximately $1 \mathrm{~mm} \times 3 \mathrm{~mm}$ so that not all of the filament image of the Maxwellian view that was focused on the cornea $\left(5 \mathrm{~mm}^{2}\right.$ for the background, $2.5 \times 4 \mathrm{~mm}$ for the spot) passed through the pupil. Steady background illumination at the cornea, assuming an open pupil, was $11.5 \log q \mathrm{deg}^{-2} \mathrm{sec}^{-1}$ and flash illumination was

$11.8 \log q \mathrm{deg}^{-2} \mathrm{sec}^{-1}$. (From Frishman and Steinberg, 1990, with permission from Journal of Neurophysiology.)

cat are most sensitive between 556-565 nm (Daw and Pearlman, 1969; Loop et al., 1987). These results, taken together with the pharmacological data presented above, show that the sustained negative response represented the rod receptor potential in the ERG.

\subsubsection{PROMINENCE OF THE ROD RECEPTOR POTENTIAL}

Part of the explanation for the prominence of the rod receptor potential in the light-adapted ERG rests in the predominance of rods in the cat retina, and the especially large contribution of peripheral rods to the ERG. Even in the area centralis where cones are most numerous, the lowest rod/cone ratio is $10: 1$ and it increases to $40: 1$ at $5^{\circ}$, and $60: 1$ to $70: 1$ at $10^{\circ}$ (Steinberg et al., 1973). It is rather difficult, even at high adapting backgrounds, to illuminate the periphery evenly enough to erase the rod contribution and to emphasize the small components that depend upon cones. It should be noted though, that the rod receptor potential did not become absolutely larger with increasing background adaptation as shown in the amplitude-intensity plot of Fig. 33 (inset). Although the negative potential dominated the ERG when the background was 9.5 (and 9.8) $\log q \mathrm{deg}^{-2} \mathrm{sec}^{-1}$, it was actually smaller than it was at lower backgrounds.

Neither the prevalence of rods in the retina, nor the decrease of the signal with increasing adaptation explains, however, why the rod receptor potential should increase in amplitude relative to the other rod-dependent ERG components, namely, the b-and c-waves. For the b-wave, it is known that it is reduced more in threshold and in size by dim backgrounds than is the receptor potential. This has been explained previously by postulating stages of adaptation post-synaptic to the photoreceptors, i.e. post-receptoral or neural adaptation (e.g. Green et al., 1975; Witkovsky et al., 1975).

The c-wave also has long been described as especially sensitive to light adaptation in roddominated retinas (Granit, 1947). In fact, the c-wave, which directly depends on the rod photoresponse, behaves like the rods with background adaptation. In intracellular recordings of its RPE component, responses decreased with increasing background intensity (Steinberg, 1971), in a manner similar to that predicted from direct 
A

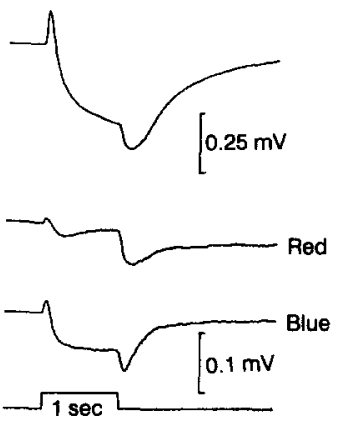

B Control

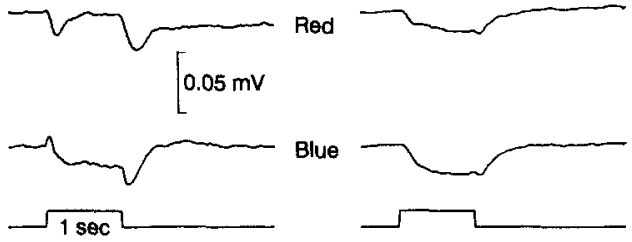

C

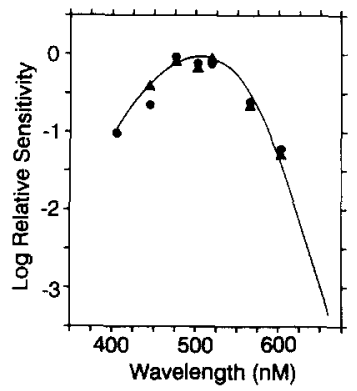

After aspartate

FIG. 38. Light-adapted vitreal ERGs in response to diffuse red (Wratten \#25) and blue (Wratten \#47B) stimuli, essentially scotopically matched (A and B), and spectral sensitivity of the sustained negative response $(C)$. A: Response to diffuse white (top), red (middle) and blue (bottom) stimuli. Steady background illumination at 9.8 $\log q \mathrm{deg}^{-2} \mathrm{sec}^{-1}$, white diffuse flash illumination at $10.1 \log q \mathrm{deg}^{-2} \mathrm{sec}^{-1}, \quad$ red diffuse flash $10.8 \log q \mathrm{deg}^{-2} \mathrm{sec}^{-1}$, blue diffuse flash $10.0 \mathrm{log}$ $q \operatorname{deg}^{-2} \mathrm{sec}^{-1}$. Note that the unattenuated blue filter should be only a slightly better stimulus for rods, since the filters were scotopically matched, with only $0.15 \log$ ND attenuation added to the blue filter. However, the unattenuated red filter should be a much better stimulus for cones, since the scotopically matched red filter was $1.65 \mathrm{log}$ units stronger photopically for the cone dominated M-wave in the area centralis. B: Responses to diffuse red (top) and blue (bottom) stimuli $1 \mathrm{hr} 30 \mathrm{~min}$ after an intravitreal injection of aspartate $(50 \mathrm{~mm})$. Steady background illumination at $9.5 \log q \mathrm{deg}^{-2} \mathrm{sec}^{-1}$, red flash illumination $10.8 \log q \mathrm{deg}^{-2} \mathrm{sec}^{-1}$, blue flash illumination $10.0 \log q \mathrm{deg}^{-2} \mathrm{sec}^{-1}$. C: Spectral sensitivity of the sustained negative response in the light-adapted ERG. Narrow band interference filters were balanced, using neutral density filters, to deliver equal quanta, and response amplitude at each wavelength was measured. Data were normalized to the maximum response, which was placed at $0 \log$ relative sensitivity. The curve $(507 \mathrm{~nm}$ peak) was fit by Nelson and Kolb (1985) to data from pigment epithelial cells in the cat to form a template for rod spectral sensitivity. Data are shown for two cats. (From Frishman and Steinberg, 1990, with permission from Journal of Neurophysiology.)

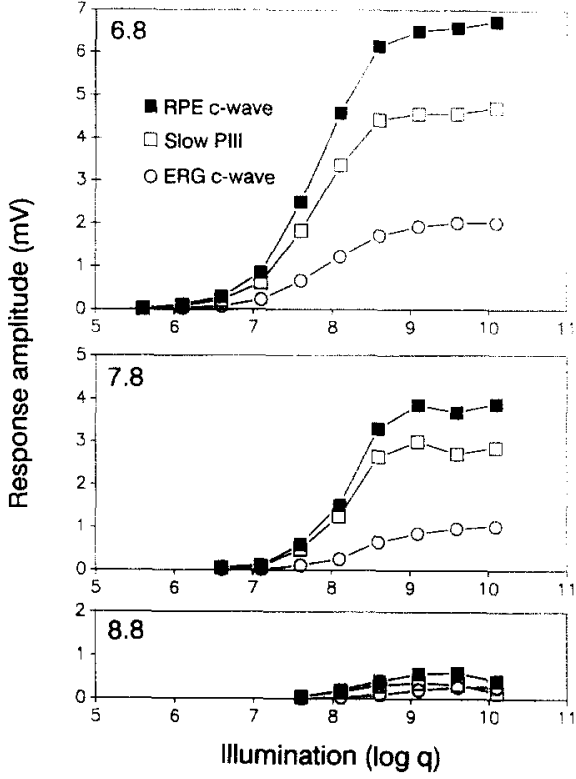

FIG. 39. Amplitude of ERG c-waves (open circles), and simultaneously recorded trans-retinal (open squares, slow PIII) and trans-epithelial potentials (filled squares, RPE c-wave) to stimuli of increasing illumination for three different levels of steady background illumination. Responses were measured at steady backgrounds of $6.8 \log q \mathrm{deg}^{-2} \mathrm{sec}^{-1}$ (top), $7.8 \log q \mathrm{deg}^{-2} \mathrm{sec}^{-1}$ (middle), and $8.8 \mathrm{log} q \mathrm{deg}^{-2} \mathrm{sec}^{-1}$ (middle) at $2 \mathrm{sec}$ after stimulus onset. Responses were also measured at a steady background illumination of $9.8 \log q \mathrm{deg}^{-2} \mathrm{sec}^{-1}$ (not shown), but c-waves were not present. (From Frishman and Steinberg, 1990, with permission from Journal of Neurophysiology.)

recordings from mammalian rods (Baylor et al., 1984; Tamura et al., 1989).

Unlike the photoreceptor response, however, the ERG c-wave represents the algebraic sum of two components of opposite sign, the RPE c-wave and slow PIII, and this means that the c-wave will be exquisitely sensitive to the way these components change relative to each other as a function of intensity and background level (Linsenmeier and Steinberg, 1983). This can be seen in the plots of Fig. 39, where the RPE c-wave and slow PIII were measured for several different backgrounds. Since slow PIII is a negative potential in the vitreous, the amplitude of the ERG c-wave in Fig. 39 represents the difference between the two functions at each background. ERG c-wave amplitude increases with intensity as the amplitude of the RPE response rises more steeply than slow PIII. 
Note, that at low intensities at a moderate background (6.8 $\left.\log q \mathrm{deg}^{-2} \mathrm{sec}^{-1}\right)$, while each component may have an appreciable amplitude itself, the difference is very small such that the c-wave is absent or very small in the ERG (Linsenmeier and Steinberg, 1983). At a higher background ( $7.8 \log q \mathrm{deg}^{-2} \mathrm{sec}^{-1}$ ), the maximum amplitude of both functions decreases as expected for the dynamic range of the rod response (Baylor et al., 1984; Tamura et al., 1989), and the responses are quite small, with a background (8.8 $\log q \mathrm{deg}^{-2} \mathrm{sec}^{-1}$ ) that saturates most of the rods. Now, the ERG c-wave is again absent or very reduced because it represents a very small difference between two small responses. In comparison, the rod receptor potential follows a function that resembles the component functions of the c-wave (compare Fig. 33, inset, with Fig. 39), but it will not be reduced in the ERG by the addition of a potential of opposite sign.

\subsubsection{COMPARISON WITH OTHER SPECIES}

A prominent negative response, analogous to the sustained negative response in the lightadapted ERG of the cat, has been observed in other species. In sheep, Knave et al. (1972) raised intraocular pressure to suppress post-receptoral activity and revealed a corneal negative potential. Since the retina was light-adapted, they attributed it to cone photoreceptors but the striking resemblance of their response to the one in cat would strongly suggest that it also represents the rod receptor potential. Similarly, the negative response is normally present in the ERG of rabbit obtained with incremental stimuli (Knapp and Schiller, 1984). When APB was used to eliminate On-bipolar cell responses, the rabbit b-wave was suppressed and the negative response was isolated as in cat (Fig. 40A). APB also eliminated the negative-going Off response, evidence for an origin similar, in part, to that of cat. Thus, sheep, rabbits and cat, all species with large rod populations, appear to have a prominent rod receptor potential in the light-adapted ERG. Finally, Knapp and Schiller (1984), in macaque monkey, found a sustained negative response in the moderately light-adapted ERG that closely resembled
A

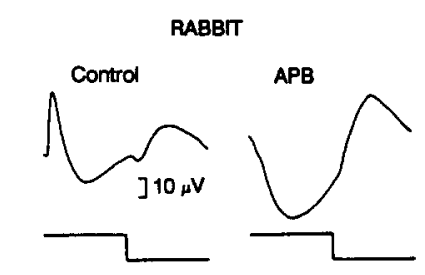

B
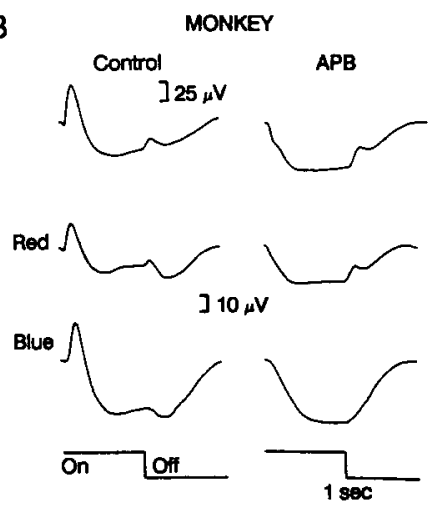

FIG. 40. Sustained negative response in the light-adapted ERG of other species. A: Rabbit, before and after APB. B: Monkey, in response to white light (top) and with colored filters (middle and bottom) before and after APB. The sustained negative response was considerably larger with a broad band blue filter than a red filter, suggesting a substantial rod contribution (the filters were not, it appears, scotopically matched). (Modified from Knapp and Schiller, 1984, with permission from Vision Research.)

that of rabbit and cat (Fig. 40B). After APB the blue filter response in monkey (Fig. 40B) looked very much like the blue filter response in cat after aspartate (Fig. 38B), suggesting that it also was the rod receptor potential. The response with the red filter, which also contained a prominent sustained negative portion, showed a faster onset than the response with the blue filter, and a fast positive offset. These fast responses, and the negative plateau, are characteristic of the cone system.

\subsection{Cone ERG}

\subsubsection{CONE RECEPTOR POTENTIAL IN THE ERG}

In primate retina with more cones than cat, and a high concentration in the central fovea, a cone ERG can be isolated more easily. Furthermore, the contribution of the cone receptor potential to 
A

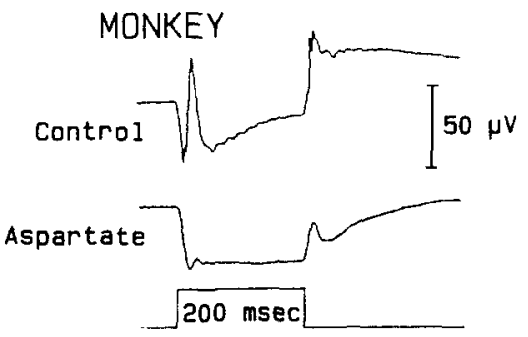

B

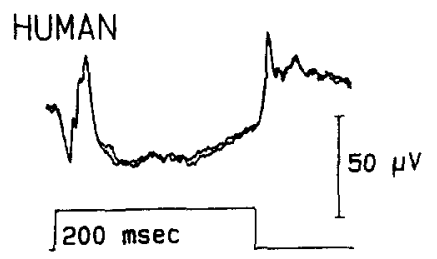

FIG. 41. Light-adapted diffuse flash ERG in monkey and human. A: Top; control light-adapted ERG for monkey. Bottom; after an intravitreal injection of sodium Laspartate $(2 \mathrm{M}, 0.07 \mathrm{ml}$ at $\mathrm{pH}$ 7) B: Light-adapted ERG in human. ERGs were recorded at the cornea with a Ganzfeld stimulus of $175 \mathrm{~cd} / \mathrm{m}^{2}$ (4.04 log photopic $\mathrm{Td}$ for the human), on a white adapting background of $35 \mathrm{~cd} / \mathrm{m}^{2}$ (3.5 log scotopic Td for human).

the ERG can be seen in the light-adapted diffuse ERG when backgrounds are very intense. Figure 41 shows the primate ERG, macaque monkey and human, in response to a bright stimulus on a rod saturating background [about 2 log units above that used by Knapp and Schiller (1984)], and about $0.5 \log$ units above the intensity that is rod saturating in human increment thresholds (Aguilar and Stiles, 1954). This ERG shows an initial transient a-wave, followed by a positive $b$-wave, and then a negative plateau. It has a positive-going response at stimulus offset, that is initially very rapid, and then overshoots the baseline. This predominantly negative ERG is characteristic of the ERG in cone dominated retinas (e.g. Meservey and Chaffee, 1927; Arden and Tansley, 1955; Brown, 1968). Granit (1947) associated the negative cone ERG with PIII, and described the terminal positive wave as the Off effect of PIII, or d-wave. When aspartate isolated the photoreceptor response (Fig. 41), the ERG showed a sustained negative response and a positive deflection at stimulus offset that was reduced in amplitude, suggesting the presence of post-receptoral positive Off components in the normal ERG. The aspartate-isolated response resembles the response isolated by Knapp and Schiller (1984) with the red filter after APB (Fig. 40B), and responses after aspartate previously reported in macaque (Baron and Boynton, 1975), and in an eyecup preparation of excised human retina (Yonemura et al., 1974; Yonemura and Kawasaki, 1979).

The negative response revealed in the primate ERG by aspartate resembles responses of single mammalian cones (e.g. Baylor et al., 1987; Kraft, 1988), and can be identified as the cone receptor potential. It was first isolated in macaque monkey by Brown and Watanabe (1962) in recordings of the intraretinal ERG from the foveal region after clamping the retinal circulation to remove postreceptoral components. They showed that the short latency and fast initial slope of the cone intraretinal ERG formed the leading edge of the light-adapted a-wave, and that the cones also contributed significantly to the rapid decay of the response at stimulus offset, as a positive-going response, the ERG d-wave (see also Brown et al., 1965; Brown and Murakami, 1964; Brown, 1968). Later studies showed that the spectral sensitivity of the foveal responses matched that of cone vision, and the responses exhibited a Stiles Crawford effect (Whitten and Brown, 1973). Intraretinal depth profiles of the receptor potential showed maximal responses adjacent to the photoreceptors for the initial cone transient (Brown and Watanabe, 1962; Brown et al., 1965; Brown, 1968), and for the negative cone plateau (Baron and Boynton, 1974). A current source density analysis, which was focused on the fast offset of the intraretinally recorded response (not clamped) identified a source in the outer segments, and a sink in the outer plexiform layer of macaque retina (Heynen and van Norren, 1985).

Figure 41 shows that the human ERG can look very much like that of monkey when the same stimulus conditions are used. Clinical studies usually employ very brief flashes which show neither the cone plateau, nor the d-wave, separately. Yonemura and Kawasaki (1979) have used the rapid decay of the light-adapted receptor potential as a measure of cone activity in human 
recordings, but generally, the clinical value of analyzing the cone photoreceptor contribution to the ERG has not been fully realized.

\section{CONCLUDING REMARKS}

In this chapter we have considered only the negative components of the electroretinogram. In this way we have been able to summarize new findings about the threshold negative responses and the rod photoresponse and to distinguish the negative components from one another. While this subdivision of the ERG by polarity is somewhat artificial we hope the reader benefited from the attention given to these few components.

The chapter has also been weighted towards the rod-dependent components because more is known about them than the cone-dependent ones and because most of the research was performed on the cat retina. PIII, defined by Granit (1947) as the negative component of the ERG, can now be considered as having four separate rod-dependent subcomponents: the two threshold responses from proximal retina - scotopic threshold response and slow negative response; the Müller-cell component of the c-wave - slow PIII; and the rod receptor potential (fast PIII).

The currents generating these four components are thought to originate from only two cell types, the Müller cell and the rods, themselves. At present, there is convincing evidence that slow PIII originates at the Müller cell in response to changes in extracellular potassium concentration and the evidence also indicates that the STR and slow negative response originates by the same mechanism. It is of interest that current flow at the Müller cell for these quite different components is actually rather similar (Section 4.4.3). A comparison of Müller-cell models for the STR and slow PIII in Fig. 42 shows that the $\mathrm{i}_{2} \mathrm{r}_{2}$ loop is dominant for these components. For slow PIII this current is generated by a decrease in $\left[\mathrm{K}^{+}\right]_{0}$ at the distal end of the cell, while for the STR, and presumably the slow negative response as well, a similar current is produced by an increase in $\left[\mathrm{K}^{+}\right]_{0}$ at the proximal end of the cell. According to the $\mathrm{K}^{+}$spatial buffering hypothesis (Newman et al.,

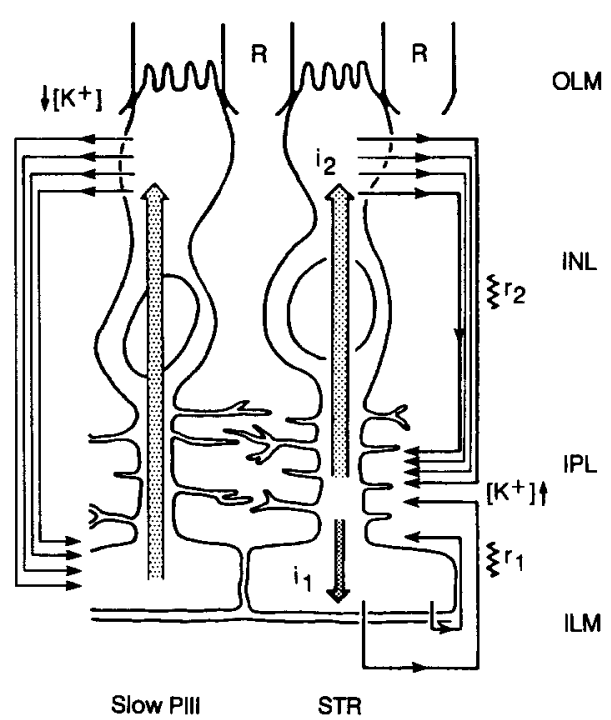

FiG. 42. Model of $\mathrm{K}^{+}$-induced current flow through Müller cells and the extracellular space for slow PIII (left) and the STR (right). Both of these negative ERG responses show dominance of the $\mathrm{i}_{2} \mathrm{I}_{2}$ current loop. For slow PIII the current is generated by a distal decrease in $\left[\mathrm{K}^{+}\right]_{\mathrm{o}}$, which hyperpolarizes the Müller cell. For the STR (and slow negative response) the current is thought to be generated by a proximal increase in $\left[\mathrm{K}^{+}\right]_{0}$, which depolarizes the Müller cell. (Modified from Frishman and Steinberg, 1989b, with permission of Journal of Neurophysiology.)

1984), these currents will produce a net movement of potassium in a direction from the vitreal end of the Müller cell towards its distal end in the subretinal space.

The four negative components make their appearance in the ERG as a function of intensity, beginning with the threshold negative responses from proximal retina (Section 3). The two threshold components, STR and slow negative response, reflect the activity of a rod-dependent retinal circuit that activates at the threshold for seeing. While they are small signals, best seen with response averaging, they are also observed in individual traces and are present in the ERG because of the amplification that occurs as a result of processing in this circuit. Apparently, the increase in potassium concentration that results from the activation of the circuit preserves this amplification so that the consequent Müller-cell depolarization is large enough to produce ERG responses. 
This circuit was first identified in ERG responses and intraretinal field potentials. That it can be activated in relative isolation from other retinal activity at dim illuminations, and that it can be readily recorded in field potentials, may offer advantages towards the eventual solution of its precise structure and function. We are hopeful that on-going and future studies, employing a variety of anatomical, physiological and pharmacological methods, will accomplish this goal.

We are especially hopeful about the future clinical usefulness of the STR. It is readily recordable in the human ERG (Section 4.1.3), and appears as an isolated response near threshold that can be measured unambiguously. The STR, then, could be a sensitive measure of rod system function that may be affected early in certain retinal diseases. However, since the STR depends on the normal activity of the rods themselves, as well as on the neuronal circuitry that amplifies rod output, it may be affected by disease processes involving either the rods, or the more proximal retinal circuitry. It may be most clinically useful, then, to compare affects on the STR with affects on the other rod-dependent ERG components.

At higher intensities, when each rod absorbs at least one quanta, the rod receptor potential and slow PIII become large enough to contribute to the ERG. In contrast with the rod receptor potential, slow PIII is not, to our knowledge, a component of the mammalian ERG that appears in isolation. Its contribution is generally thought to be one of subtraction from the RPE c-wave component, which is usually larger and has a positive polarity. In subjects without c-waves, however, it is likely that slow PIII does contribute to the negative response that appears after the b-wave but this needs to be verified by experiment. It is clear that slow PIII can appear in the ERG when the RPE component of the c-wave has been experimentally depressed, for example, by sodium iodate. Similarly, it is likely that slow PIII is part of the negative response that will be present in the human ERG when the RPE component of the c-wave is reduced in amplitude by diseases that affect the RPE.

The rod receptor potential appears in its classical position immediately after the onset of illumination as the scotopic a-wave. We have emphasized that this represents a relatively high threshold event in cat, monkey and human retinas, where the rod receptor potential appears first at more than four log units above the threshold for the STR. The presence of the STR with dim illuminations in the position of the a-wave creates a possible problem for ERG interpretation where this "false" a-wave, the STR from proximal retina, might be confused with the true a-wave, the rod receptor potential.

The rod receptor potential also can be found in the ERG following the b-wave, where it contributes to the b-wave trough. This trough deepens with progressively more intense light adaptation until a sustained negative component, the rod receptor potential, comes to dominate the ERG. This type of ERG, which is so prominent under experimental conditions, is usually not seen clinically. One reason is the difference in the conditions of stimulation and recording, i.e. the use of very brief flashes, $\mathrm{AC}$ cutoff, and bright backgrounds. Also, the more prominent cone contribution to the ERG in humans may make the rod receptor potential a less obvious component of the human light-adapted ERG.

The cone receptor potential can be seen in the monkey and human ERG when intense backgrounds are used to saturate most or all of the rods. The ERG shows an initial a-wave, which is interrupted by a brief positive b-wave, and then forms a negative plateau. At light offset there is a positive going d-wave, which is the offset of the cone receptor potential, and this is followed by additional post-receptoral positive components that are currently under investigation (Sieving, unpublished observations) and could be of clinical value.

Acknowledgements - The work of our own laboratories was supported by grants from the National Institute of Health, EY 01429 (R. H. Steinberg), EY 06671 (L. J. Frishman) and EY 06094 (P. A. Sieving).

\section{REFERENCES}

Aguilar, M. and Stiles, W. S. (1954) Saturation of the rod mechanism of the retina at high levels of stimulation. Optica Acta 1: $59-63$. 
Arden, G. B. and TANSLEY, K. (1955) The spectral sensitivity of the pure-cone retina of the grey squirrel (Sciurus carlinensis leucotis). J. Physiol. 127: 592-602.

ARDEN, G. B. and Brown, K. T. (1965) Some properties of components of the cat electroretinogram revealed by local recording under oil. J. Physiol. 176: 429-461.

BARON, W. S. and BoYNTON, R. M. (1974) The primate foveal local electroretinogram: an indicator of photoreceptor activity. Vision Res. 14: 495-501.

BAYLOR, D. A. and LAMB, T. D. (1982) Local effects of bleaching in retinal rods of the toad. J. Physiol. 328: $49-71$.

Baylor, D. A., NunN, B. J. and Schnapf, J. L. (1984) The photocurrent, noise and spectral sensitivity of rods of the monkey Macaca Fascicularis. J. Physiol. 357: $575-607$

BAYloR, D. A., NUNN, B. J. and SchNaPf, J. L. (1987) Spectral sensitivity of cones of the monkey Macaca Fascicularis. J. Physiol. 390: 145-160.

BERSON, E. L. (1987) Electrical phenomena in the retina. In: Adler's Physiology of the Eye. 8th edition, pp. 506-564. CV Mosby Co., St. Louis, MO.

Berson, E. L. and GoldsteIN, E. B. (1970) The early receptor potential in sex-linked retinitis pigmentosa. Invest. Ophthalmol. Vis. Sci. 9: 58-63.

Böck, J., Bornschein, H. and Hommer, K. (1965) Die negative komponente des warmbluter-ERG. I. Isolierung und charakteristik bei Mensch und Kaninchen. Albrecht v. Graefes Arch. Ophthalmol. 168: $264-289$.

BORNSCHEIN, H. and VON LÜTZOW, A. (1965) Die negative komponente des warmbluter-ERG. II. Beeinflussung durch stoffwechselwirksame substanzen. Albrecht $v$. Graefes Arch. Ophthalmol. 168: $455-467$.

BornsChEIN, H., HANITZSCH, R. and von LÜTZOW, A. (1966) Off-effekt und negative komponente des enukleierten bulbus und der isolierten netzhaut des kaninchens. I. Einflusz der reizparameter. Vision Res. 6: 733-734.

BRABAENDER, B. and ZRENNER, E. (1989) The threshold scotopic threshold response (STR) in the electroretinogram of the dog. Doc. Ophthalmol. (in press).

BRINDLEY, G. S. and Gardner-Medwin, A. R. (1965) Evidence that the "early receptor potential" of the retina does not depend on changes in permeability of membranes to specific ions. Proc. Physiol. Soc. May 22, 1965.

Brown, K. T. (1968) The electroretinogram: its components and their origins. Vision Res. 8: $633-677$.

Brown, K. T. and WIESEL, T. N. (1961) Localization of origins of electroretinogram components by intraretinal recording in the intact cat eye. J. Physiol. 158: $257-280$.

Brown, K. T. and WATANABE, K. (1962) Isolation and identification of a receptor potential from the pure cone fovea of the monkey retina. Nature 193: 958-960.

Brown, K. T. and Murakami, M. (1964) A new receptor potential of the monkey retina with no detectable latency. Nature 201: 626-628.

Brown, K. T. and Flaming, D. (1978) Opposing effects of calcium and barium in vertebrate photoreceptors. $J$. Physiol. 175: $1587-1590$.

Brown, K. T., Watanabe, K. and Murakami, M. (1965) The early and late receptor potentials of monkey cones and rods. Cold Spring Harb. Symp. quant. Biol. 30: $457-482$.

BurkhardT, D. A. (1970) Proximal negative response in the frog retina. J. Neurophysiol. 33: 405-420.

Byzov, A. L. (1959) Analysis of the distribution of potentials and currents within retina on light stimulation. I: Activity of the bipolars of two types. Biophysics 4: $46-59$.

CONE, R. A. (1964) Early receptor potential of the vertebrate retina. Nature 204: 736-749.

CONE, R. A. and CoBbs, W. H. (1969) The rhodopsin cycle in the living eye of the rat. Nature 221: $820-822$.

Copenhagen, D. R., Hemilä, S. and Reuter, T. (1990) Signal transmission through the dark-adapted retina of the toad Bufo marinus: gain, convergence and signal/noise. J. gen. Physiol. 95: 717-732.

Dacheux, R. F. and Raviola, E. (1986) The rod pathway in the rabbit retina: $A$ depolarizing bipolar and amacrine cell. J. Neurosci. 6: $331-345$.

Daw, N. and Pearlman, A. L. (1969) Cat colour vision: one cone process or several? J. Physiol. 201: 745-764.

Dick, E. and Miller, R. F. (1978) Light-evoked potassium activity in mudpuppy retina: its relation to the b-wave of the electroretinogram. Brain Res. 154: 388 - 394.

Dick, E. and MilleR, R. F. (1985) Extracellular $\mathrm{K}^{+}$activity changes related to electroretinogram components. I. Amphibian (I-type) retinas. J. gen. Physiol. 85: $885-909$.

Dick, E., Miller, R. F. and Bloomfield, S. (1985) Extracellular $\mathrm{K}^{+}$activity changes related to electroretinogram components. II. Rabbit (E-type) retinas. J. gen. Physiol. 85: 911 - 931 .

FABER, D. S. (1969) Analysis of Slow Transretinal Potentials in Response to Light (PhD thesis). Buffalo NY: State University of New York.

FamiglietTI, E. V. and KolB, H. (1975) A bistratified amacrine cell and synaptic circuitry in the inner plexiform layer of the retina. Brain Res. 84: 293-300.

Finkelstein, D., Gouras, P. and HoFf, M. (1968) Human electroretinogram near the absolute threshold of vision. Invest. Ophthalmol. Vis. Sci. 7: 214-218.

Frishman, L. J. and SteinberG, R. H. (1989a) Intraretinal analysis of the threshold dark-adapted ERG of cat retina. J. Neurophysiol. 61: $1221-1232$.

Frishman, L. J. and SteinberG, R. H. (1989b) Light-evoked changes in $\left[\mathrm{K}^{+}\right]_{\mathrm{o}}$ in proximal portion of the darkadapted cat retina. J. Neurophysiol. 61: 1233-1243.

Frishman, L. J. and SteinberG, R. H. (1990) Origin of negative potentials in the light-adapted ERG of cat retina. $J$. Neurophysiol. (in press).

Frishman, L. J., Sieving, P. A. and Steinberg, R. H. (1988) Contributions to the electroretinogram of currents originating in proximal retina. Visual Neurosci. 1: $305-315$.

Fujimoto, M. and TomitA, T. (1979) Reconstruction of the slow PIII from the rod potential. Invest. Ophthalmol. Vis. Sci. 18: $1090-1093$.

Goldstein, E. B. and Berson, E. L. (1970) Rod and cone contributions to the human early receptor potential. Vision Res. 10: $207-218$.

Goldstein, E. B., Frishman, L. J. and Schweitzer-Tong, D. (1975) Cone contributions to the cat early receptor potential. Vision Res. 15: $873-874$. 
Granit, R. (1933) The components of the retinal action potential in mammals and their relation to the discharge in the optic nerve. J. Physiol. 77: $207-239$.

Granit, R. (1947) Sensory Mechanisms of the Retina. London: Oxford University Press.

GRANIT, R. (1959) Neural activity in the retina. In: Handbook of Physiology. Section 2, Vol. I, pp. 575-691, $693-712$, Am. Physiol. Soc., Washington DC.

Granit, R. (1962) Neurophysiology of the retina. In: The Eye. (H. Davson, ed.) Vol. 2, pp. 575-691. Academic Press, New York.

GRANIT, R. and RIDDELL, L. A. (1934) The electrical responses of dark-adapted frogs' eyes to rhythmic and continuous stimuli. J. Physiol. 81: 1-28.

Graves, A. L., Green, D. G. and Fisher, L. J. (1985) Light exposure can reduce selectively or abolish the c-wave of the albino rat electroretinogram. Invest. Ophthalmol. Vis. Sci. 26: $388-393$.

Grefn, D. G., Dowling, J. E., Siegel, I. M. and Ripps, H. (1975) Retinal mechanisms of visual adaptation in the skate, J. gen. Physiol. 65: $483-502$.

GrifF, E. R., Shirno, Y. and SteinberG, R. H. (1985) $\mathrm{Ba}^{2+}$ unmasks $\mathrm{K}^{*}$ modulation of the $\mathrm{Na}^{+}-\mathrm{K}^{-}$pump in the frog retinal pigment epithelium. J. gen. Physiol. 86: $853-876$.

Hagins, W. A. and McGaughy, R. E. (1968) Membrane origin of the fast photovoltage of squid retina. Science 159: $212-215$.

HANITZSCH, R. (1973) Intraretinal isolation of PIII subcomponents in the isolated rabbit retina after treatment with sodium aspartate. Vision Res. 13: $2093-2102$.

HANitzSCH, R. and ByKow, K. (1981) Characteristics of receptor potential and slow PIII-component to light and dark flashes in the isolated superfused rabbit retina. Vision Res. 21: 1709-1712.

HANitzsch, R., Hommer, K. and Bornschein, H. (1966) Der nachweis langsamer potentiale im menschlichen erg. Vision Res. 6: $245-250$.

Harding, T. H. and Enroth-Cugell, C. (1978) Absolute dark sensitivity and center size in cat retinal ganglion cells. Brain Res. 153: $157-162$.

Heckenlively, J. and Arden, G. A. (1990) Handbook of Clinical Electrophysiology of Vision Testing. Year Book Medical Publishers, Inc.

Hendrickson, A. E., Koontz, M. A., Pourcho, R. G., SARThy, P. V. and GoebBel, D. J. (1988) Localization of glycine-containing neurons in the Macaca monkey retina. J. comp. Neurol. 273: $473-487$.

HeYNeN, H, and VAN NorReN, D. (1985) Origin of the electroretinogram in the intact macaque eye-I. Principal component analysis. Vision Res. 25: $697-707$.

HoCk, P. A. and MARMOR, M. F. (1983) Variability of the human c-wave. Doc. Ophthalmol. Proc. Ser. 37: $151-157$.

IKEDA, H. (1987) Retinal mechanisms and the clinical electroretinogram. In: A Textbook of Clinical Neurophysiology. (A. M. Halliday, S. R. Butler and R. Paul, eds) Vol, 22, pp. 569-594. John Wiley, New York.

J ACOBSON, S. G. and IKEDA, H. (1983) Electroretinogram below b-wave threshold in the cat: studies of retinal development and retinal degeneration. Doc. ophthatmol. Proc. Ser. 37: 65-72.
KARWoSk1, C. J. and ProEnzA, L. M. (1977) Relationship between Müller cell responses, a local transretinal potential, and potassium flux. $J$. Neurophysiol. 40: $244-259$.

Karwoski, C. J. and ProenzA, L. M. (1978) Light-evoked changes in extracellular potassium concentration in mudpuppy retina. Brain Res. 142: $515-530$.

Karwoski, C. J. and Proenzı, L. M. (1980) Neurons, potassium and glia in proximal retina of Necturus. $J$. gen. Physiol. 75: $141-162$.

Karwoski, C. J., Frambach, D. A. and Proenza, L. M. (1985a) Laminar profile of resistivity in frog retina. $J$. Neurophysiol. 54: $1607-1619$.

Karwoski, C. J., Newman, E. A., Shimazaki, H. and ProenzA, L. M. (1985b) Light-evoked changes in extracellular $\mathrm{K}^{-}$in the plexiform layers of amphibian retinas. J. gen. Physiol. 86: $189-213$.

Karwoski, C. J., Lu, H.-K. and Newman, E. A. (1989) Spatial buffering of light-evoked potassium increases by Müller (Glial) cells. Science 244: $578-580$.

Kline, R. P., Ripps, H. and Dowling, J. E. (1978) Generation of $b$-wave currents in the skate retina. Proc. natn. Acad. Sci. U.S.A. 75: $5727-5731$

Kline, R. P., Ripps, H. and Dowling, J. E. (1985) Lightinduced potassium fluxes in the skate retina. Neurosci. 14: $225-235$

KNAPP, A. G. and SCHIller, P. H. (1984) The contribution of on-bipolar cells to the electroretinogram of rabbits and monkeys. Vision Res. 24: $1841-1846$.

Knave, B., Moller, A. and Perrson, H. (1972) A component analysis of the electroretinogram. Vision Res. 12: $1669-1684$.

KNAVE, B., Nilsson, S. E. and LUNT, T. (1973) The human electroretinogram: DC recordings at low and conventional stimulus intensities. Acta Ophthalmol. 51: $716-726$.

KolB, H. (1977) The organization of the outer plexiform layer in the retina of the cat: Electron microscopic observations. J. Neurocytol. 6: $131-153$.

KoLB, H. (1979) The inner plexiform layer of the retina of the cat: Electron microscopic observations. J. Neurocytol. 8: $295-329$.

Kol.B, H. and NELSON, R. (1983) Rod pathways in the retina of the cat. Vision Res. 23: $301-312$.

KRAFT, T. W. (1988) Photocurrents of cone photoreceptors of the golden-mantled ground squirrel. J. Physiol. 404: $199-213$.

LinSENMEIER, R. A. and SteinberG, R. H. (1982) Origin and sensitivity of the light peak in the intact cat eye. $J$. Physiol. 331: $653-673$.

LiNSENMEIER, R. A. and STEINBERG, R. H. (1983) A lightevoked interaction of apical and basal membranes of retinal pigment epithelium: c-wave and light peak. $J$. Neurophysiol. 50: $136-147$.

Loop, M. S., Millican, C. L, and Thomas, S. R. (1987) Photopic spectral sensitivity of the cat. J. Physiol. 382: $537-553$.

Lurie, M. and MArmor, M. F. (1980) Similarities between the c-wave and slow PIII in the rabbit eye. Invest. Ophthalmol. Vis. Sci. 19: 1113-1117.

MARC, R. E. and Lul, W.-L. S. (1985) (3H) Glycineaccumulating neurons of the human retina. J. comp. Neurol. 232: $241-260$. 
MARG, E. (1953) The effect of stimulus size and retinal illumination on the human electroretinogram. $A m . J$. Optom. 30: $417-433$.

McGuire, B., Stevens, J. K. and Sterling, P. (1984) Microcircuitry of bipolar cells in cat retina. $J$. Neurosci. 4: $2920-2938$.

Meservey, A. B. and Chaffee, E. L. (1927) Electrical response of the retina in different types of cold-blooded animals. J. Opt. Soc. Am. 15: 311-330.

MONNIER, M. (1949) L'electro-retinogramme de l'homme. EEG Clin. Neurophysiol. 1: $87-108$.

Müller, F., Wässle, H. and VOIGT, T. (1988) Pharmacological modulation of the rod pathway in the cat retina. J. Neurophysiol. 59: $1657-1672$.

Murakami, M. and Kaneko, A. (1966) Differentiation of PIII subcomponents in cold-blooded vertebrate retinas. Vision Res. 6: $627-636$.

NAAREndorP, F. and Sieving, P. A. (1990) The scotopic threshold response of the cat ERG is suppressed selectively by GABA and glycine Vision Res. (in press).

NAARENDORP, F. and Sieving, P. A. (1990) The scotopic threshold response of the cat ERG is suppressed selectively by GABA and glycine. Vision Res. (in press).

NELSON, R. (1977) Cat cones have rod input: A comparison of response properties of cones and horizontal cell bodies in the retina of the cat. J. comp. Neurol. 172: 109-136.

Nelson, R. (1980) Functional stratification of cone bipolar axons in the cat retina. Invest. Ophthalmol. Vis. Sci. (ARVO Suppl.) p. 130.

NELSON, R. (1982) AII amacrine cells quicken time course of rod signals in the cat retina. J. Neurophysiol. 47: $928-947$.

NELSON, R. and KolB, H. (1985) A17: A broad field amacrine cell in the rod system of the cat retina. $J$. Neurophysiol. 54: $592-614$

Newman, E. A. (1980) Current source-density analysis of the b-wave of frog retina. $J$. Neurophysiol. 43: 1355-1366.

NewmAN, E. A. (1984) Regional specialization of retinal glial cell membrane. Nature 309: $155-157$.

NEWMAN, E. A. (1985a) Membrane physiology of retinal glial (Müller) cells. J. Neurosci. 5: $2225-2239$.

NEWMan, E. A. (1985b) Voltage-dependent calcium and potassium channels in retinal glial cells. Nature 317: $809-811$

Nimman, E. A. (1987) Distribution of potassium conductance in mammalian Müller (glial) cells: a comparative study. J. Neurosci. 7: 2423-2432.

NI:WMAN, E. A. (1988) Electrophysiology of retinal glial cells. In: Progress in Retinal Research (N. N. Osborne and G. J. Chader, ecis) pp. 154-171. Pergamon Press, Oxford.

NFW'MAN, E. A. (1989) Potassium conductance block by barium in amphibian Müller cells. Brain Res. 498: 308-314.

Newman, E. A. and ODETTE, L. L. (1984) Model of electroretinogram b-wave generation: A test of the $\mathrm{K}^{+}$ hypothesis. J. Neurophysiol. 51: $164-182$.

Nenman, E. A., Frambach, D. A. and Odette, L. L. (1984) Control of extracellular potassium levels by retinal glial cell K siphoning. Science 225: $1174-1175$.

Nilsson, S. E. G. (1984) Interactions between PI and slow PIII in the generation of the electroretinogram c-wave. Devl Ophthalmol. 9: 53-58.

Not:L., W. K. (1953) Studies on the Electrophysiology and the Metabolism of the Retina. USAF School of Aviation Medicine, Project No. 21-1201-0004, Rep. No. 1.
OAKLEY, B. II (1977) Potassium and the photoreceptordependent pigment epithelial hyperpolarization. J. gen. Physiol. 70: $405-425$.

OAKLeY, B. II and GreEN, D. G. (1976) Correlation of lightinduced changes in extracellular potassium concentration with the c-wave of the electroretinogram. J. Neurophysiol. 39: $1117-1133$.

Oakley, B. II, Flaming, D. G. and Brown, K. T. (1979) Effects of the rod receptor potential upon extracellular potassium ion concentration. $J$. gen. Physiol. 74: $713-737$.

OzawA, K. (1978) Studies on the c-wave of the normal wistar rat and spontaneous retinal dystrophic rat. Acta Soc. ophthal. jap. 82: $442-448$.

Pautler, E. L., Murikami, M. and Nosaki, H. (1968) Differentiation of PIII subcomponents in isolated mammalian retinas. Vision Res. 8: $489-491$.

Pourcho, R. G. (1980) Uptake of $\left({ }^{3} \mathrm{H}\right)$ glycine and $\left({ }^{3} \mathrm{H}\right) \mathrm{GABA}$ by amacrine cells in the cat retina. Brain Res. 198: $333-346$

Pourcho, R. G. and Goebel, D. J. (1983) Neuronal subpopulations in cat retina which accumulate the GABA agonist, $\left({ }^{3} \mathrm{H}\right)$ Muscimol: a combined golgi and autoradiographic study. J. comp. Neurol. 219: 25-35.

Pourcho, R. G. and Goebel, D. J. (1985) A combined golgi and autoradiographic study of $\left({ }^{3} \mathrm{H}\right)$ glycineaccumulating amacrine cells in cat retina. J. comp. Neurol. 233: $473-480$.

Raviola, E. and Gilula, N. B. (1975) Intramembrane organization of specialized contacts in the outer plexiform layer of the retina. A freeze-fracture study in monkeys and rabbits. J. Cell Biol. 65: 192-222.

RIPPS, H. and WITKovskY, P. (1985) Neuron - glia interaction in the brain and retina. In: Progress in Retinal Research (N. N. Osborne and G. J. Chader, eds) pp. 181-220. Pergamon Press, Oxford.

RoDIECK, R. W. (1972) Components of the electroretinogram - a reappraisal. Vision Res. 12: $773-780$.

Rodieck, R. W. (1973) The Vertebrate Retina. Principals of Structure and Function. W. H. Freeman and Company, San Francisco.

RODIECK, R. W. and FORD, R. W. (1969) The cat local electroretinogram to incremental stimuli. Vision Res. 9: 1-24.

ScHMidT, R. and STEINBERG, R. H. (1971) Incremental responses to light recorded from pigment epithelial cells and horizontal cells of the cat retina. J. Physiol. 217: $93-110$.

Schweitzer, N. M. J. and Troelstra, A. (1965) A negative component in the b-wave of the human ERG. Ophthalmologica 149: 230-235.

SiEviNG, P. A. (1990) Retinal ganglion cell loss does not abolish the scotopic threshold response (STR) of the cat and human ERG. Clin. Visual Sci. (in press).

Sieving, P. A. and Fishman, G. A. (1982) Rod contribution to the human ERP estimated from monochromats' data. Doc. Ophthalmol. Proc. Ser. 31: 95-102.

Sieving, P. A. and SteinberG, R. H. (1985) Contribution from proximal retina to intraretinal pattern-ERG: the M-wave. Invest. Ophthalmol. Vis. Sci. 26: $1642-1647$.

SiEving, P. A. and Nino, C. (1988) Scotopic threshold response (STR) of the human electroretinogram. Invest. Ophthalmol. Vis. Sci. 29: 1608-1614. 
SiEving, P. A. and WAKABAYASHI, K. (1990) Comparison of rod threshold ERGs from monkey, cat, and human. Clin. Visual Sci. (in press).

Sieving, P. A., Fishman, G. A., Alexander, K. R. and GOLDBERG, M. F. (1983) Early receptor potential (ERP) measurements in human ocular siderosis. Archs Ophthalmol. 101: 1716-1720.

Sieving, P. A., Frishman, L. J. and Steinberg, R. H. (1986a) M-wave of proximal retina in cat. $J$. Neurophysiol. 56: $1039-1048$.

Sieving, P. A., Frishman, L. J. and Steinberg, R. H. (1986b) Scotopic threshold response of proximal retina in cat. J. Neurophysiol. 56: $1049-1061$.

Sieving, P. A., WAKABAYASHi, K. and Lemmon, W. J. (1988) Current source density analysis of the cat scotopic threshold response. Invest. Ophthalmol. Vis. Sci. (Suppl.) 29: 103.

Sillman, A. J., Ito, H. and Tomita, T. (1969) Studies on the mass receptor potential of the isolated frog retina. I. General properties of the response. Vision Res. 9: $1435-1442$

SKoog, K.-O. and Nilsson, S. E. G. (1974) The c-wave of the human D. C. registered ERG. II. Cyclic variations in cwave amplitude. Acta Ophthalmol. 52: $904-912$.

Slaughter, M. M. and Miller, R. F. (1981) 2-amino-4phosphonobutyric acid-a new pharmacological tool for retina research. Science $N Y$ 211: $182-185$.

Smith, R. G., Freed, M. A. and Sterling, P. (1986) Microcircuitry of the dark-adapted cat retina: Functional architecture of the rod-cone network. $J$. Neurosci. 6: $3505-3517$.

SteINBERG, R. H. (1969a) Comparison of the intraretinal bwave and d.c. component in the area centralis of cat retina. Vision Res. 9: $317-331$.

SteInberg, R. H. (1969b) Rod and cone contributions to $S$ potentials from the cat retina. Vision Res. 9: $1319-1329$.

STEINBERG, R. H. (1969c) The rod after-effect in S-potentials from the cat retina. Vision Res. 9: $1345-1355$.

SteinberG, R. H., Schmidt, R. and Brown, K. T. (1970) Intracellular responses to light from the cat retinal pigment epithelium: origin of the electroretinogram cwave. Nature 227: $728-730$.

SteinberG, R. H., Reid, M. and Lacey, P. (1973) The distribution of rods and cones in the retina of the cat. $J$. comp. Neurol. 148: $229-248$.

Steinberg, R. H., OAKley, B. II, and Niemeyer, G. (1980) Light-evoked changes in $\left[\mathrm{K}^{+}\right]_{0}$ in retina of intact cat eye. J. Neurophysiol. 44: $897-921$.

SteinberG, R. H., Linsenmeier, R. A. and Griff, E. R. (1985) Retinal pigment epithelial cell contributions to the electroretinogram and electrooculogram. In: Progress in Retinal Research (N. N. Osborne and G. J. Chader, eds) Vol. 4, pp. 33-66. Pergamon Press, Oxford.

Tamura, T., Nakatani, K. and YaU, K.-W. (1989) Light adaptation in cat retinal rods. Science 245: 755-758.

TÄUMER, R., Rohde, N., WichmanN, W. and Röver, J. (1976a) Experiments concerning the human c-wave. Albrecht v. Graefes Arch. klin. exp. Ophthalmol. 198: $139-153$.
TAUMER, R., WichmanN, W., Rohde, N. and Rover, $i$ (1976b) ERG of humans without c-wave. Albrecht 1 Graefes Arch. klin. exp. Ophthalmol. 198: $275-289$.

TAZAWA, Y. (1980) Human ERG c-wave; its characteristics and clinical application. Folio Ophthalmol. Jap. 31: $1223-1248$

Thaler, A., Lessel, M. R. and Hellig, P. (1988) The c-wave in achromats. Doc. Ophthalmol. 69: 203-207.

Tomita, T. (1959) Study on electrical activities in the retina with penetrating microelectrodes. Proc. XXI Int. Congr. Physiol. (Symposia and Special Lectures) pp. $245-248$.

VALETON, J, M. and VAN NORREN, D. (1982) Fractional recording and component analysis of primate LERG: separation of photoreceptor and other retinal potentials. Vision Res. 22: $381-391$.

Vogel, D. A. (1980) Potassium Release and the ERG b-Wave Current Flow in the Frog Retina. (PhD. Thesis). University of Michigan.

Wakabayashi, K., Gieser, J. and Sifving, P. A. (1988) Aspartate separation of the scotopic threshold response (STR) from the photoreceptor a-wave of the cat and monkey ERG. Invest. Ophthalmol. Vis. Sci. 29: $1615-1622$.

WEIDNER, C. (1976) The c-wave in the ERG of the albino rat. Vision Res, 16: $753-763$

WEIDNER, C. (1981) The presence of an albino ERG in the pigmented rat: genetic implications. J. Physiol. 77: $813-821$

Whitten, D. N. and Brown, K. T. (1973) The time-course of the late receptor potentials from monkey cones and rods. Vision Res. 13: $107-135$.

Wioland, N., Rudolf, G. and Bonaventure, N. (1988) Iodate poisoning of the retina. A highly speciesdependent process. Electrophysiological evidences. Clin. Visual Sci. 3: 19-27.

Witkovsky, P., Dudek, F. E. and Ripps, H. (1975) Slow PIII component of the carp electroretinogram. J. gen. Physiol. 65: $119-134$.

YoNEMURA, D. and KAWASAKI, K. (1978) Electrophysiological study of activities of neuronal and non-neuronal retinal elements in man with reference to its clinical application. Jap. J. Ophthal. 22: $195-213$.

YONEMURA, D. and KAWASAKI, K. (1979) New approaches to ophthalmic electrodiagnosis by retinal oscillatory potential, drug-induced responses from retinal pigment epithelium and cone potential. Doc. Ophthalmol. 48: $163-222$.

Yonemura, D., Kawasaki, K. and Hasui, I. (1966) The early receptor potential in the human ERG. Acta Soc. ophthal. Jap. 70: $766-768$.

Yonemura, D., Kawasaki, K., Shibata, N. and Tanabe, J. (1974) The electroretinographic PIII component of the human excised retina. Jap. J. Ophthal. 18: 322-333.

Yoshimura, Y., Onoe, S., Takahashi, Y., Mori, T., Sato, T. and TAZAWA, Y. (1988) Electroretinogram c-wave and slow PIII of the rabbit: Changes in peak time and amplitude under various stimulus durations. Doc Ophthalmol. 69: 187-194. 